\title{
OSO-4 ELECTRON OBSERVATIONS \\ IN THE EDGE OF THE INNER RADIATION ZONE
}

Richard J Knox

MS date: Febmiary 23,1972

Prepared for US Atomic Energy Commission under contract No.W-7405:Eng 48

\section{University of calfomial wemore}

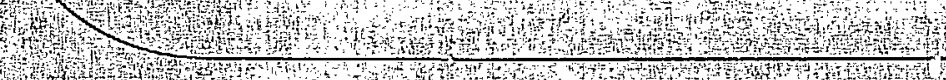

\section{LAWRENCE \\ IIVERMORE \\ LABORATORY}

whth

the 
TID-4500, UC-34

Physics

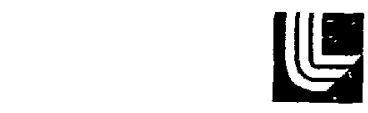

LAWPENCE UVERMOPE LABORATOAY

Uhiversity ol Cafiomia Livermone, Caffornia/94550

\title{
UCRL - 51185 \\ OSO-4 ELECTRON OBSERVATIONS \\ IN THE EDGE OF THE INNER RADIATION ZONE
}

\author{
Richard J. Knox
}

February 23, 1972

\begin{abstract}
This teport was prepared as an gccount of work sponsored by the United States Government. Neither the United States nor the Uni1ed States Atomic Energy Commission, nor any of their employess, nor any of their contractors, subcontractors, makes any warranty, express or implied, or assumes any logel if bility or responsibility for the accuracy, completeness or usefuness of any information, apparatus, product or process disclosed, or represents that its use would not iffringe privately owned tights.
\end{abstract}




\section{Contents}

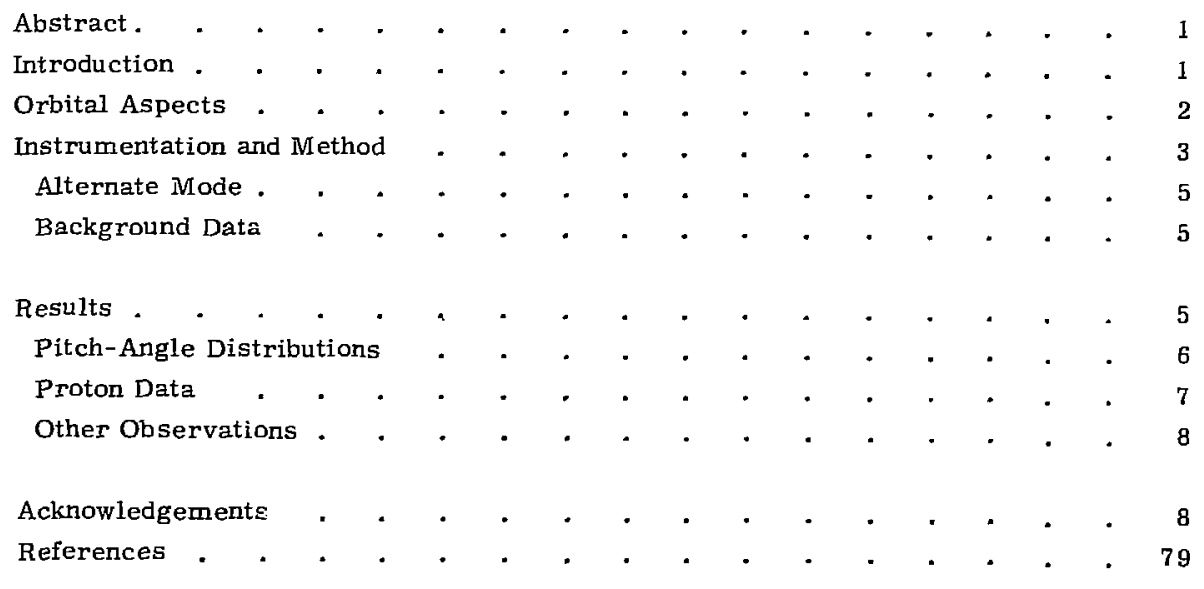




\title{
OSO-4 ELECTRON OBSERVATIONS IN THE EDGE OF THE INNER RADIATION ZONE
}

\begin{abstract}
Unidirectional electron flux intensities and differential energy spectra for 1.25 $\leq \mathrm{L} \leq 1.9$ measured in March 1968 using a directional electron spectrometer on the OSO-4 spacecraft are reported. Unidirectional differential intensities normal to the field line $\left(j_{1}\right)$ are given for $E_{e} \geq 80.5 \mathrm{keV}$ and for eight energy ranges to $5.33 \mathrm{MeV}$. Integral pitch-angle distributions are presented. Pitch-angle plots are also shown for November 1967 data, Favorable comparisons have been made with LLL's OGO- 5 electron energy-spectra (March 1968), particularly at energies less than $1.0 \mathrm{MeV}$.

Although the instrument was also designed to measure protons $(1.73$ to 65 $\mathrm{MeV})$, the proton data was made invislid due to penetrating high-energy protons. Data were accumulated along the edge of the inner belt for $1.1 \leq \mathrm{L} \leq 2.2$ within a narrow band of $\lambda$ values that approached within a few degrees of the magnetic equator at the lower $\mathrm{L}$ values and increased to about $45^{\circ}$ at the higher $L$ values.

It appears that the more complete analysis of OSO-4 electron data can, in part, fill a gap in the time history of inner-zone electron events during the 1967-1968 time period.
\end{abstract}

\section{Introduction}

The purpose of this paper is to exhibit portions of the OSO-4 electron data. These data have been organized in terms of conventional space coordinates. Little effort has been made to analyze the data in terms of physical phenomena occurring in the earth's radiation belt. However, the data appear reasonable on the basis of expected fluxes and spectra resulting from our current knowledge of the inner zone.

The orbiting spectrometer has provided useful measurements of energyanalyzed trapped electron fluxes and angular distributions on the outer edges of the inner Van Allen zone during late 1967 and early 1968. The spatial coverage during this period was attained by means of a near-circular orbit that constrained measurements to a narrow range of $\lambda$ values on each L-shell. Nevertheless, this constraint is offset by the advantages offered by acquisition of many data samples over a compact region of space.

Several investigators have followed the time decay of trapped electron fluxes since the Starfish nuclear detonation on 
July 9, 1962 that injected voluminous fission-decay beta particles into the inner zone. One such group, Bostrom et al $^{1}$, has studied the omnidirectional electron fluxes over the time period of September 1963 to December 1968. Their solid state electron spectrometer made integral measurements at $\mathrm{E}_{\mathrm{e}} \geq 0.28$ and $\mathrm{E}_{\mathrm{e}} \geq 1.2 \mathrm{MeV}$ on the 1963 38C satellite. Rosen et al $^{2}$ have observed the long-term temporal behavior of the inner belt by acquiring continuous samples of electron data for the period of February 1965 to October 1967. They used scintillation counters providing unidirectional electron fluxes of $\mathrm{E}_{\mathrm{e}} \geq \mathbf{0 . 5}$ and $0.3 \mathrm{MeV}$ on the Pegasus $A$ and $B$ spacecrafts, respectively. These satellites had similar orbits that were practically identical to the spatial coverage of the OSO-4 satellite.

Imhof ${ }^{3}$ has evaluated omnidirectional electron data $\left(E_{e} \geq 400 \mathrm{keV}\right)$ taken from an earth-oriented pola:--orbiting satellite that covered the $1.6 \leqslant L \leqslant 7$ range. The experiment was performed using a plas- tic scintillation spectrometer. From these data, detailed studies were made concerning the rates of flux buildup and precipitation during the longitudinal drift of electrons.

Pfitzer and Winckler ${ }^{4}$ have reported data measured with magnetic electron spectrometers flown on the OGO-1 and OGO-3 satellites. They reported energyanalyzed $\left(j_{\perp}\right)$ electron data $\left(50 \leq \mathrm{E}_{e} \leq 4000\right.$ $\mathrm{keV}$ from September 1964 to August 1966.

West ${ }^{5}$ has provided energetic electron observational studies throughout the magnetosphere. The measurements were made using a 7-channel, magnetic electron spectrometer aboard the OGO-5 spacecraft launched in March 1968. We have compared the OSC -4 electron data with unpublished OGO-5 data for $L<2$.

Much of the OSO-4 data has not been reduced, but further processing of the 1968 data would provide an extensive time history of electron events so that detailed studies of electron injection (following more intense magnetic storms) and decay rates could be performed.

\section{Orbital Aspects}

The OSO-4 satellite was launched into a circular orbit at a nominal $550 \mathrm{~km}$ alitude and $33^{\circ}$ inclination to the equatorial plane on October 18, 1967. The satellite contained two on-board tape recorders and played back telemetry data for 5 min during each pass over the Fort Myers, Florida ground station. The satellite was spin stabilized at approximately $0.5 \mathrm{rps}$ and maintained a 96-min orbital period. The LLL experiment was located in one of nine sectors of the revolving wheel of the satellite (Figs. 1 and 2). Operation was successful until the second tape recorder failed in May 1968 ( orbit 3100) after which time data was acquired at reduced coverage over a world-wide network of ground stations. The spacecraft was put in standby condition in November 1969, to be turned on only for recording special events in real time.

Figure 3 shows the coverage in $B, L$ space obtained from October 1967 through March 1968 and is representative of the 
coverage during the satellite lifetime. Figure 4 shows the equivalent coverage in $\lambda, \mathrm{L}$ space. The orbits are such that several traversals are made daily through the high-count-rate South Atlantic anomaly region, The areas of highest counts were consistently founded to stretch from just east of the tip of South Africa along a trajectory over southern Brazil; the most intense peaks being observed just over the Atlantic Ocean southeast of Brazil. Hot spots have also been noticed on trajectories passing through and just west of southern Australia.

Much of the data presented here is done so in terms of $\mathrm{L}$ and the geomagnetic latioude angle $\lambda$. We have used $\lambda$ rather than the equivalent $B$ simply because it provides a physically more meaningful picture of the data.

\section{Instrumentation and Method}

The LLL electron-proton spectrometer was a phoswich scintillation counter, consisting of a thin stilbene crystal backed up by a plastic scintillator. This type counter uses pulse shape discrimination to identify protc:ss and electrons. The entrance aperture to the detector was collimated to an $11.6^{\circ}$ acceptance cone by a set of tungsten alloy disks. The effective solid angle subtended by the detector area of $1.267 \mathrm{~cm}^{2}$ was $4.41 \times 10^{-2}$ steradians resulting in a geometric factor of $5.59 \times 10^{-2} \mathrm{~cm}^{2}-\mathrm{sr}$. The detector housing provided shielding that consisted of low $\mathrm{Z}$ material (aluminum) to minimize bremsstrahlung and an inner shield of heavimet (a tungsten alloy) to attenuate the residual bremsstrahlung.

A mechanical shutter wheel, mounted in front of the spectrometer entrance window, provided either a ${ }^{147} \mathrm{Pm}$ beta inflight calibration source, a combination aluminum-heavimet absorber for background measurements ox an open collimator for data accumulation. This wheel was driven by an on-board stepping motor upon command from ground stations.
A detailed description of the instrument logic and calibration details has been written by Waggoner et al. ${ }^{6}$

The pulses from the photomultiplier were identified by particle pulse-shape identifier circuitry and were amplitude discriminated and digitized, The digitized output was routed and stored into one of a set of eight, time-shared. counter-shift registers. A spacecraft clock pulse provided timing for the proper sequencing of all data collection and readout. Table 1 summarizes the spectrometer characteristics.

In the "normal mode" of operation of the spectrometer, a total of 48 samples of 4 different types of cata were acquired during each courting cycle of $15.36 \mathrm{sec}$. The data types were energy-analyzed $P+E$ and $P$ data and $P+E$ and $P$ angle values. The first type was the acquisition of 8 channels of energy-analyzed combined proton and electron counts in which each channel (or shift-register) accumulated for a $2.52 \mathrm{sec}$ period: The start of accumulation times for each successive channel was delayed by 320 msec. Each register was read out in a 
Table 1. OSO-4 spectrometer characteristics.

\begin{tabular}{|c|c|c|c|c|c|}
\hline $\begin{array}{l}\text { Discrimina- } \\
\text { tor number }\end{array}$ & $\begin{array}{l}\text { Channel } \\
P \cdot \mathbf{E}\end{array}$ & No. & $\begin{array}{c}\text { Flectron } \\
\text { incident } \\
\text { pnergy } \\
\text { (keV) }\end{array}$ & $\begin{array}{l}\text { Proton } \\
\text { incident } \\
\text { enerey } \\
\text { (Alev) }\end{array}$ & $\begin{array}{c}\text { Proton } \\
\text { detertion } \\
\text { efriciency } \\
r_{i}(\sigma)\end{array}$ \\
\hline 1 & I & & 80.5 & & \\
\hline 2 & 2 & & 121 & & \\
\hline 3 & 3 & 1 & 171 & 1.73 & 50 \\
\hline 7 & $t$ & 1 & 258 & 1.97 & 80 \\
\hline 5 & 5 & 2 & 537 & 2.71 & 95 \\
\hline 6 & 6 & 3 & פ00 & 3. 61 & 98 \\
\hline 7 & 7 & 4 & 1600 & 5. 19 & 95 \\
\hline 8 & 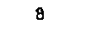 & $\overline{5}$ & 3080 & B. $1 \mathrm{~J}$ & 07 \\
\hline $\mathbf{9}$ & & 6 & 5330 & 11.9 & 97 \\
\hline 10 & & 7 & & 21.2 & 100 \\
\hline 11 & & B & & 36.7 & 100 \\
\hline
\end{tabular}

40-msec interval immediately following its accumulation period.

Proton counts were separated by the instrument logic and routed through a similar pulse-height-analyzing program. Due to the overlapping channels (note alignment of $P+E$ and $P$ channels in Table 1), efficiency-corrected proton counts had to be subtracted from most $P+E$ channels to obtain corrected electron counts as indicated in the formulae below:

$$
\begin{aligned}
& E_{4}=(P+E)_{4}-P_{1} / 0.80 \\
& E_{5}=(P+E\rangle_{5}-P_{2} / 0.95 \\
& E_{6}=(P+E)_{6}-P_{3} / 0.98 \\
& E_{7}=(P+E)_{7}-P_{4} / 0.95 \\
& E_{8}=(P+E)_{8}-P_{5} / 0.97
\end{aligned}
$$

These corrected electron counts constituted an average flux measured over 1 to $1-1 / 3$ revolutions of the detector and obtained with ambiguous angular aspect.

Finally, both $P+E$ and proton angle data were obtained. The satellite spin stabilization afforded adequate determination of the direction of "look" for the instrument at any moment and allowed the angular distribution of the incident radiation to be measured in 16 bins (each of approximately 22.5\%; during each rotation. A small computer in the experiment was used to determine the 16 angles and relate them to the local magnetic field as determined by a single-axis magnetumeter. B cause of the experiment geometry, only 9 of the 16 angular measu rements were made at unique pitch-angles except in the rare case where the magnetic field vector aligned perpendicular to the wheel plane--then all measurements were made at $90^{\circ}$ pitch-angles. The angular spread of data points depicted in the pitch-angle distribution plots of Figs. 37 through 51 was governed by the relative angle between the magnetic field vector and its projection on the wheel plane of the satellite.

The actual accumulation time for each "angle" count was $T_{\text {acc }}=1 /(16, w)(w=$ spin rate of the satellite wheel) and varied from about 113 to $130 \mathrm{msec}$ depending on whether the satellite was in orbital daylight or night. Thus, sequential angle data were typically collected over $5 \%$ of the normal accumulation period. It can be seen in the instrument timing diagram (Fig. 5), that on most occasions all 16 angular entries were not recorded on the same rotational cycle. However, instrument logic assured proper angular synchronizing for suc eassive samples taken during the next rotation. Figure 6 shows a top view of the wheel piane at the moment of collecting $\mathbf{P}+\mathrm{E}$ or $\mathrm{P}$ angle 1 data. It should be noticed thi $t$ the angular bir was then oriented at $90^{\circ}$ ( $\Sigma$ s shown) to the projection of the magnetic field vector at that time. Thus, a direct 
measurement of integral $j_{j_{-}}\left(E_{e} \geq B 0.5\right.$ $\mathrm{kaV}$ or $\mathrm{E}_{\mathrm{p}} \geq 1.73 \mathrm{MeV}$ ) was available by averaging the sum of data obtained at angles \#1 and \#9. Differential perpendicular fluxes as function $c^{\prime}$ energy were derived by a ratio-type calculation using as inputs a given PHA channel count, $j_{1}$ (as described above), and the $>80.5 \mathrm{keV}$ integral-PHA channel counts.

The proton contribution in the $\mathrm{P}+\mathrm{E}$ angle data was separated by subtracting the proton value measured at the identical angle during the same 15.36sec couniting period. All final values were then normalized to units of counts/sec-cm ${ }^{2}-\mathrm{sr}-\mathrm{keV}$ by using the appropriate geometric factor and energy bin widths.

\section{Alternate Mode}

This mode of data collection was initiated whenever the data in P + E PHA channel flit exceeded $2^{13}$ (8192) counts, a value that would overflow the counters in the "normal mode" of operation. The instrument logic immediately began a sequence of counting in which 16 angle values for each of the electron and proton energy channels were provided. These measurements allowed a detailed scrutiny of the angular direction of counts in each energy group in the high-count regions. Approximately $10 \%$ of the orbital data processed was in the "alternate-mode" operation. However, no data from these orbits are presented in this paper.

Background Data

Background measureinents for all parameters described were taken by means of identical internal logic but with the insertion of a lead disk in front of the detector aperture. The lead shielding was affixed to an external rotatable-shutter wheel that responded to ground-based telemetry commands. Generally, all background information was obtained over selected sequences of 10 to 15 orbits; therefore, $P+E$ and $P$ backgrounds were not measured at the same time as their data. Both electron and proton backgrounds were found to be essentially constant over the examination period ard a time-independent model was put together and employed in the subtraction of backgrounds for the $j_{\perp}(E)$ plots.

Counting-rate data between the time of instrument turn-on and the end of 1967 and also for a single week in March 1968 have been reduced using a CDC 6600 computer. The raw data have been smoothed of telemetry noise and selectively organized to prcvide $j_{\perp}$ and pitch-angle distributions. Computer tapes containing this reduced main-frame data have been submitted to the National Space Science Data Center for archival storage together with full documentation of all applicable computer codes used in the reduction process (Knox ${ }^{7}$ ).

\section{Results}

The data of Figs. 7 through 16 show the perpendicular electron intensities $\left(j_{1}\right)$ vs magnetic latitude $(\lambda)$ at several discrete values of $L$ for each of the five lowest-energy channels. These data were accumulated over the week of March 19 
through 25, 1968 and cover approximately 100 orbits. Data are presented for L values of 1.2, 1.25, 1.3.1.4,1.5, 1.6, 1.7, 1.8, and 1.9. It can be seen that the extent of the data was limited to a narrow range of $\lambda$ values due to the satellite orbital parameters. For this range of $\lambda$ values, the intensities can be seen to rapidly fall off several orders of magnitude with increasing $\lambda$. The cluster of points at the base of each plot is a conglomerate of low-level data measured at the higher $\lambda$ values on each $L$-shell and is probably representative of the background to be found outside of the trapping region.

The solid curved lines represent best fits to the background data at each $L$ value. These electron backgrounds were measured during 15 successive orbits of this same week and were arrived at after subtraction of all proton contributions. The plots clearly illustrate the sharp decrease in net electron flux at the low $L$ values $(L \leq 1.2)$. This phenomenon is generally assumed to be due to the loss of electrons into the atmosphere, occurring predominately in the region of the South Atlantic anomaly.

The electron flux for channel $\mathrm{E}_{2}$ (1乞े) $171 \mathrm{keV}$ ) was background-reduced and compared with a channel of data from the OGO-5 experiment ( $158 \pm 14 \mathrm{keV})$ that was also measured in March 1968. Figures 17 through 21 indicate these comparisons. It can be seen that there is reasonably good agreement for $L \cong 1.5$. Above this $\mathrm{L}$ value, an increasing disagreement is noticeable and a lateral shift in $\lambda$ of 0.5 $\pm 1.5^{\circ}$ is necessary to align the two data sets. This effect is similarly observed in the energy channels. Such discrepan- cies may have been caused by ephemeris errors incurred by the OGO- 5 satellite as it rapidly swept through low $L$ values in the perigee of its highly eccentric orbit. It should be mentioned that the same B-field model (1965-GSFC) was used in the reduction of both OSO-4 and OGO- 5 data.

Differential electron energy spectra were measured on several L-shells. Figures 22 through 35 present these results at the lowest $\lambda$ values obtained. All backgrounds have been subtracted and the error bars are based on counting statistics and also include an estimate of the maximum fluctuation of the data from a best fit curve through each point. The horizontal bars denote the energy range for each channel.

The observed spectra generally conform in shape to most OGO- 5 spectra measured in these regions. However, discrepancies do appear toward the higher energies in that the OGO- 5 data do not reveal the same degree of hardening as shown in the OSO-4 data. An example of this phenomenon is illustrated in Fig. 36. If the spectral hardening is not a real effect, some unexplained contamination of the OSO-4 higher energy electron channels could have been responsible. It should be mentioned that the OGO-5 spectrometer simultaneously measured background with the electron data. All OGO-5 results have been accurateiy corrected for backgrounds. The OGO-5 error bars in Fig. 36 are statistical.

\section{Pitch-Angle Distributions}

Figures 37 through 45 illustrate typical electron pitch-angle distribliticins for 
$E_{e} \geq 80.5 \mathrm{keV}$ measured on March 21, 1968 on the eastern edge of the South Atlantic anomaly. The bell-shaped distribution was the only type observed over the entire period of observation. Similar distributions measurad over Capetow:, South Africa are presented in Figs. 46 through 51 for higher $L$ values on the day of November 27, 1967.

These plots have been selected for I shells roughly 0.05 earth radii apart beginning at $L \cong 1.25$. All of these distributions have been fitted to the functional form:

$$
j(\alpha)=A \sin ^{n} \alpha+B \quad\{23 \leq n \leq 30\}
$$

where $\alpha$ is the pitch-angle, $A=j_{1}$, and $B$ is the constant background level. The "skirts" on each plot have been identified as true background (to $\pm 5 \%$ ) upon conversion and comparison to the PHA backgrounds that were measured with the shutter shield over the detector aperture. No atteinpts have been made to remove effects of the angular resolution of the detector. This resolution is reasonably well represented by a unit triangle having a base width of $90 \pm 11.6^{\circ}$.

\section{Proton Data}

It has been found that the OSO-4 proton data is of questionable value since the subtraction of proton background data results in the absence of net proton data. Proton counting rates in each channel remained unaffected with or without the background shield in front of the detector aperture. The overall instrument shielding was designed to provide protection against protons up to above $150 \mathrm{MeV}$ except possibly for particles arriving along the detector axis from the rear.
Several experiments have determined that the high-energy particles in the inner zone are trapped protons of up to 800 $\mathrm{MeV}$ in energy. Secondaries made from the intense fluxes of high-energy protons penetrated the relatively massive shielding of the OSO-4 detector assembly. These secondaries probably serve to mask out the proton flux incident on the narrow detector entrance window. It has been verified that the aperture shield was properly positioned for all data acquisitions. It is possible that back-up calibrations using high-energy proton sources could salvage this data.

Figure 52 is a plot of the apparent $j_{1}$ vs $\lambda$ (raw data without background subtracted) for the lowest energy channel of protons (1.73 to $2.71 \mathrm{MeV}$ ) organized on discrete $\mathrm{L}$-shells. The proton data values shown have been normalized assuming that all particles entered the detector through the forward entrance cone.

Although backgrounds could not be correctly subtracted, the lower energy proton data have compared well with the results of Fillius and McIlwain ${ }^{8}$ and Fillius ${ }^{9}$. They have surveyed and reported proton $\left(j_{1}\right)$ trapped fluxes measured on-board the Relay I satellite in 1963 with a 6-channel, silicon, solidstate detector. Several OSO-4 energy channels have been combined to match the Relay I energy bins as closely as possible for the comparisons. Unfortunately, the $\mathrm{B}$ range of the OSO-4 results was higher in virtually every instance. Consequently, the OSO-4 proton data points provided little more than a reasonable extrapolation to the Relay I proton data. The integral energy ranges, listed in Table 2, were compared. 
Table 2. Integral energy comparisons.

\begin{tabular}{|c|c|c|}
\hline $\begin{array}{l}\text { Energy } \\
\text { group }\end{array}$ & $\begin{array}{l}\text { (a) } \mathrm{OSO}^{-4} \\
(\mathrm{MeV})\end{array}$ & $\begin{array}{l}\text { (b) Relay I } \\
(\mathrm{MeV})\end{array}$ \\
\hline 1 & $1.73-8.15$ & $1.6-7.1$ \\
\hline 2 & $1.73-5.19$ & $2.25-4.7$ \\
\hline 3 & $1.73-11.9$ & $1.1-14.0$ \\
\hline 4 & $21.2-36.7$ & $25.0-35.0$ \\
\hline
\end{tabular}

(a) Oso-4 (X)

(b) Relay I (O)

Table 3. Orbital parameters for $I=2$. 0 .

\begin{tabular}{ccccc}
$\begin{array}{c}\text { Orbit } \\
\frac{\mu}{F}\end{array}$ & $\begin{array}{c}\text { Range in } \\
\text { (degrees) }\end{array}$ & Date & $\begin{array}{c}\text { C. } 7 . \\
\text { (secs) }\end{array}$ & L range \\
\hline 2360 & $-44.05 \rightarrow-45.66$ & $3 / 23 / 58$ & 30240 & $2.01-2.10$ \\
2375 & $-44.34 \rightarrow-45.77$ & $3 / 24 / 68$ & 29880 & $2.00-2.12$ \\
2376 & $-42.96 \rightarrow-45.54$ & $3 / 24 / 68$ & 35640 & $2.01-2.14$ \\
\hline
\end{tabular}

Figures 53 through 67 summarize the comparisons over each specified energy range. No observable changes occurred in the OSO-4 proton data intensities (without background subtraction) over the 5month period.

All proton comparisons with Relay I data have been good except those that included the OSO-4 channel \#8 data (36.7 to $65 \mathrm{MeV}$ ): in this shannel the OSO-4 proton flux measured a factor of 10 to
15 higher indicating the probability of saturation effects.

\section{Other Observations}

Spot checks made of several orbits during the 5-month period (October 1967 to March 1968) indicated temporal stability of the inner-belt electron flux. Spectral shapes and flux intensities were virtually constant because of relatively low magnetic activity and the absence of major magnetic storms during the measurement period.

However, electron data for $2.0 \leq \mathrm{L}$ $\leq 2.3$ measured at high magnetic latitudes $\left(\lambda>43^{\circ}\right)$ on March 23 and 24, 1968 showed a significant rise in count rates. The rise is possibly associated with an increase in magnetic activity at this time as indicated by the ( $A_{p}$ ) index (Fig. 68 ) and, in Fig. 69 , by the mean equatorial Dst values. Figure 70 illustrates how closely the satellite trajectories were aligned for these 3 orbits in which the maximum variation in al:itude was $0.5 \mathrm{~km}$. Other orbital parameters are identified in Table 3.

The cause of this electron injection has not been completely identified.

\section{Acknowledgements}

The author wishes to express his gratitude to the principal investigator, Jim Waggoner, under whose competent supervision a considerable portion of the data reduction was completed. Sincere appreciation is also extended to Harry West, principal investigator of the LLI OGO-5 experiment, who provided access to previously unpublished
OGO-5 data and whose valuable assistance contributed in the evaluation and organization of the reduced data.

Finally, acknowledgements are due to the LLL engineering support group whose technological efforts resulted in the fabrication and testing of the $P+E$ spectrometer that continues to operate to date. 


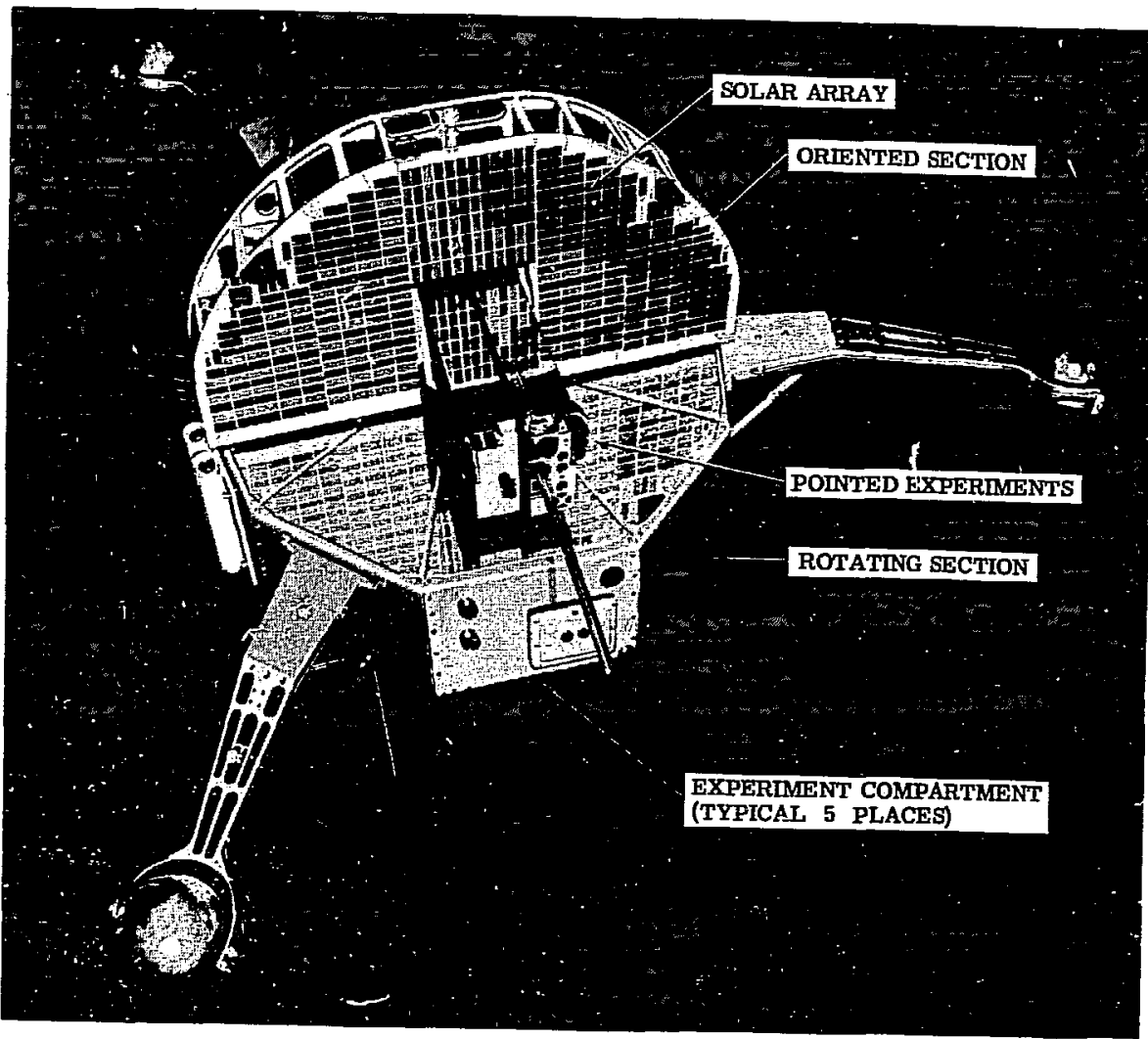

Fig. 1. Perspective view of OSO-4 spacecraft showing upper "sail" section with "wheelar-pointed experiments and the lower experiments in the rotating
"whection. 


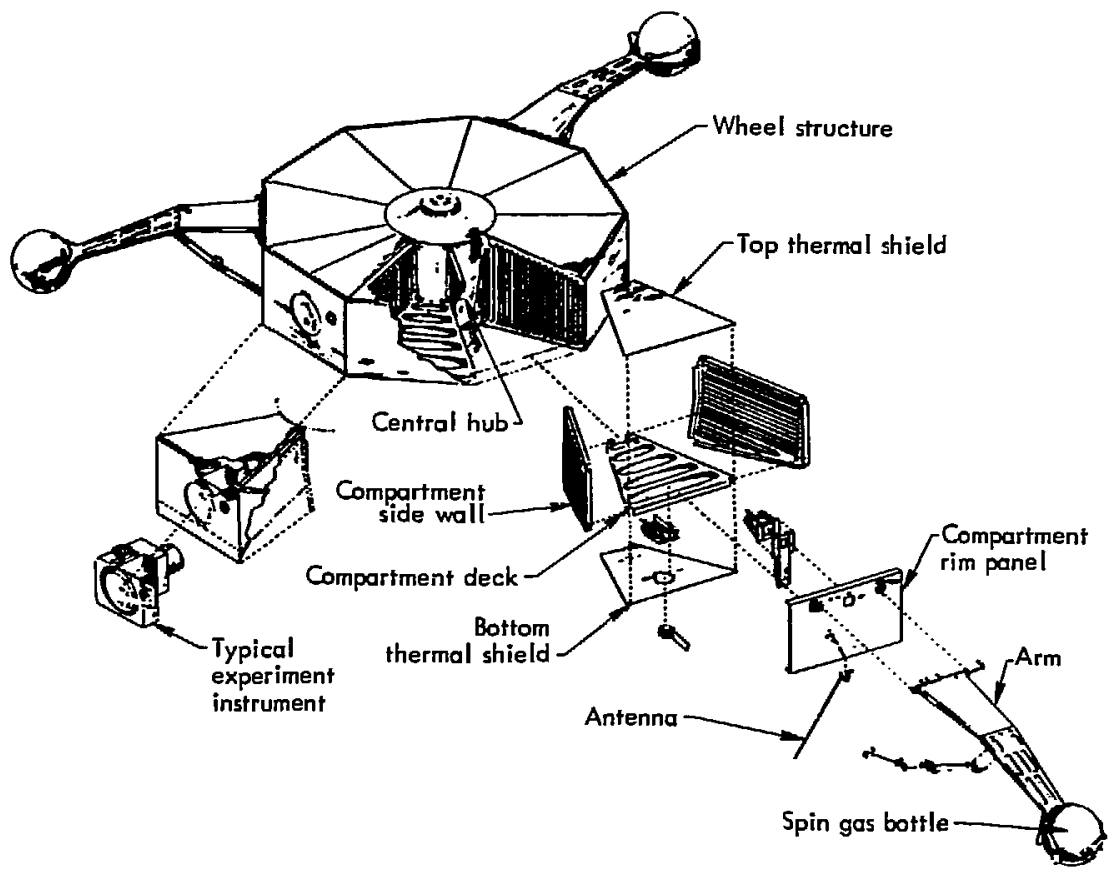

Fig. 2. Exploded diagram showing frame of wheel experiment compartment and a section containing an instrument. 


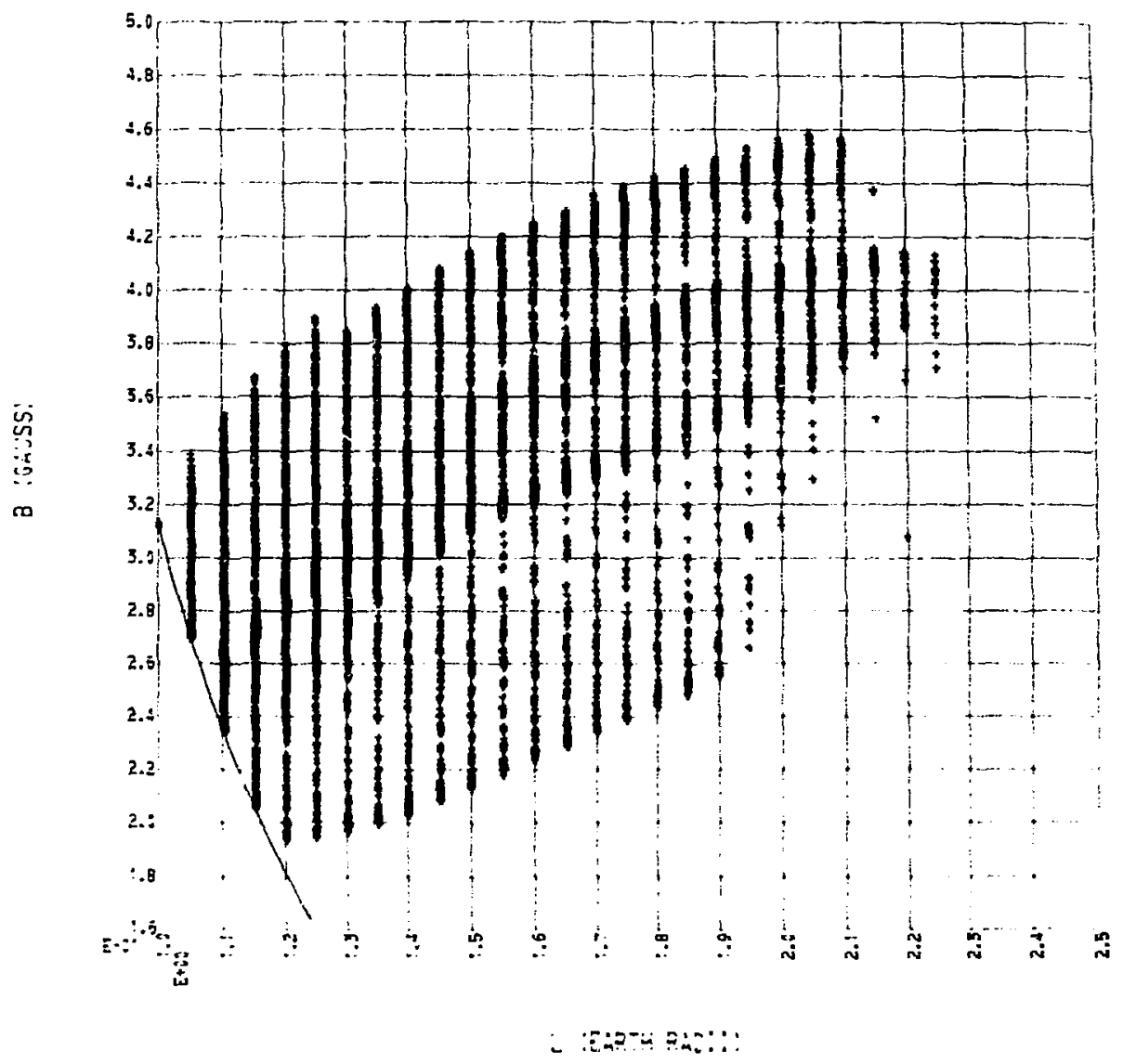

Fig. 3. Scatter map of B, L positions made with 6000 data points.

$-11-$ 


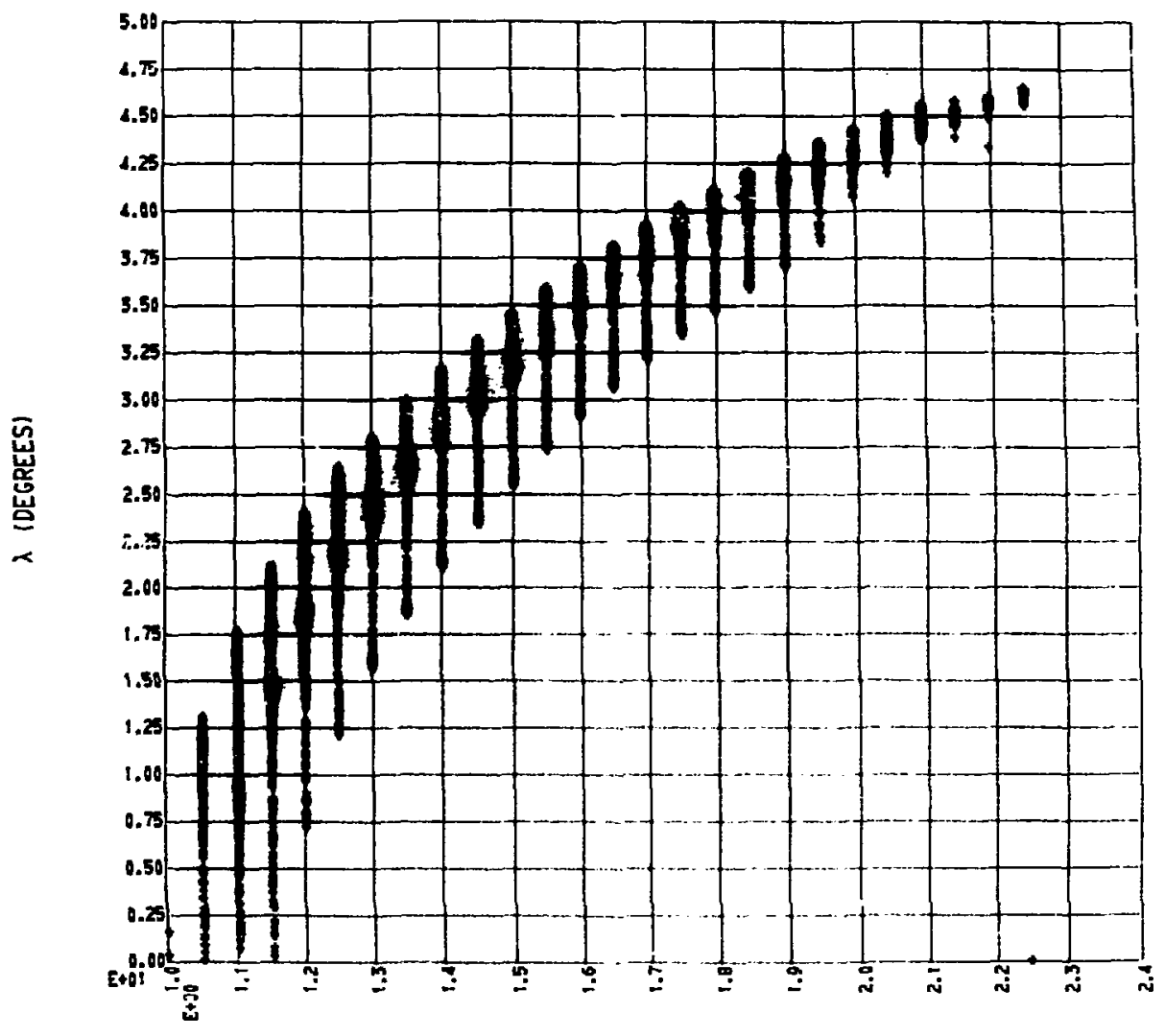

L IEARTH RADIII

Fig. 4. Map of $\lambda, L$ positions of the same points of Fig. 3. The narrow $\lambda$ coverage on a given $L-s h e l l$ due to orbital constraints is obvious. 


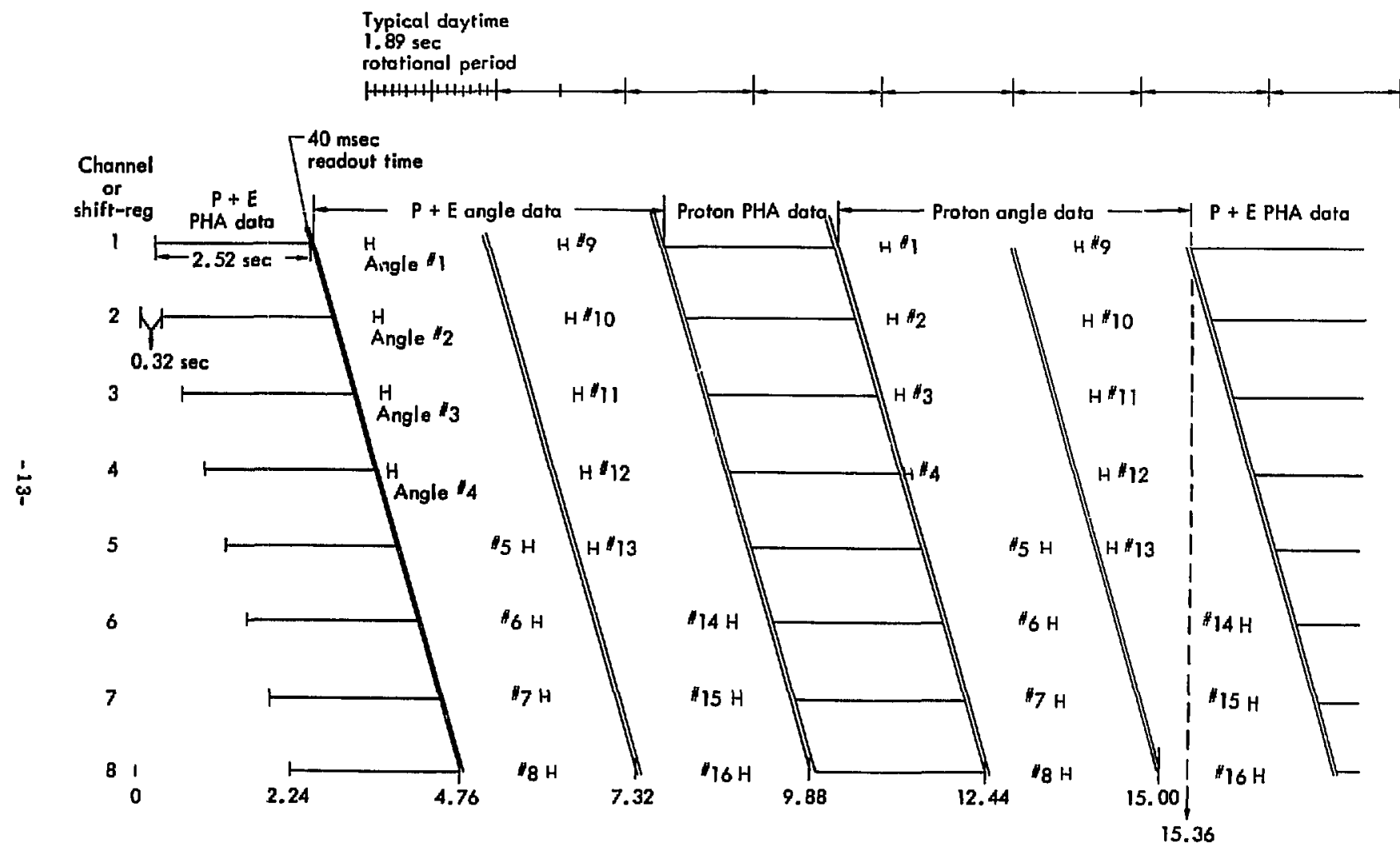

Fig. 5. OSO-4 spectrometer timing diagram illustrating the relative counting cycles for all data accumulated in each shift register. The annotated horizontal line at the top represents a series of wheel rotations below which the accumulation of "angle" data is depicted. 


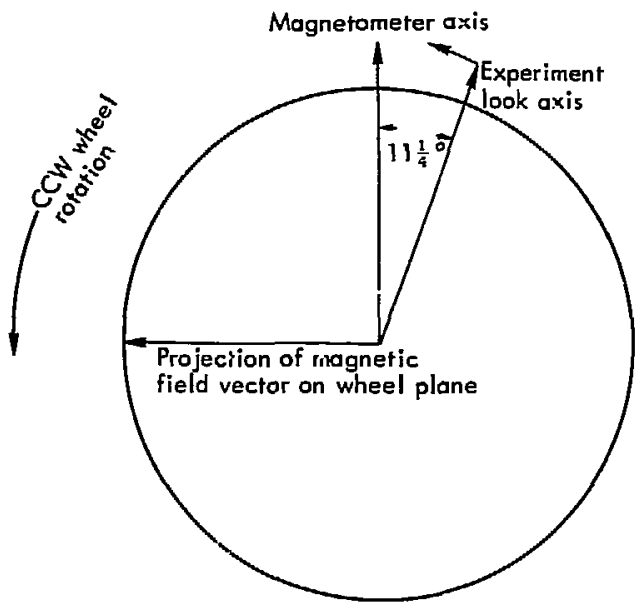

Wheel plane (top view) at start of $P+E$ angle 1 data collection

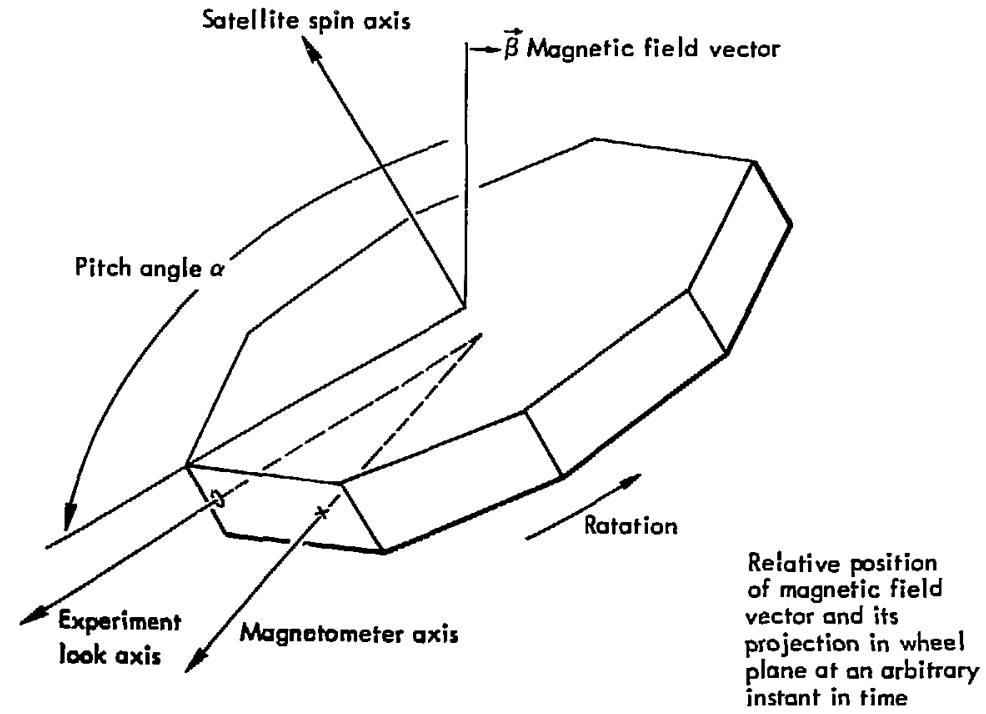

Fig. 6. Picture showing two views of the wheel plane. A B-field vector, the pitch-angle " $\alpha$ " and other physical parameters pertinent to acquisition of angle ciata are shown. 


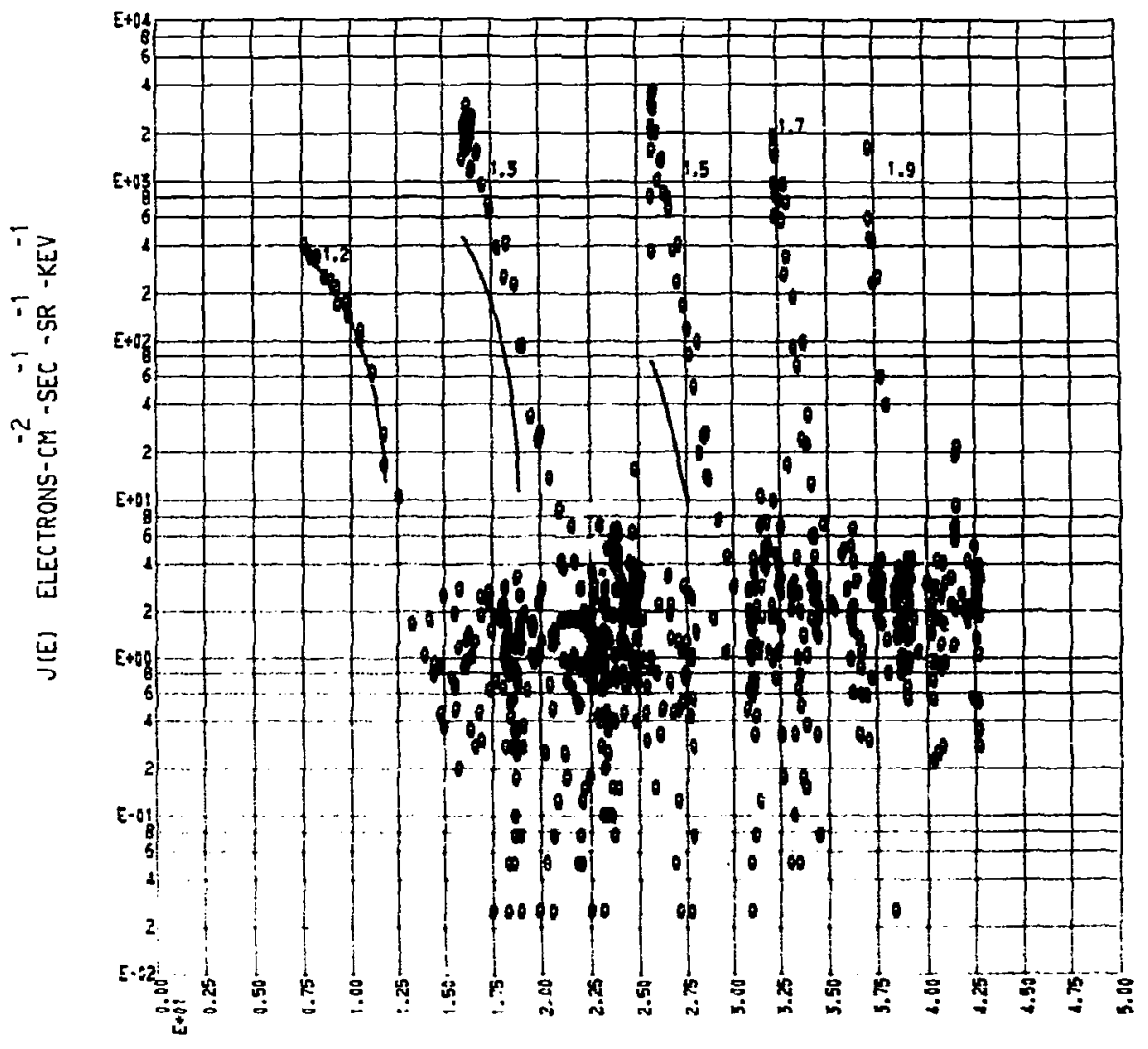

LAMBDA I: DEGREES

Fig. 7. Perpendicular electron flux measured in March 1968. Two plots are provided for each of the electron channels 1 through $5(80.5$ to $121 \mathrm{keV})$. The numbers adjacent to each trace are the L-shell values. Backgrounds are indicated by the solid lines and have not beeni subtracted from the data points. 


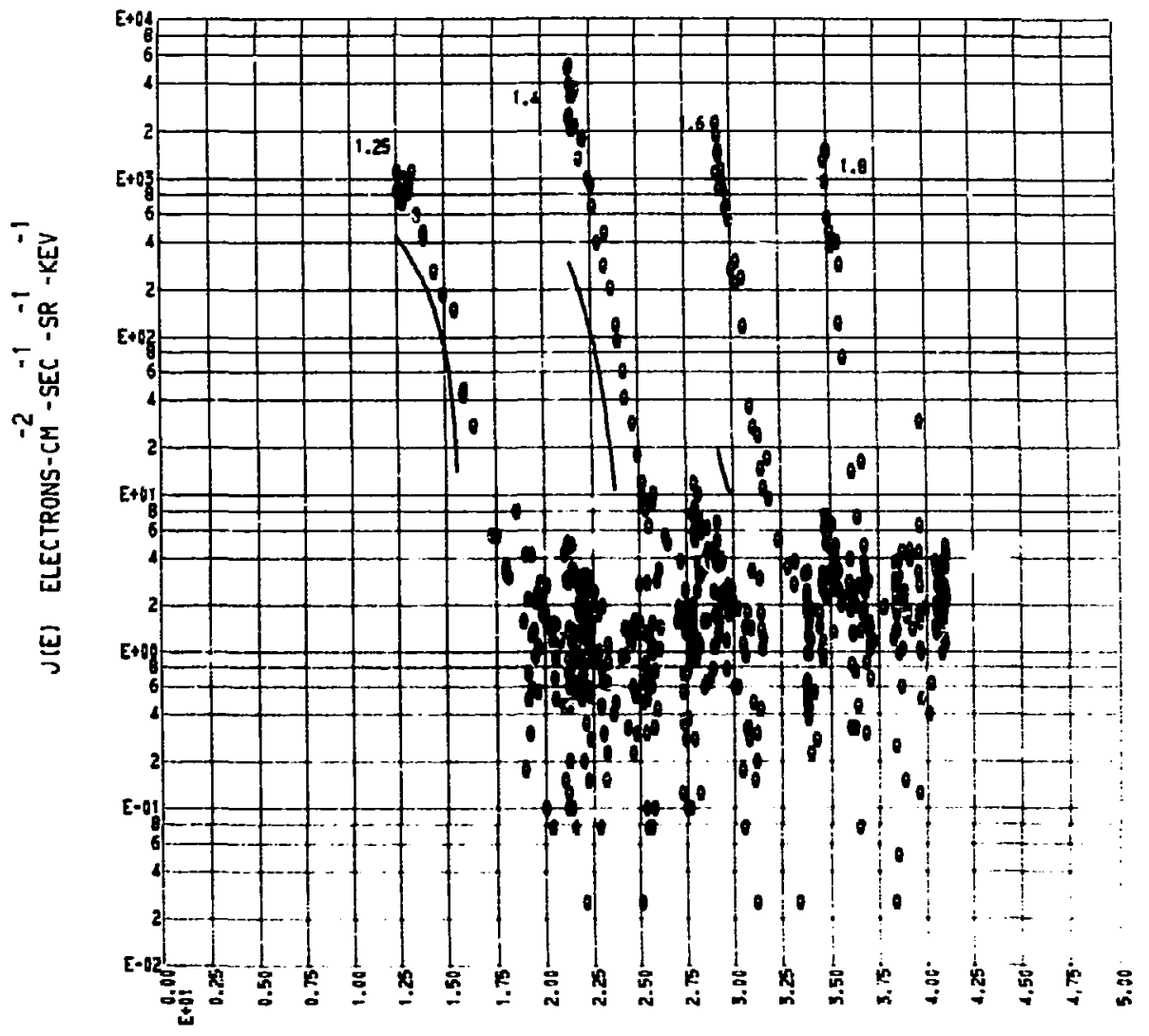

\section{LAMGDA IN DEGREES}

Fig. 8. Perpendicular electron flux measured in March 1968. Two plots are provided for each of the electron channels 1 through $5(80.5$ to $121 \mathrm{keV})$. The numbers adjacent to each trace are the L-shell values. Backgrounds are indicated by the solid lines and have not been suttracted from t'sc data points. 


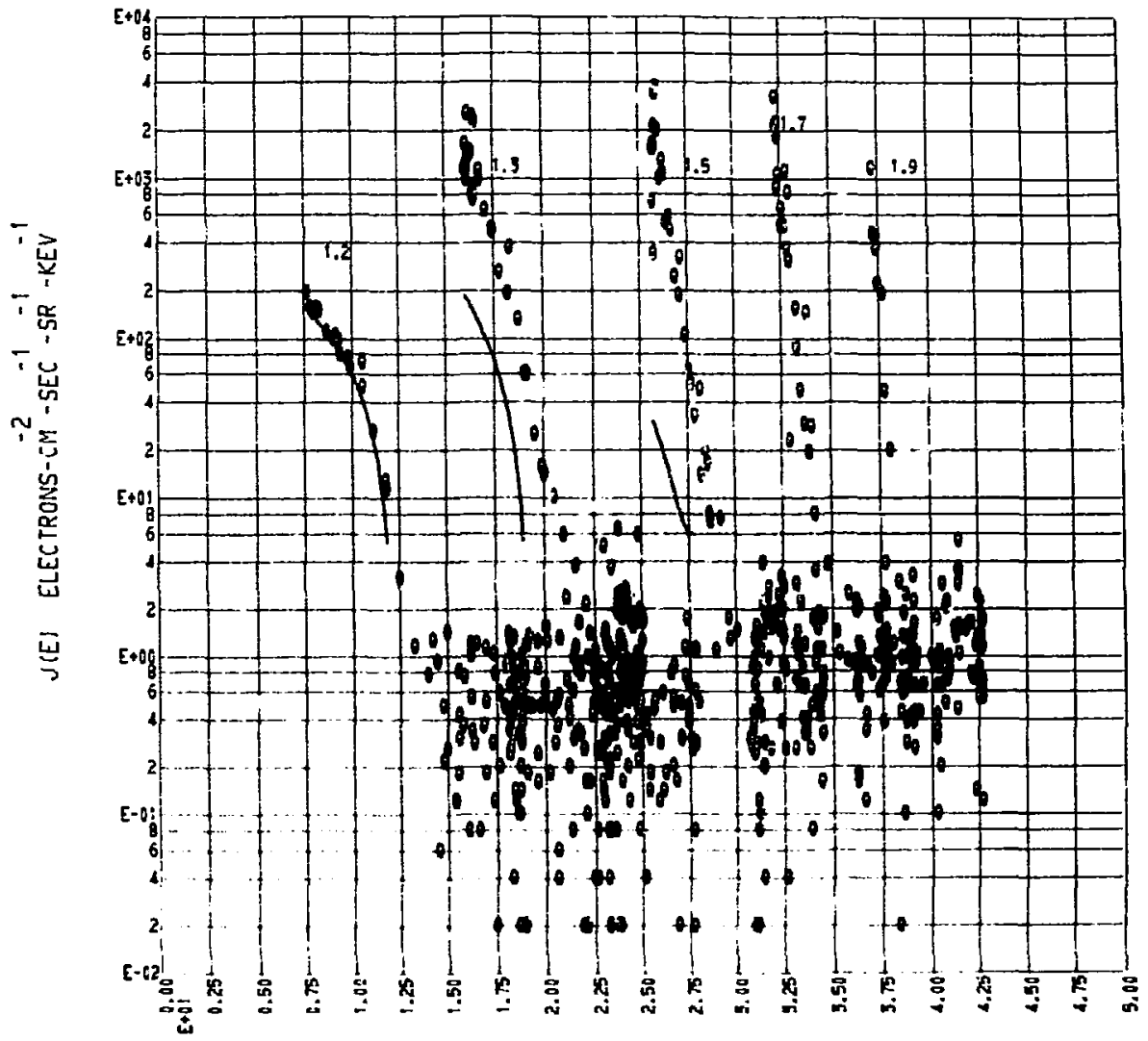

LAMGOA III DEGREES

Fig. 9. Perpendicular electron flux measured in March 1968. Two plots are provided for each of the electron channels 1 through $5(121$ to $171 \mathrm{keV})$. The numbers adjacent to each trace are the $L$-shell values. Backgrounds are indicated by the solid lines and have not been subtracted from the data points. 


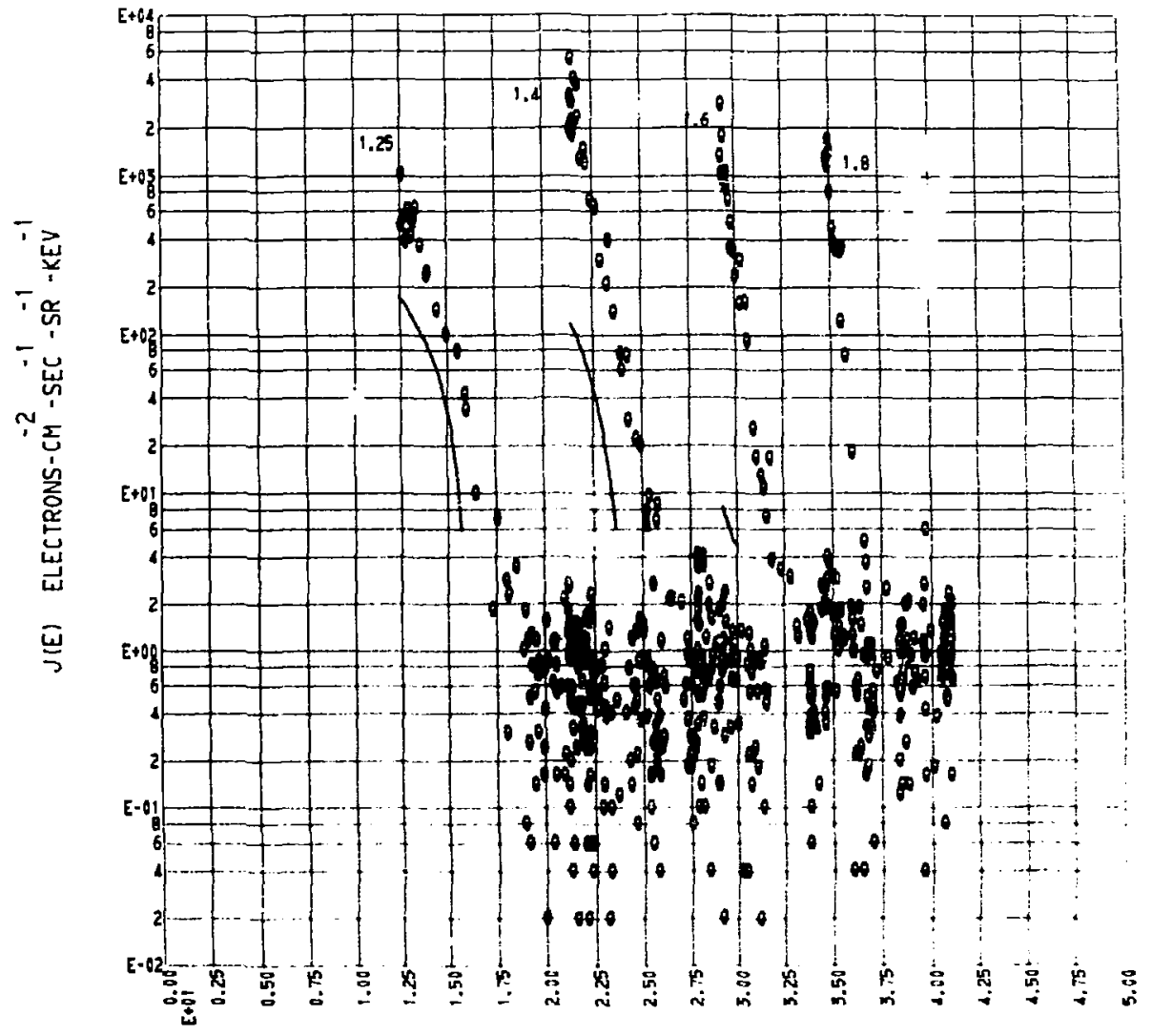

\section{LAMBOA III OEGREES}

Fig. 10. Perpendicular electron flux measured in March 1968. Two plots are provided for each of the electron channels 1 through 5 (121 to $171 \mathrm{keV}$ ). The numbers adjacent to each trace are the L-shell values. Backgrounds are indicated by the solid lines and have not been subtracted from the data points. 


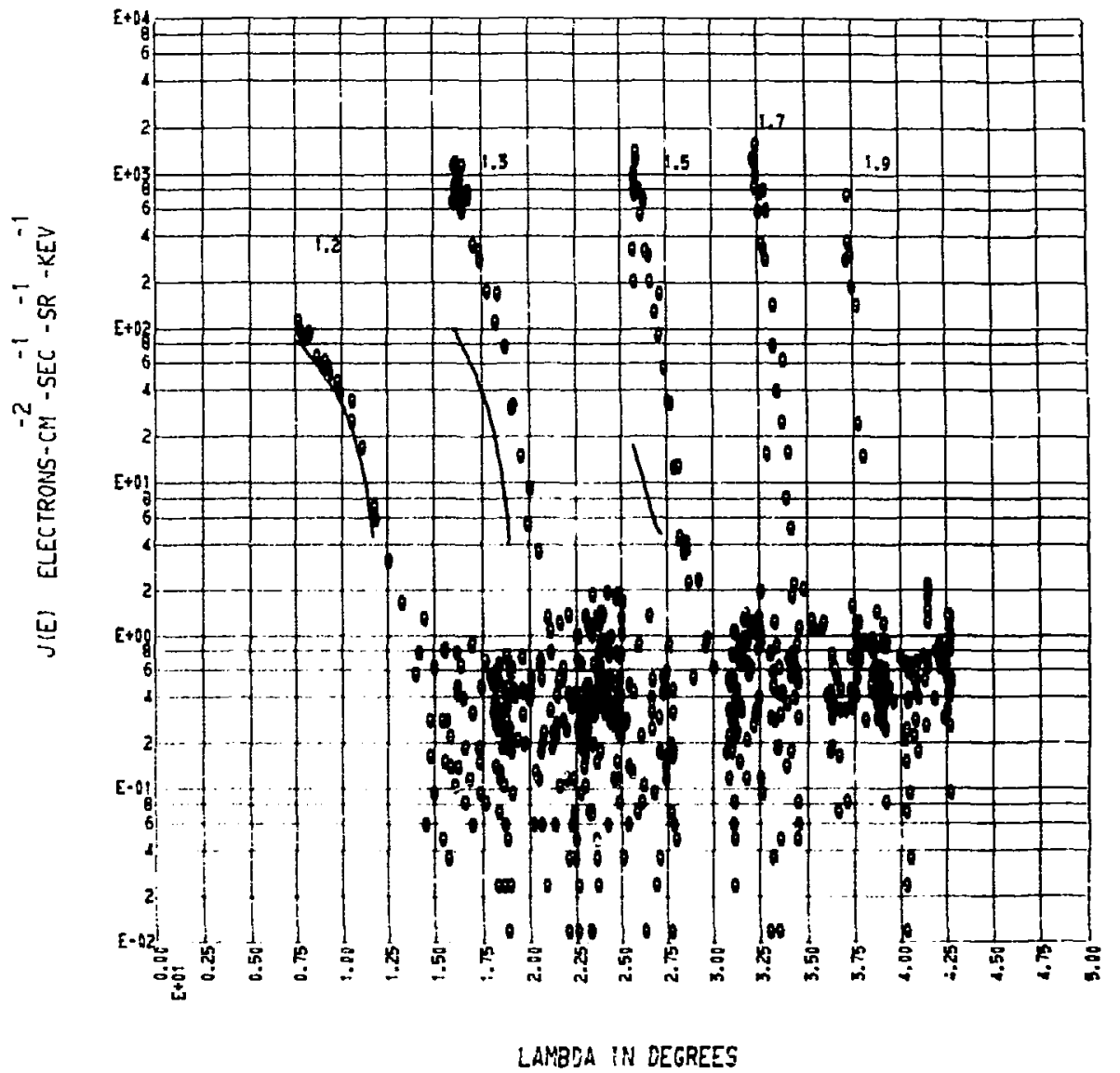

Fig. 11. Perpendicular electron flux measured in March 1968. Two plots are provided for each of the electron channels 1 through 5 (171 to $258 \mathrm{keV}$ ). The numbers adjacent to each trace are the L-shell values. Backgrounds are indicated by the solid lines and have not been subtracted from the data points. 


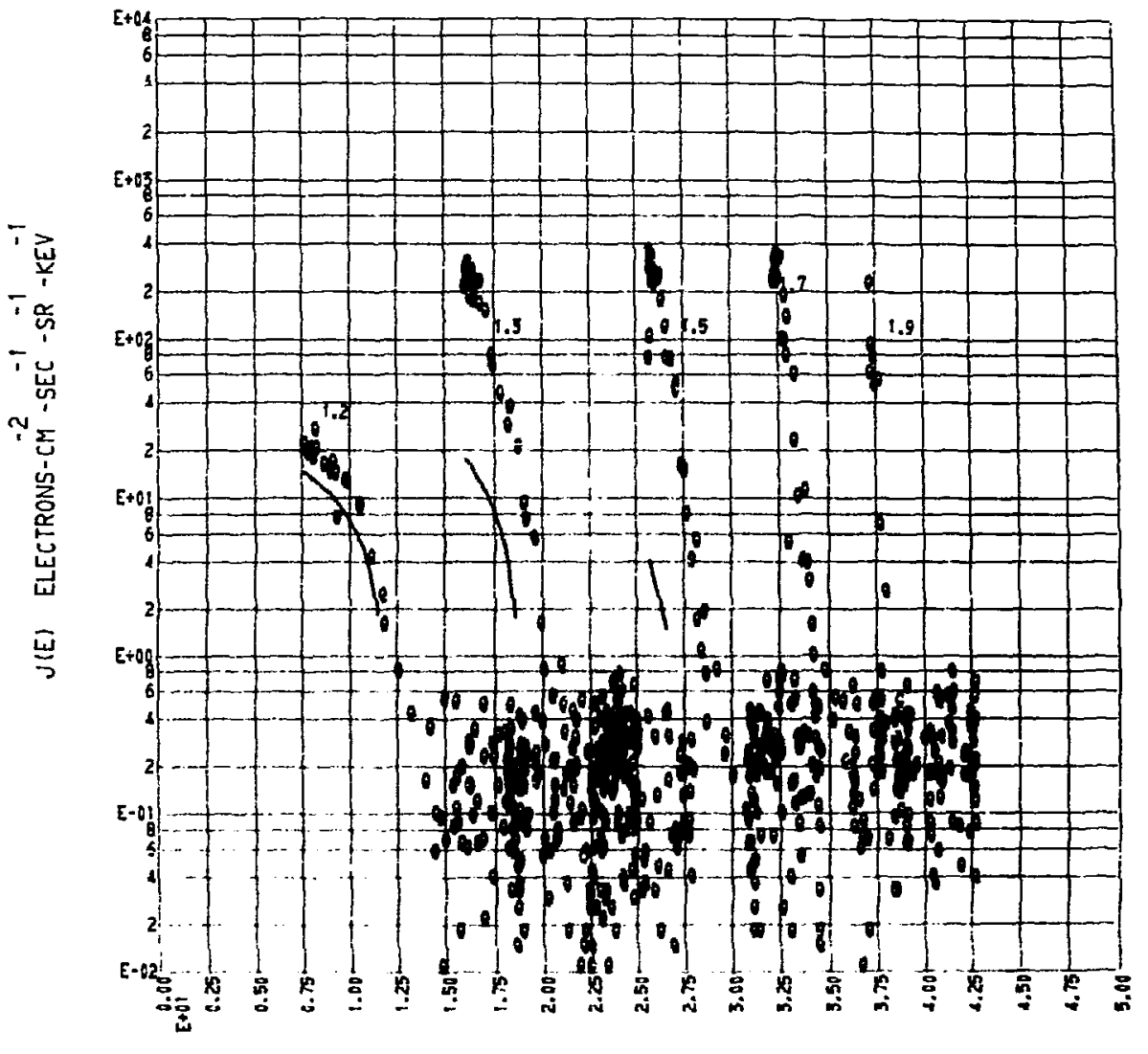

\section{LAMBDA IN DEGREES}

Fig. 13. Perpendicular electron flux measured in March 1968. Two plots are provided for each of the electron channels 1 through 5 (258 to $537 \mathrm{keV}$ ). The numbers adjacent to each trace are the $\mathrm{L}-\mathrm{shell}$ values. Backgrounds are indicated by the solid lines and have not been subtracted from the data points. 


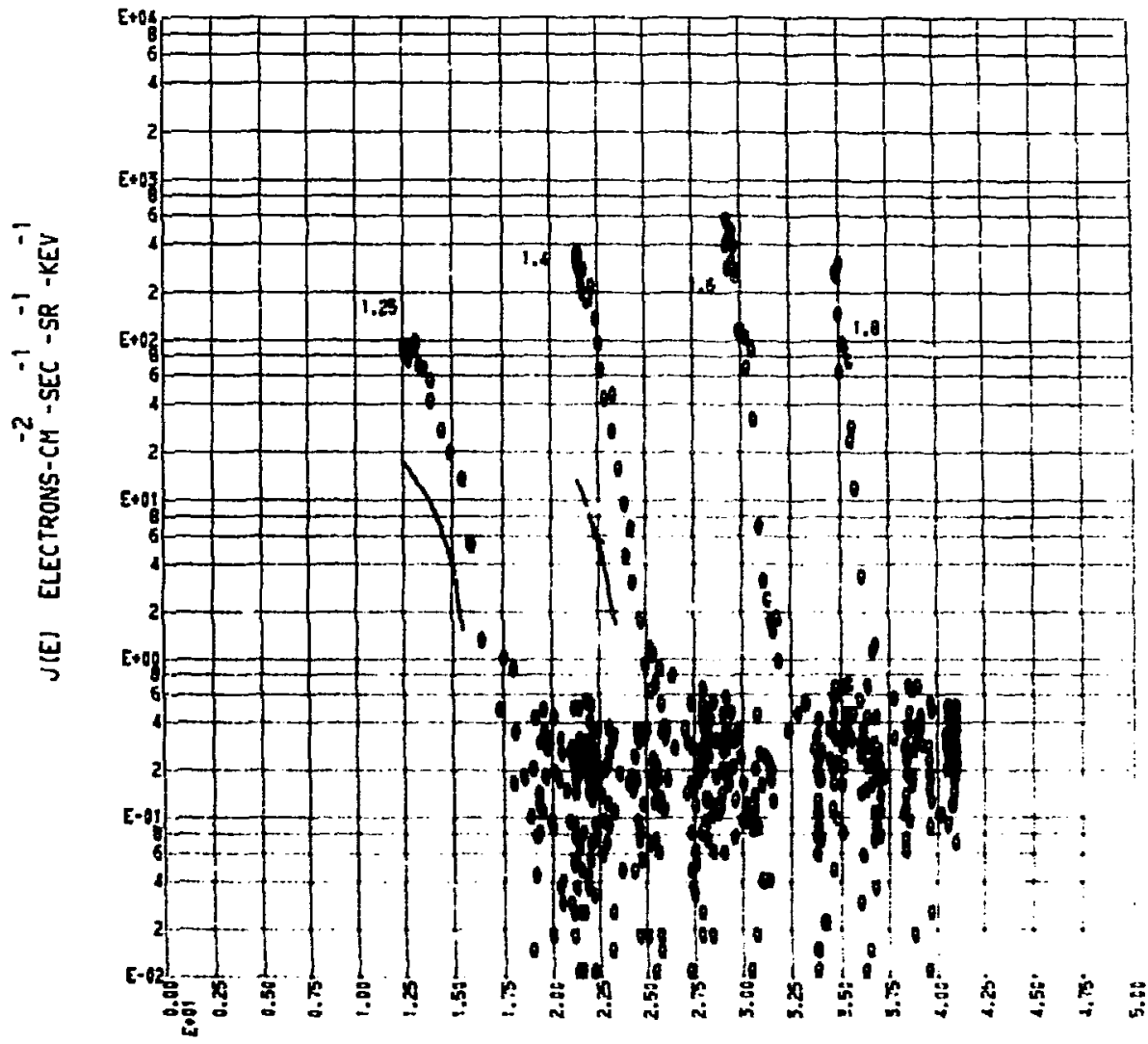

\section{LAUSOH WiI DEgREES}

Fig. 14. Perpendicular electron nux measured in March 1968. Two plots are provided for each of the electron channels I through 5 (258 to $537 \mathrm{keV}$ ). The numbers adjacent to each trace are the L-shell values. Backgrounds are indicated by the solid lines and have not been subtracted from the data points. 


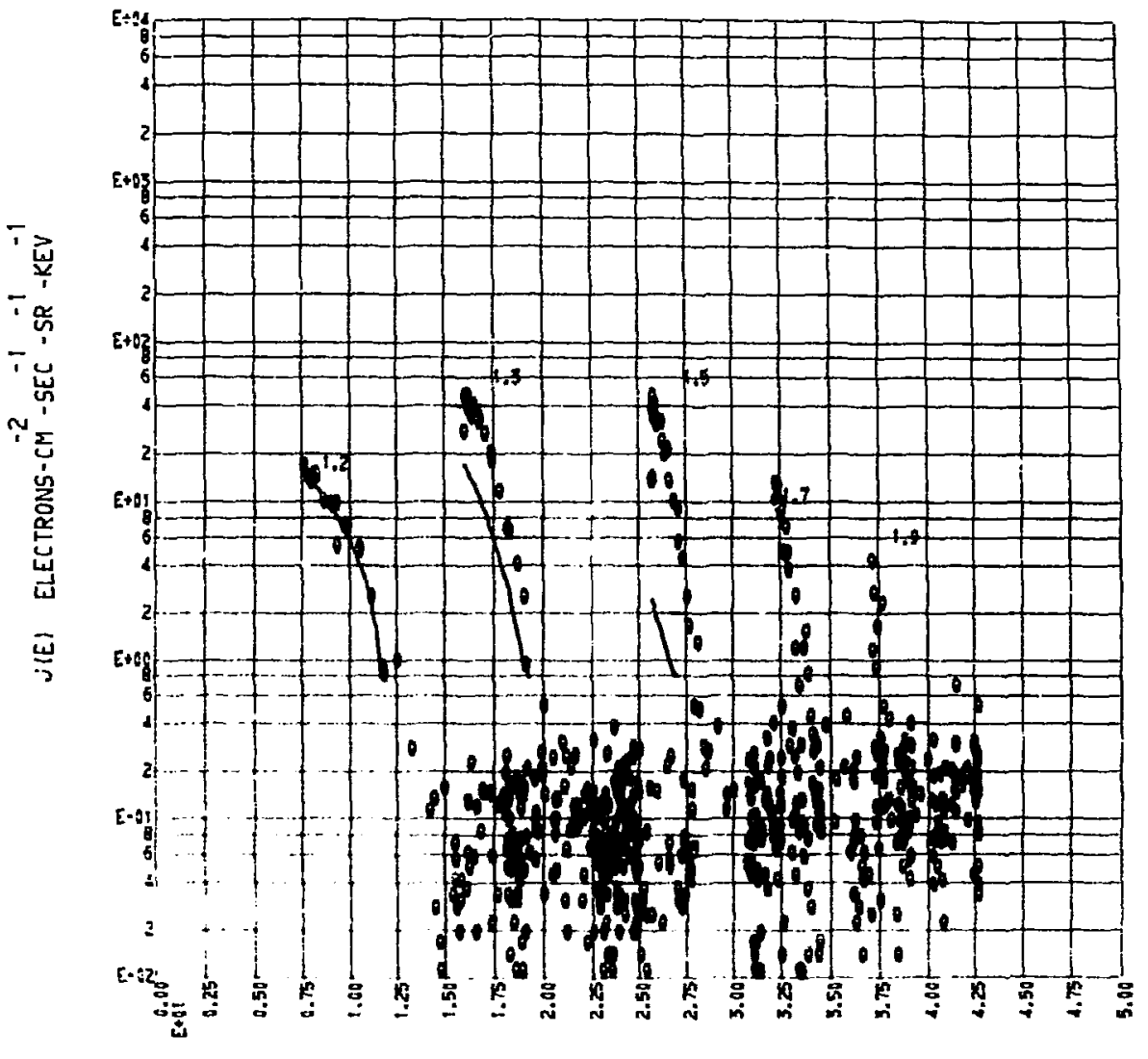

\section{LAMGDA IN DEGREES}

Fig. 15. Perpendicular electron flux measured in March 1968. Two plots are provided for each of the electron channels 1 through 5 ( 537 to $900 \mathrm{keV}$ ). The numbers adjacent to each trace are the L-shell values. Backgrounds are indicated by the solid lines and have not been subtracted from the data points. 


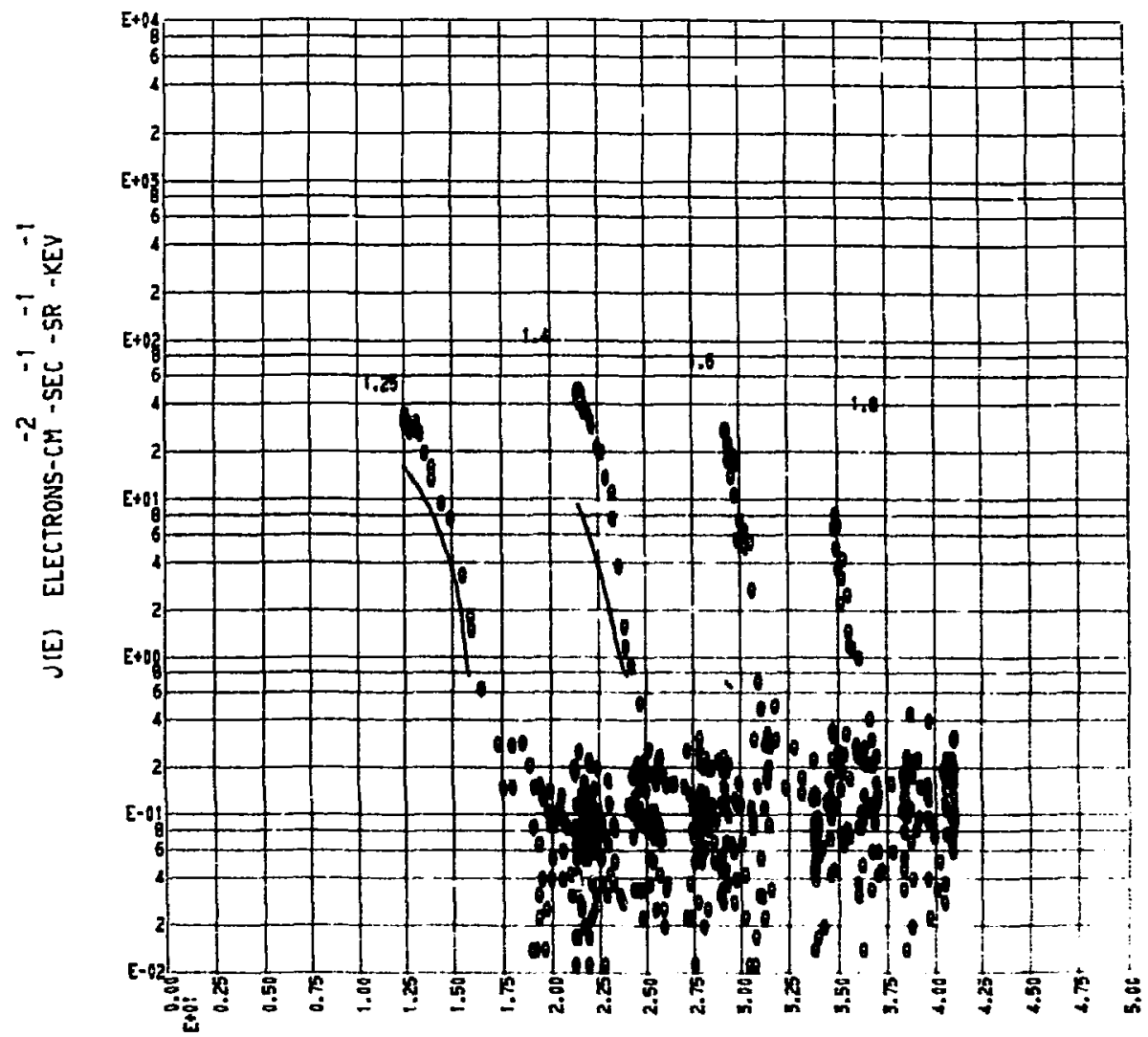

LAMBDA IN DEGREES

Fig. 16. Perpendicular electron flux measured in March 1968. Two plots are provided for each of the electron channels 1 through 5 (537 to $900 \mathrm{keV}$ ). The numbers adjacent to each trace are the L-shell values. Backgrounds are indicated by the solid lines and have not been subtracted from the data points. 


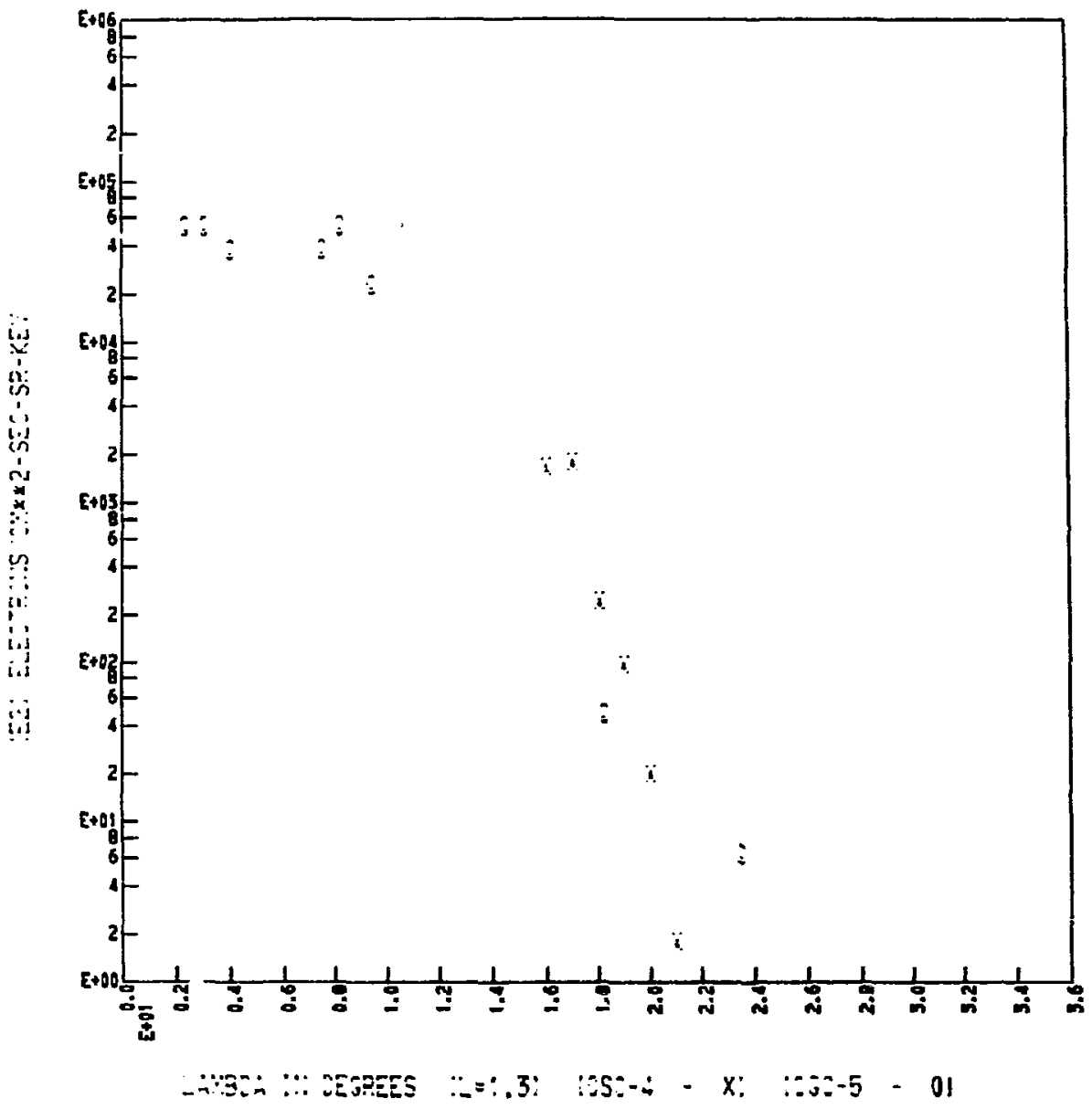

Fig. 17. Comparison of OSO-4 perpendicular $\left(E_{2}\right)$ electron flux with OGO-5 data at $L$ value of 1.3 in March 1968. Better agreement is noticeable at the lower $L$ values presented. 


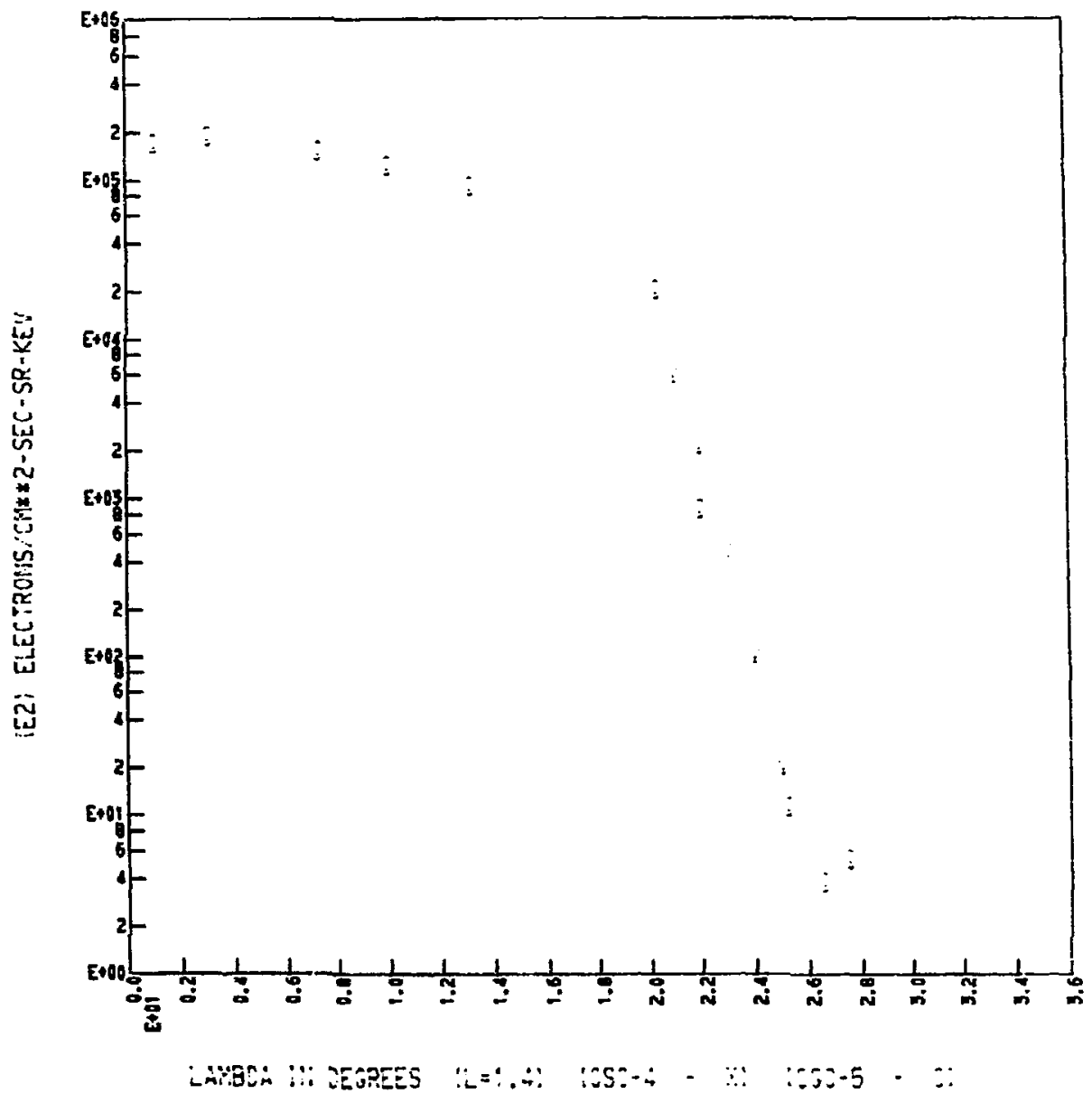

Fig. 18. Comparison of OSO-4 perpendicular $\left(E_{2}\right)$ electron flux with OGO-5 data at $L$ value of 1.4 in March 1968. Better agreement is noticeable at the lower $L$ values presented. 


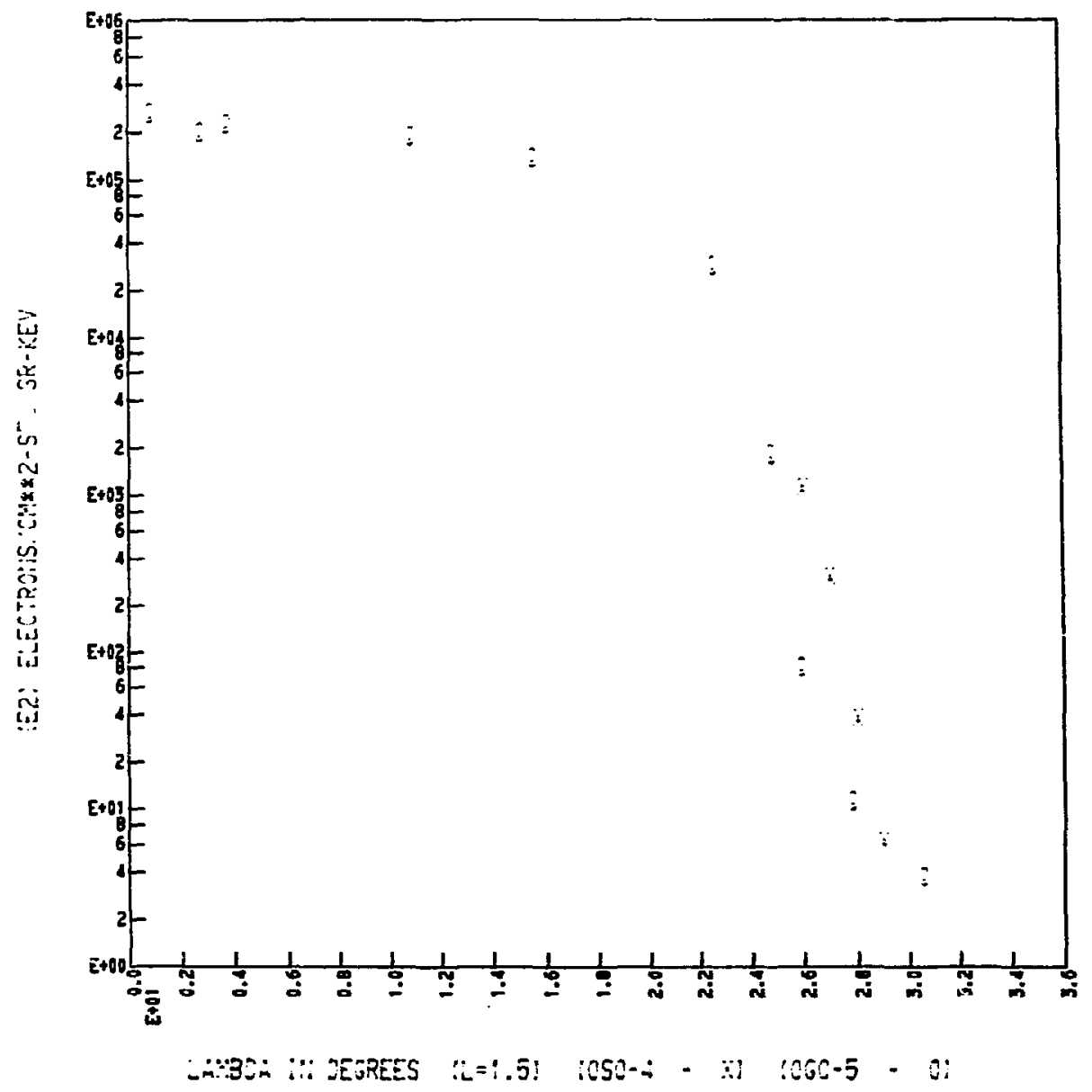

Fig. 19. Comparison of OSO-4 perpendicular $\left(E_{2}\right)$ electron nux with OGO-5 data at $L$ value of 1.5 in March 1968. Better agreement is noticeable at the lower $L$ values presented. 


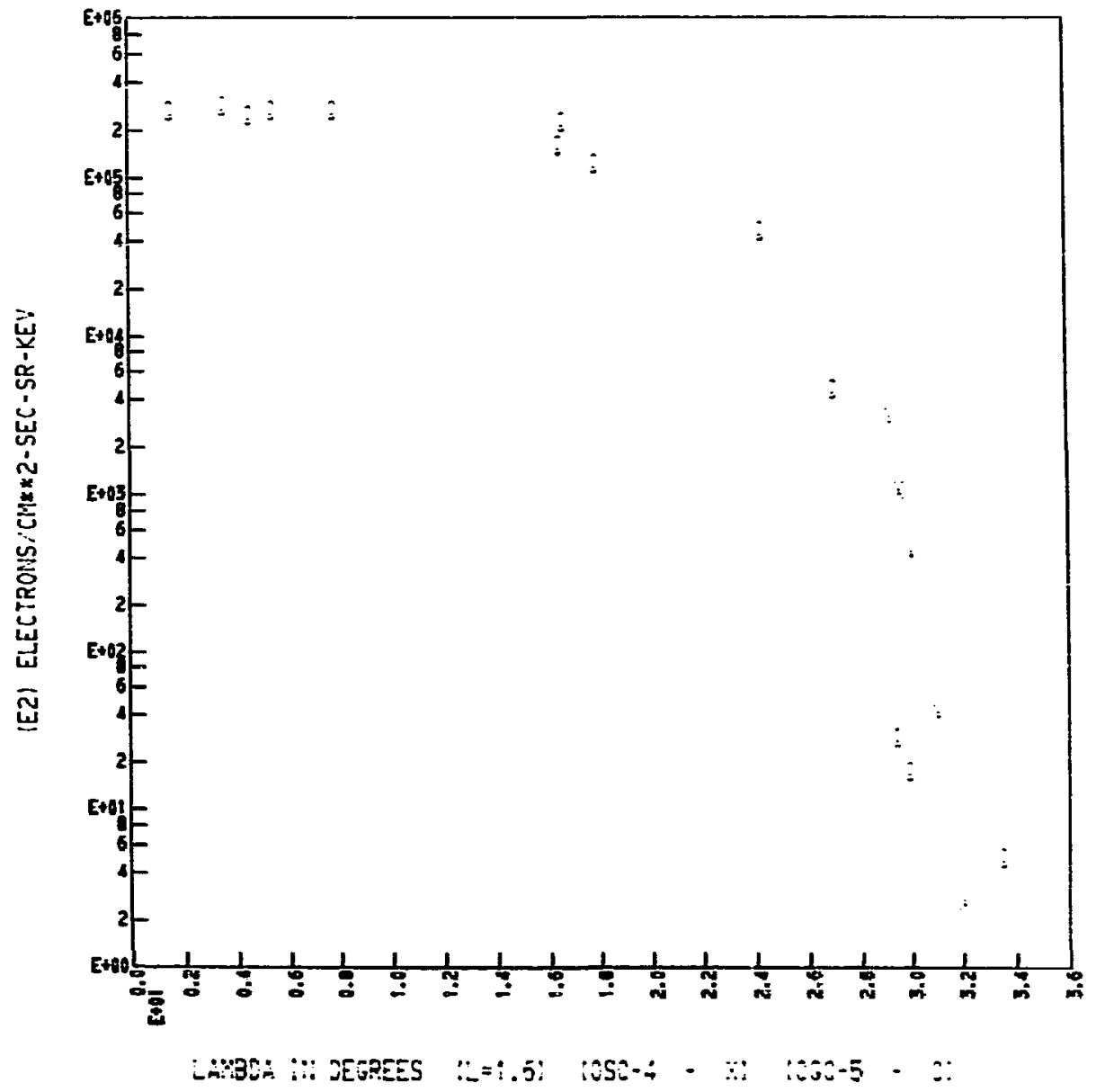

Fig. 20. Comparison of OSO-4 perpendicular $\left(E_{2}\right)$ electron nux with OGO-5 data at $L$ value of 1.6 in March 1968. Better agreement is noticeable at the lower $L$ values presented. 


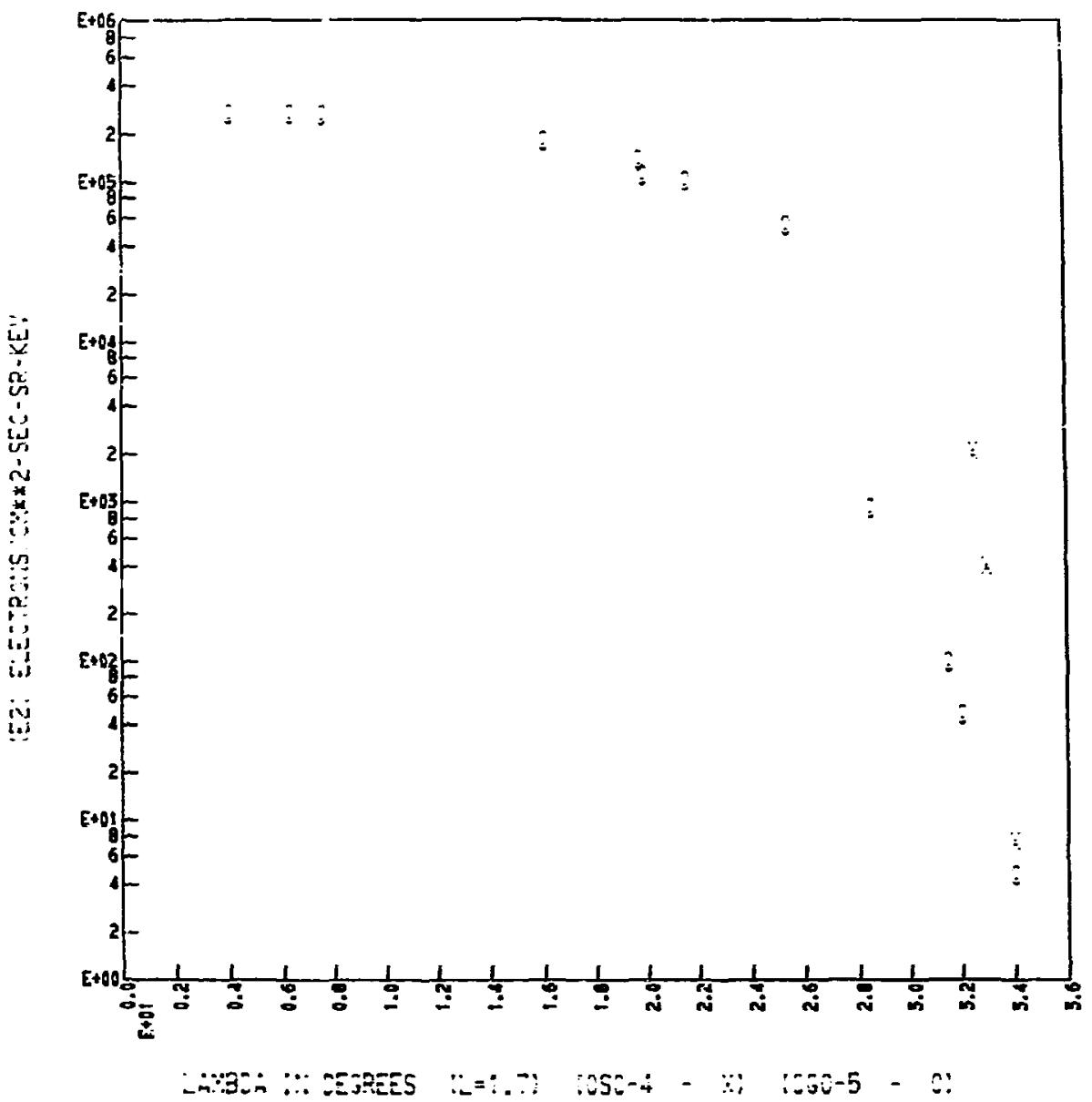

Fig. 21. Comparison of OSO-4 perpendicular ( $E_{2}$ ) electron flux with OGO-5 data at $L$ valne of 1.7 in March 1968. Better agreement is noticcable at the lower $L$ values presented. 


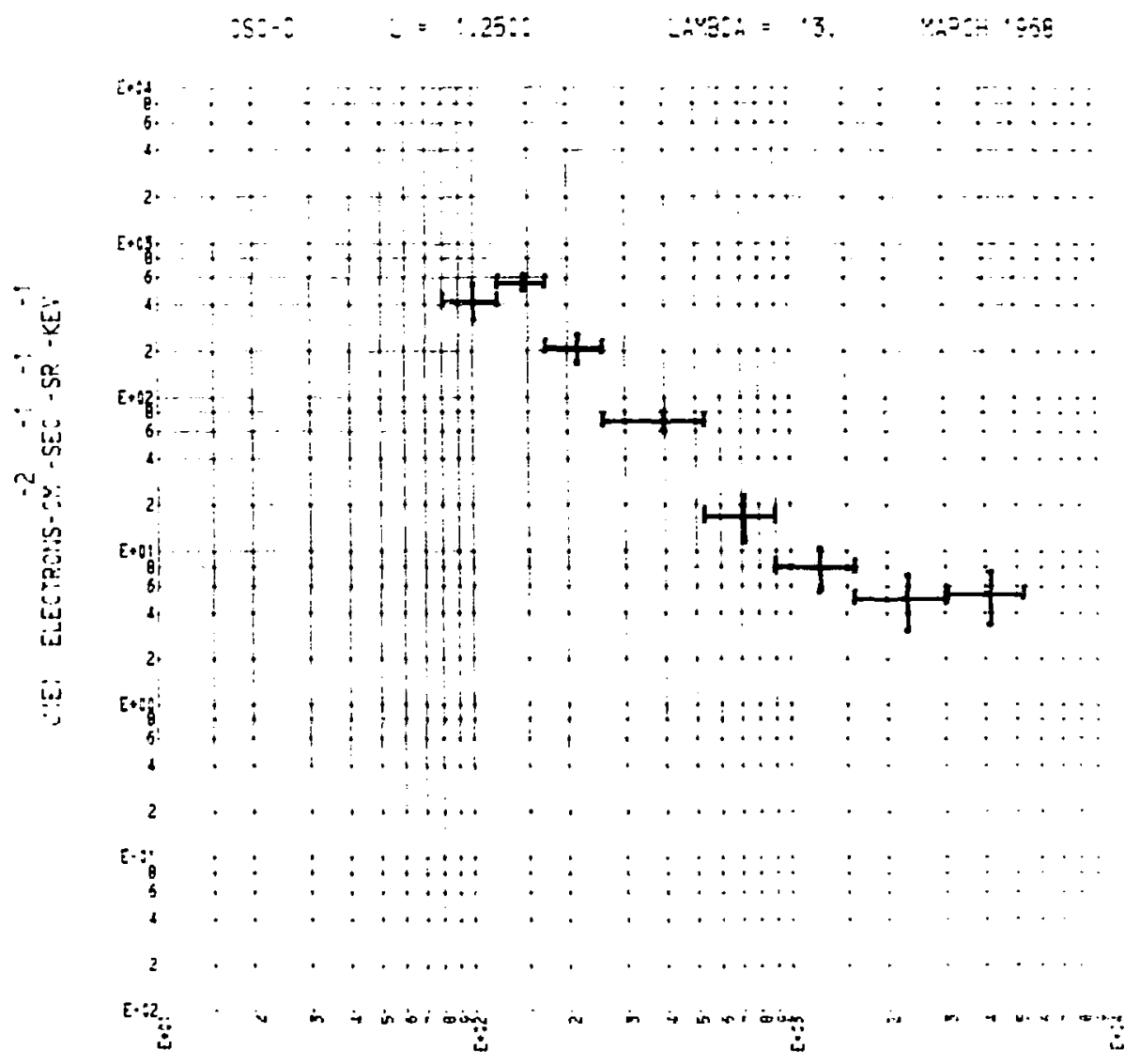

$E=8, \because \square$

Fig. 22. Energy spectra plots of OSO-4 perpendicular electron flux measured in March 1968. These spectra were selected as close to the equator as permitted by available data. The vertical bars are a measure of the uncertainty: the horizontal bars indicate the width of each energy bin. 


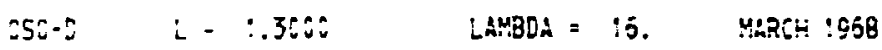

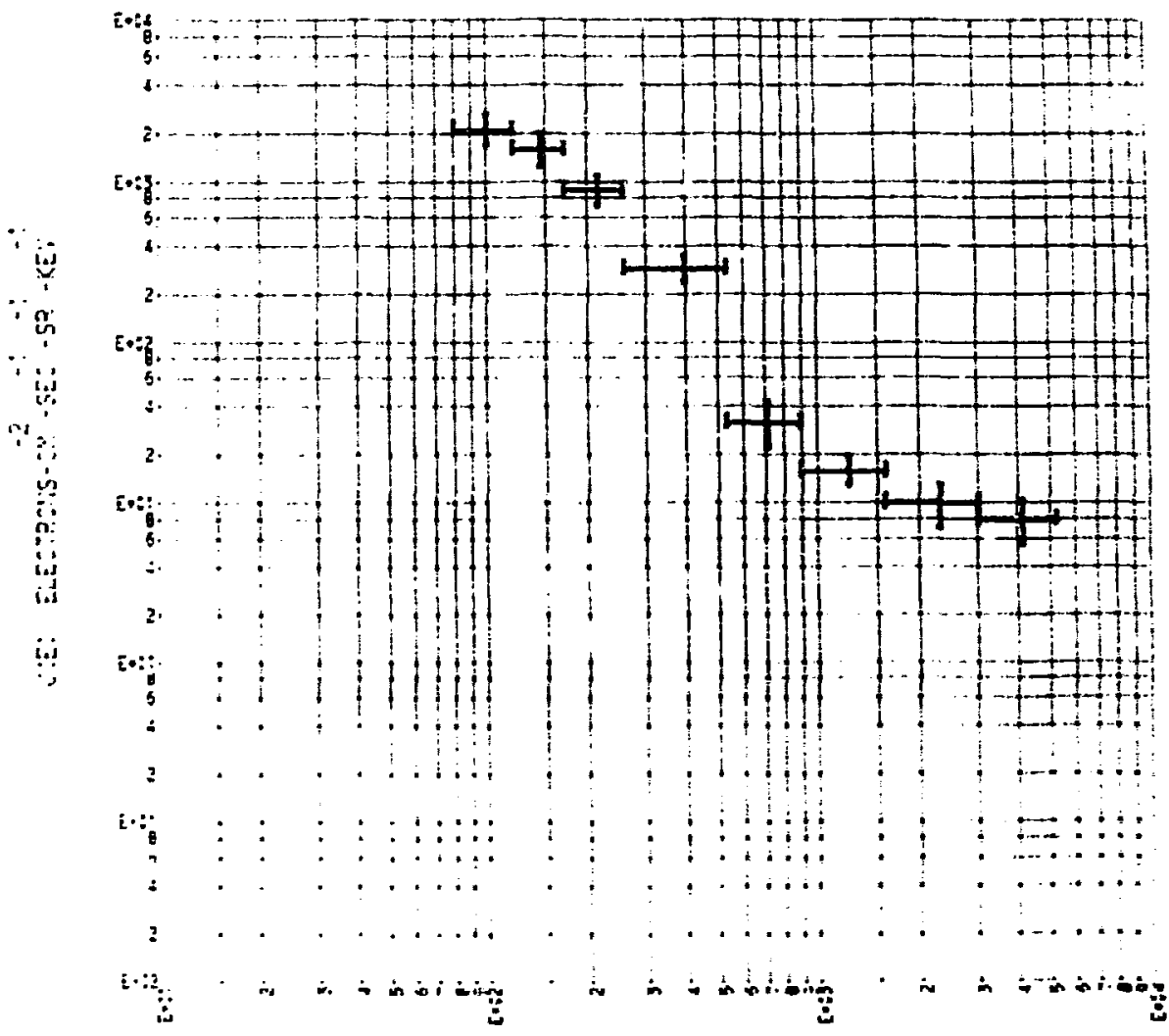

E:57: ::: E:

Fig. 23. Energy spectra plots of OSO-4 perpendicular eleetron flux measu red in March 1968. These spectra were selected as close to the equator as permitted by avallable data. The vertical bars are a measure of the uncertainty: the horizontal bars indicate the width of each energy bin. 


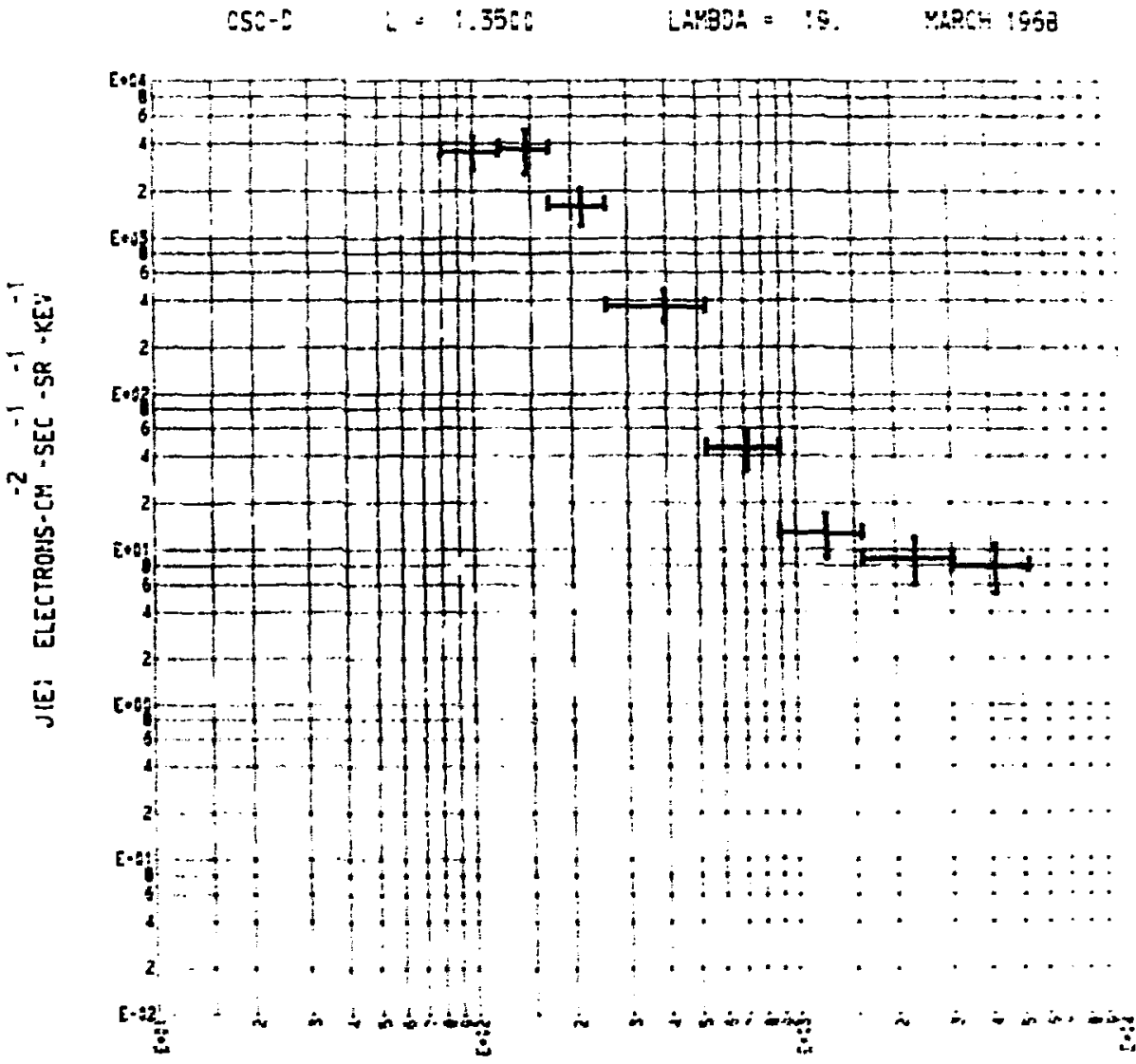

E:ERG: :-. KE:

Fig. 24. Energy spectra plots of OSO-4 perpendicular electron flux measu red in March 1968. These spectra were selected as close to the equator as permitted by available data. The vertical bars are a measure of the uncertainty: the horizontal bars indicate the width of each energy bin. 


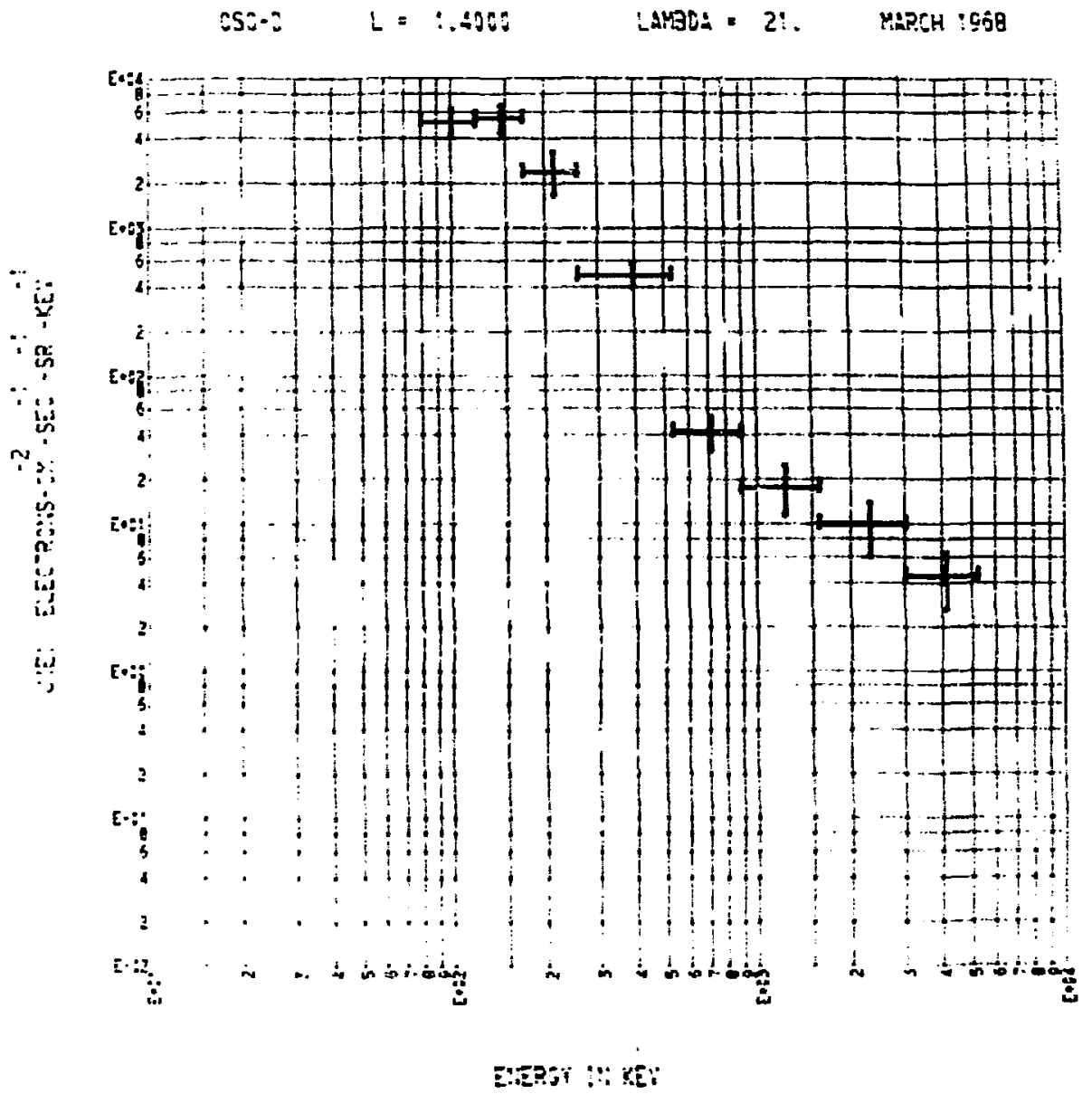

Fig. 25. Energy spectra plots of OSO-4 perpendicular electron Iux measured in March 1968. These spectra were selected as close to the equator as permitted by available data. The vertical bars are a measure of the uncertainty: the horizontal bars indicate the width of each energy bin. 


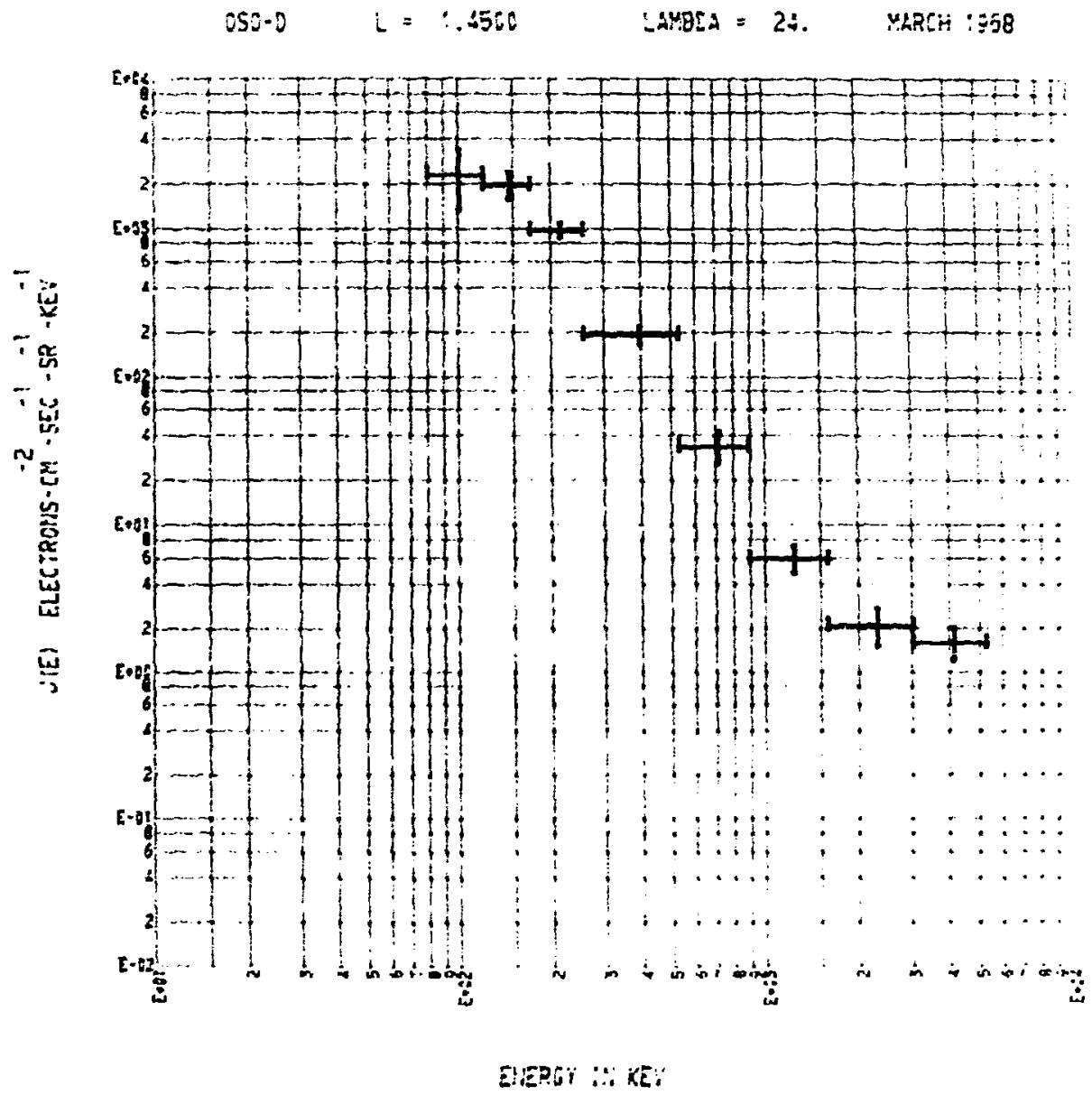

Fig. 26. Energy spectra plots of OSO-4 perpendicular electron flux measu red in March 1968. These spectra were selected as close to the equator as permitted by available data. The vertical bars are a measure of the uncertainty: the horizontal bars indicate the width of each energy bin. 


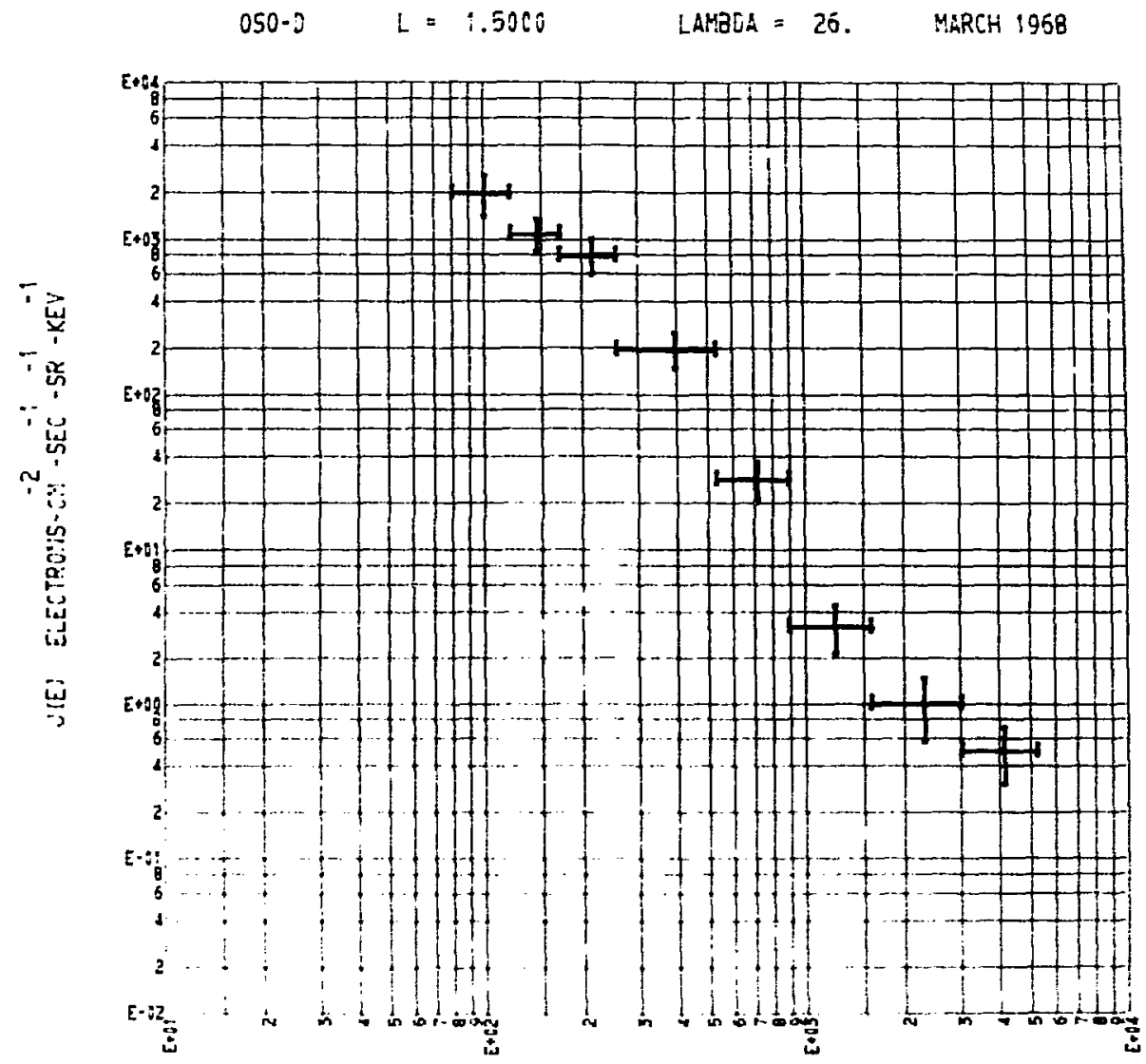

EMERGY I:i KEY

Fig. 27. Energy spectra piots of OSO-4 perpendicular electron flux measured in March 1968. These spectra were selected as close to the equator as permitted by available data. The vertical bars are a measure of the uncertainty: the horizontal bars indicate the width of each energy bin. 
CSD-D

28.

MARCH 1968

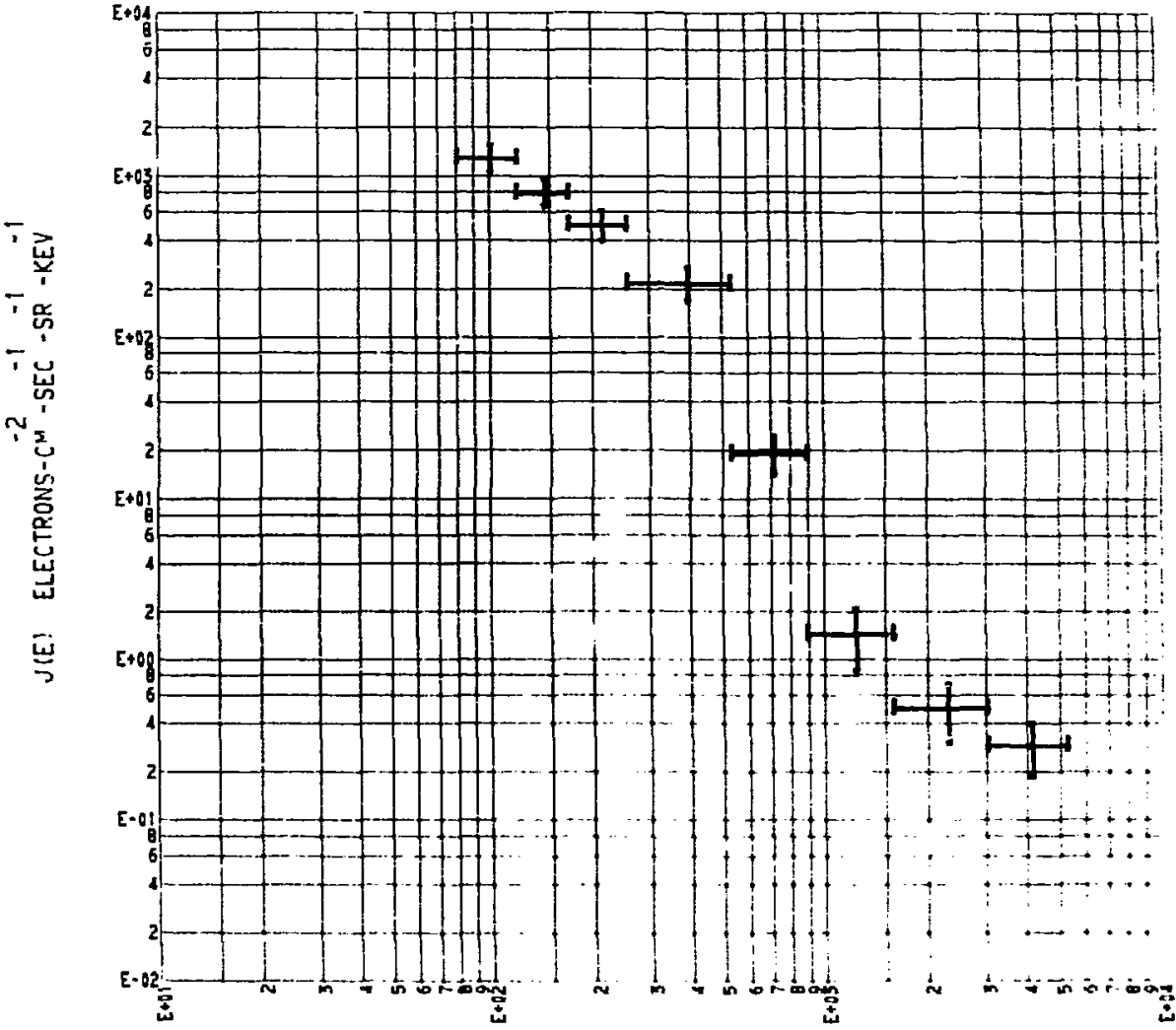

ENERGY WN KE:

Fig. 28. Energy spectra plots of OSO-4 perpendicular electron flux measured in March 1968. These spectra were selected as close to the equator as permitted by available data. The vertical bars are a measure of the uncertainty: the horizontal bars indicate the width of each energy bin. 


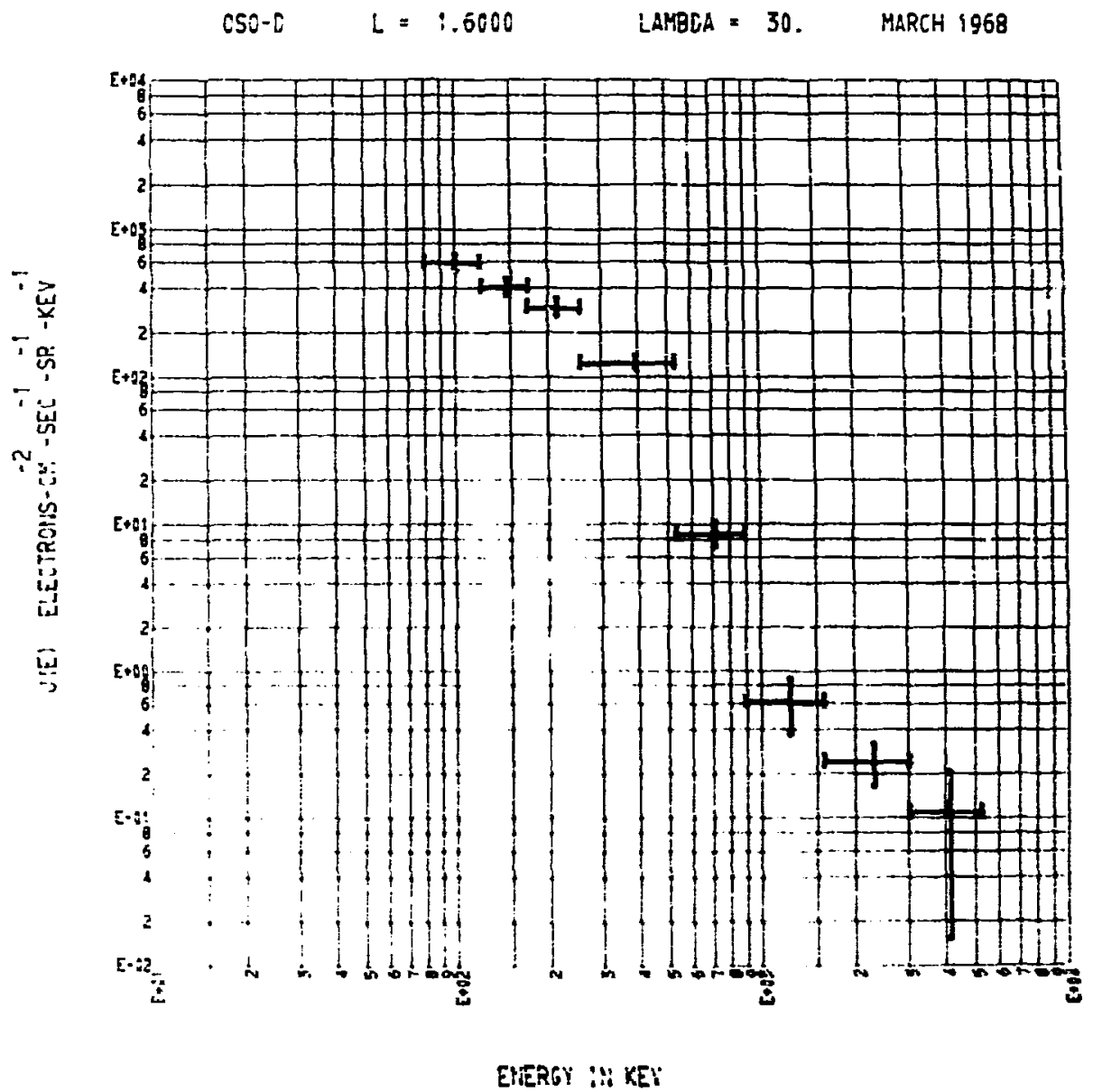

Fig. 29. Energy spectra plots of OSO-4 perpendicular electron nux measured in March 1968. These spectra were selected as close to the equator as permitted by avaiiable data. The vertical bars are a measure of the uncertainty: the horizontal bars indicate the width of each energy bin. 


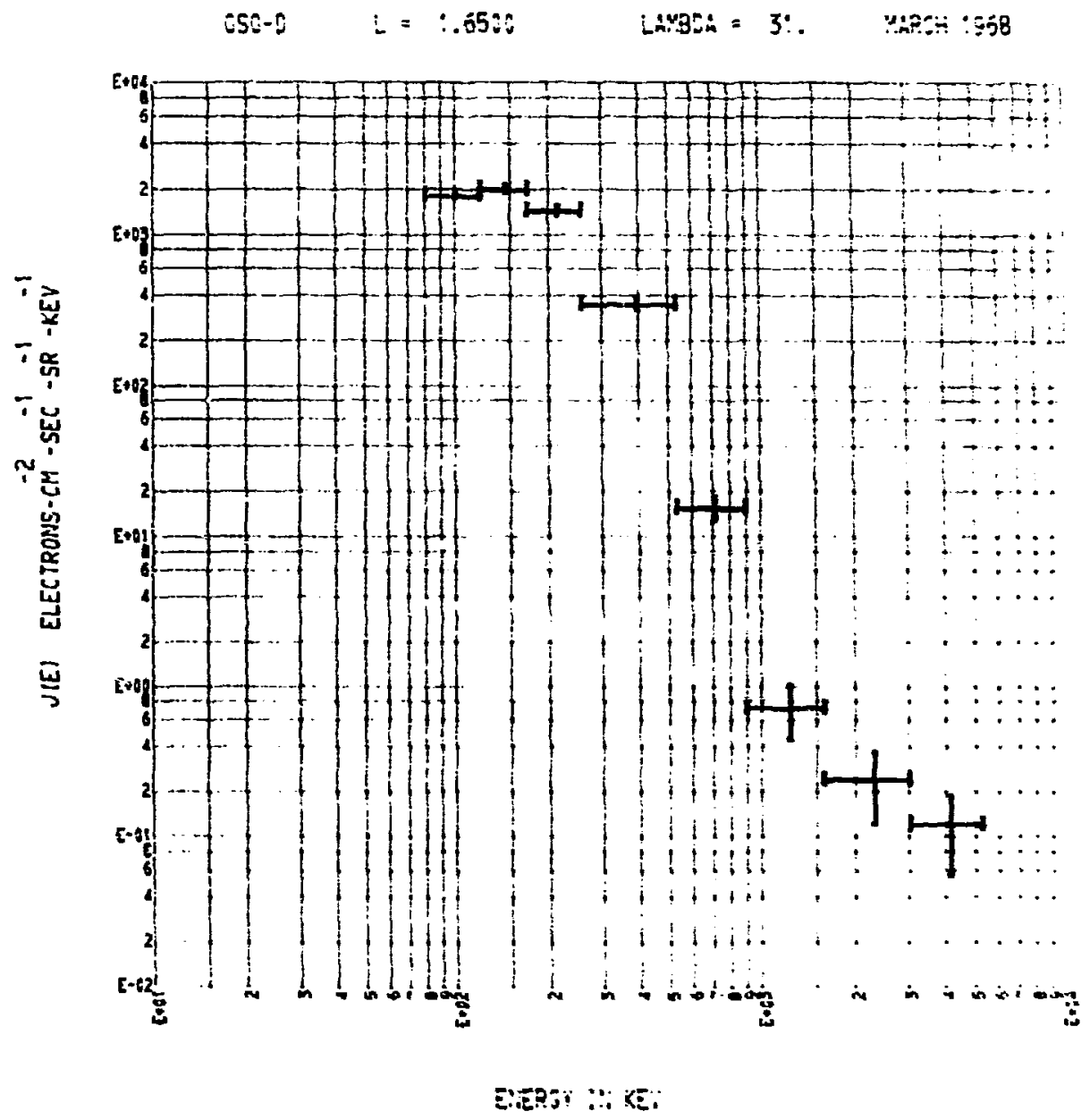

Fig. 30. Energy spectra plots of OSO-4 perpendicular electron flux measured in March 1968. These spectra were selected as close to the equator as permitted by available data. The vertical bars are a measure of the uncertainty: the horizontal bars indicate the width of each energy bin. 


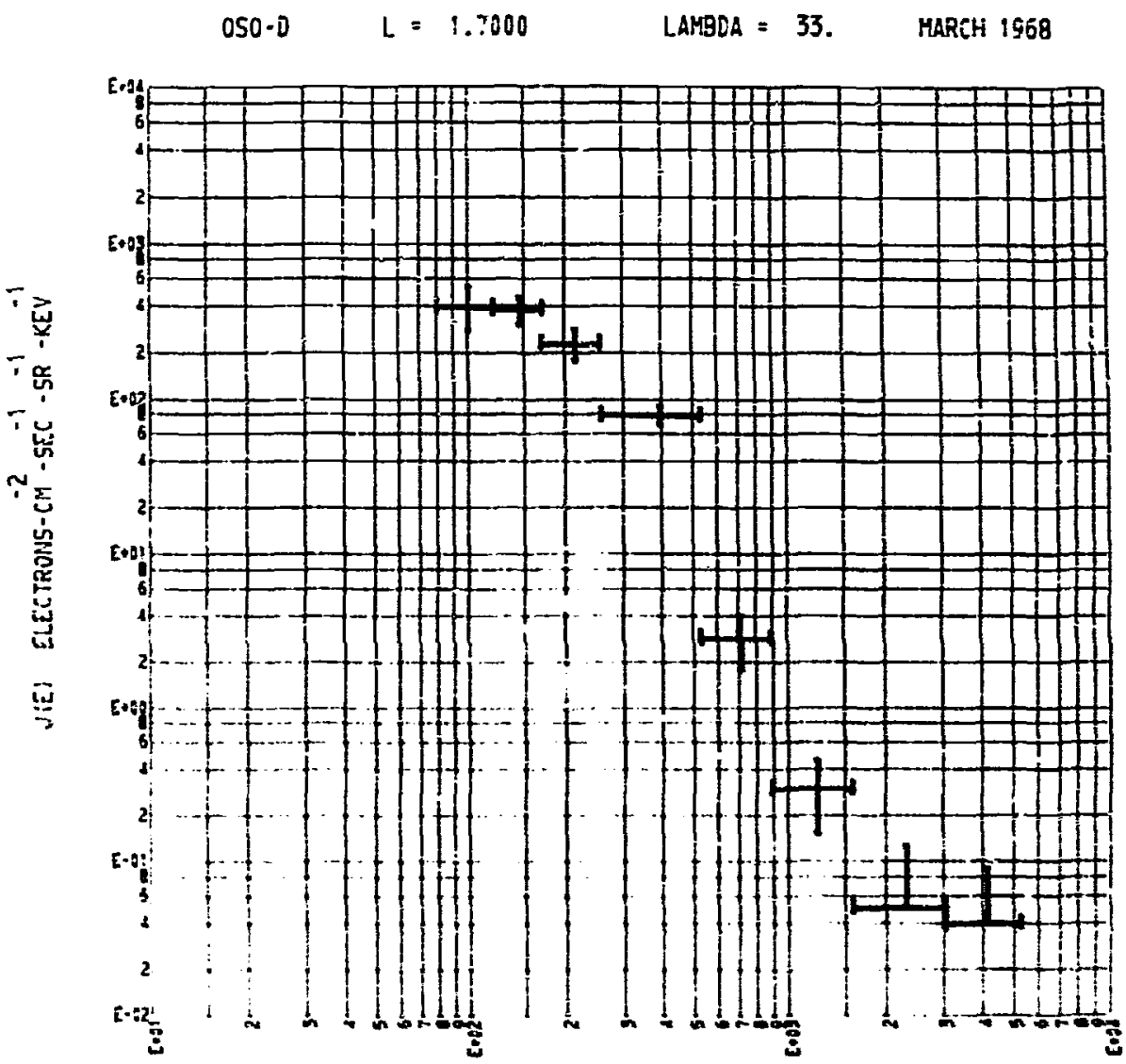

ERERTY :U KEL

Fig. 31. Energy spectra plots of OSO-4 perpendicular electron flux measu red in March 1968. These spectra were selected as close to the equator as permitted by available data. The vertical bars are a measure of the uncertainty: the horizontal bars indicate the width of each energy bin. 


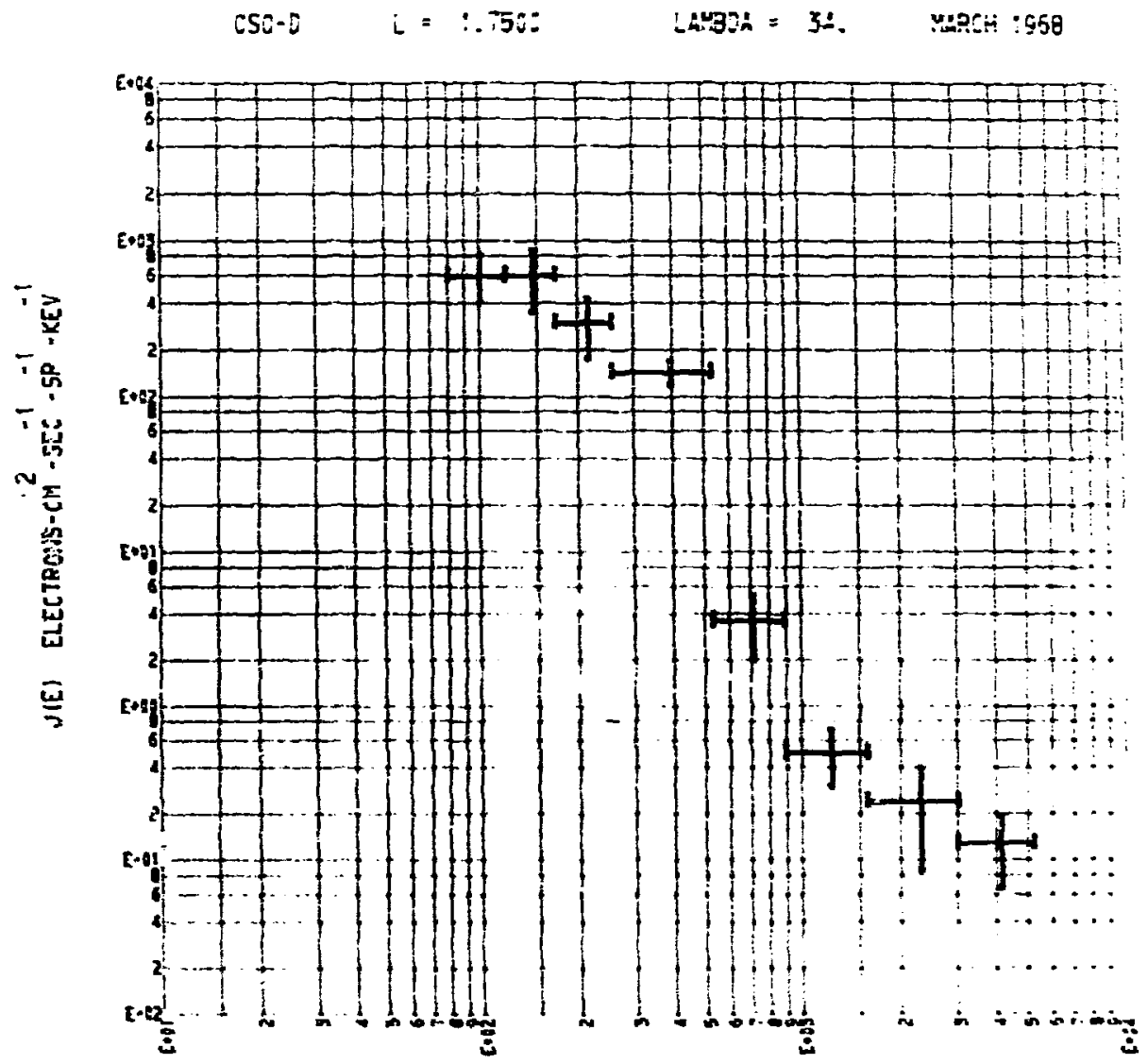

EIERG i: KEI

Fig. 32. Energy spectra plots of OSO-4 perpendicular electron tlux measured in Merch 1968. These spectra were selected as close to the equator as permitted by available data. The vertical bars are a measire of the uncers :nty: the horizontal bars indicate the width of each energy bin. 


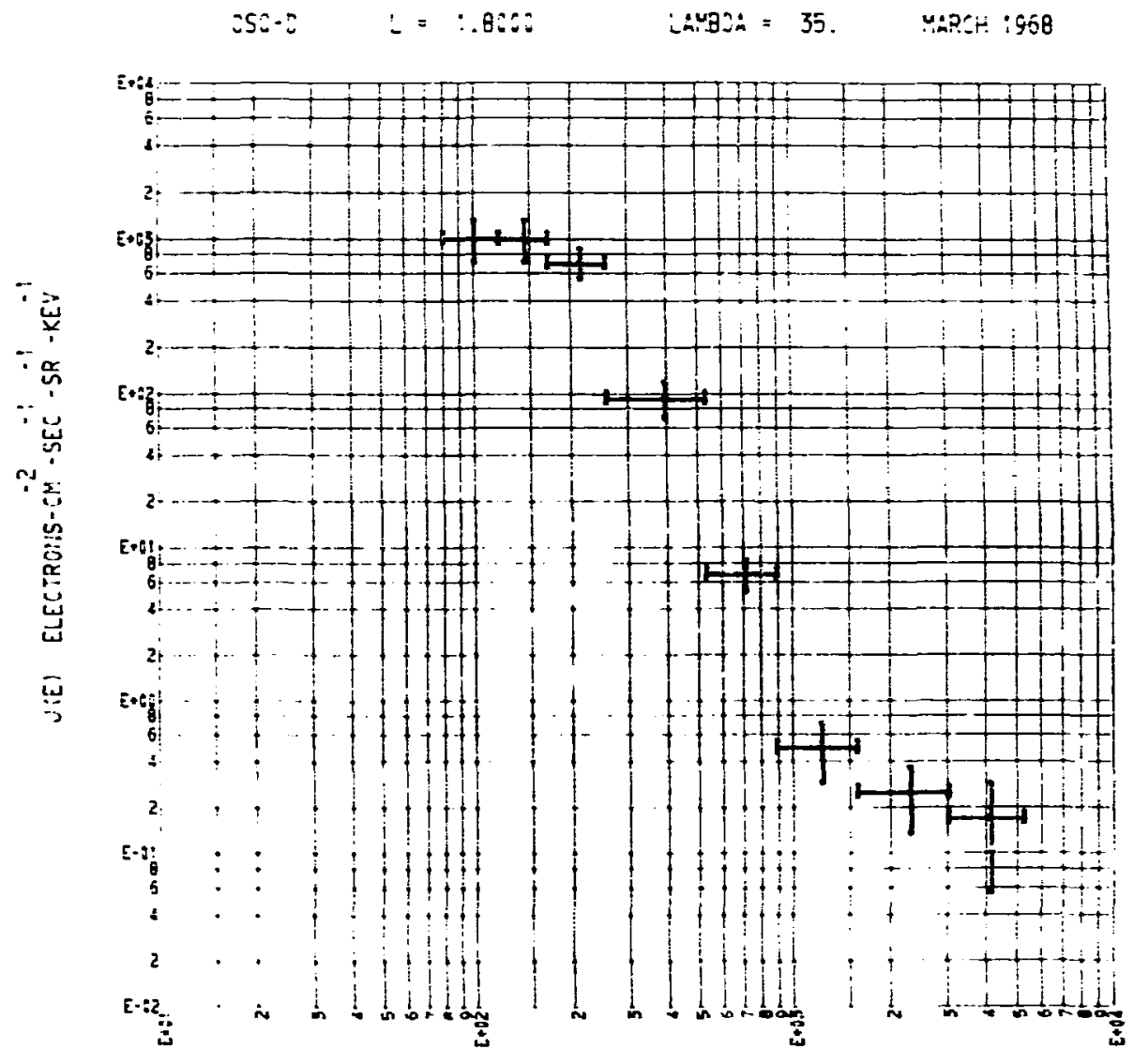

EHERG III KE:

Fig. 33. Energy spectra plots of OSO-4 perpendicular electron flux measured in March 1968. These spectra were selected as close to the equator as permitted by available data. The vertical bars are a measure of the uncertainty: the horizontal bars indicate the width of each energy bir. 


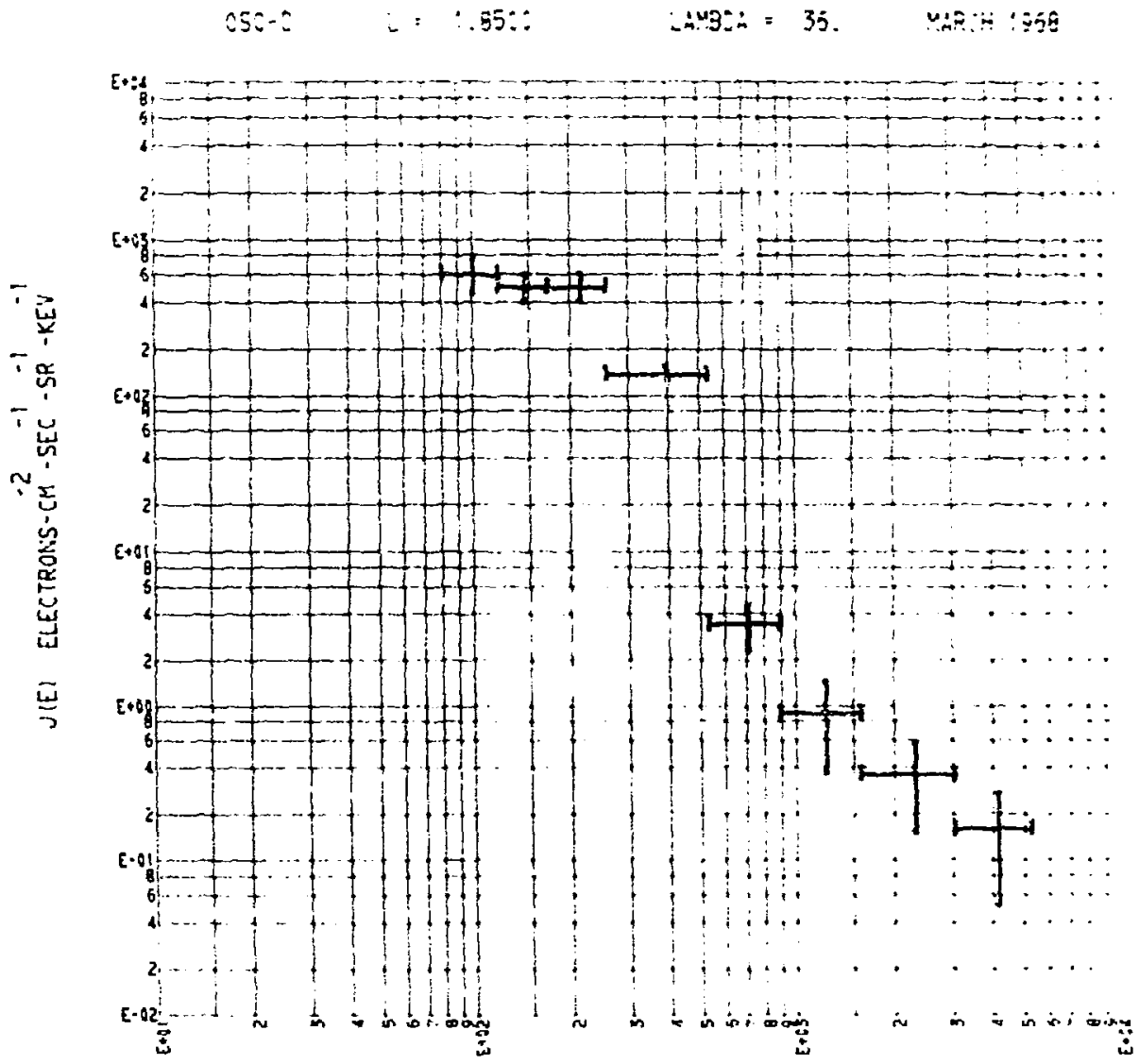

EIERSI ii KE:

Fig. 34. Energy spectra plots of OSO-4 perpendicular electron flux measured in March 1968. These spectra were selected as close to the esuator as permitted by available data. The vertical bars are a measure of the uncertainty: the horizontal bars indicate the width of each energy bin. 


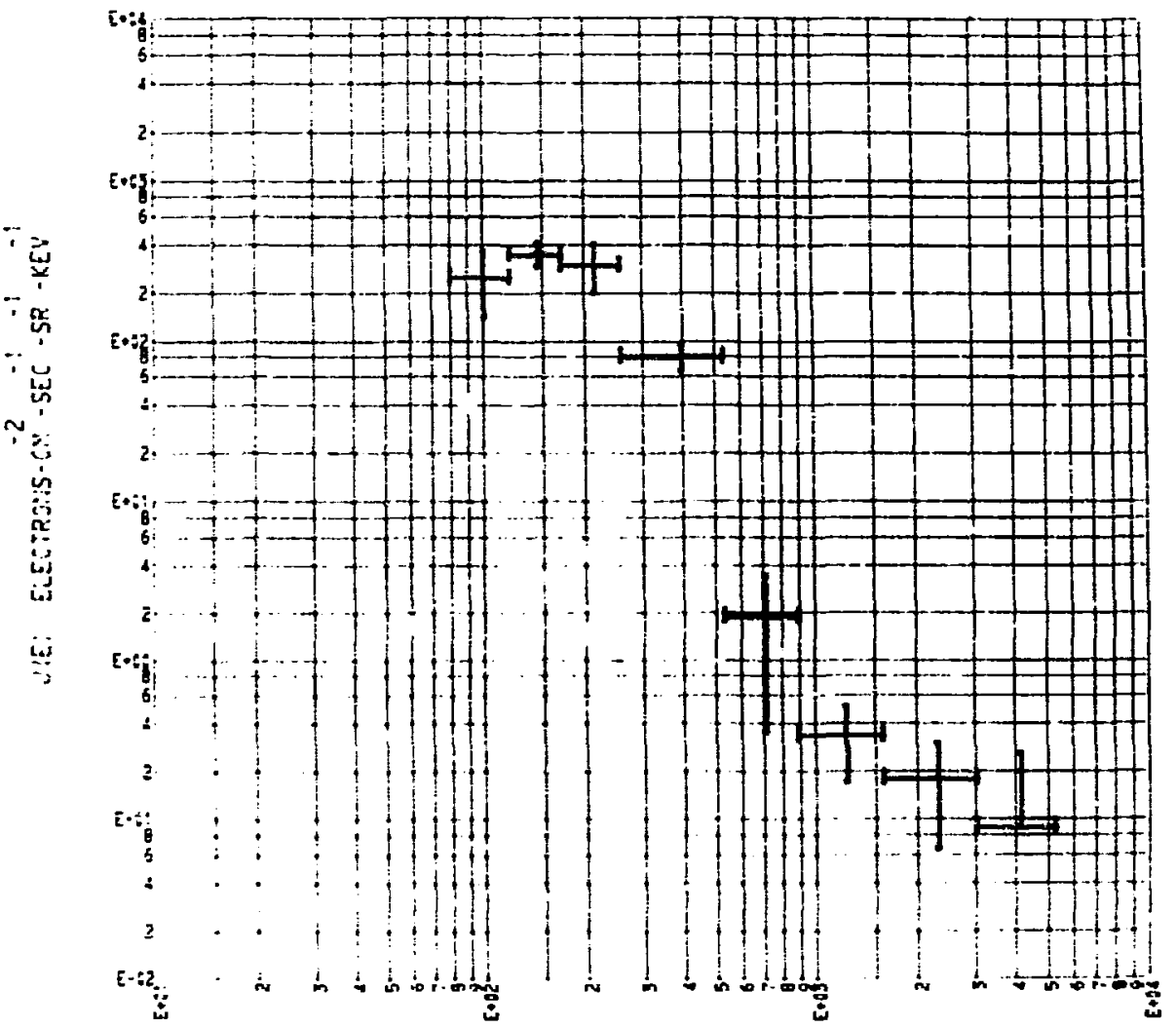

ENERTY IH KEY

Fig. 35. Energy spectra plots of OSO-4 perpendicular electron flux measu red in March 1968. These spectra were selected as close to the equator as permitted by available data. The vertical bars are a measure of the uncertainty: the horizontal bars indicate the width of each energy hin. 


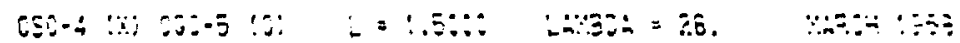

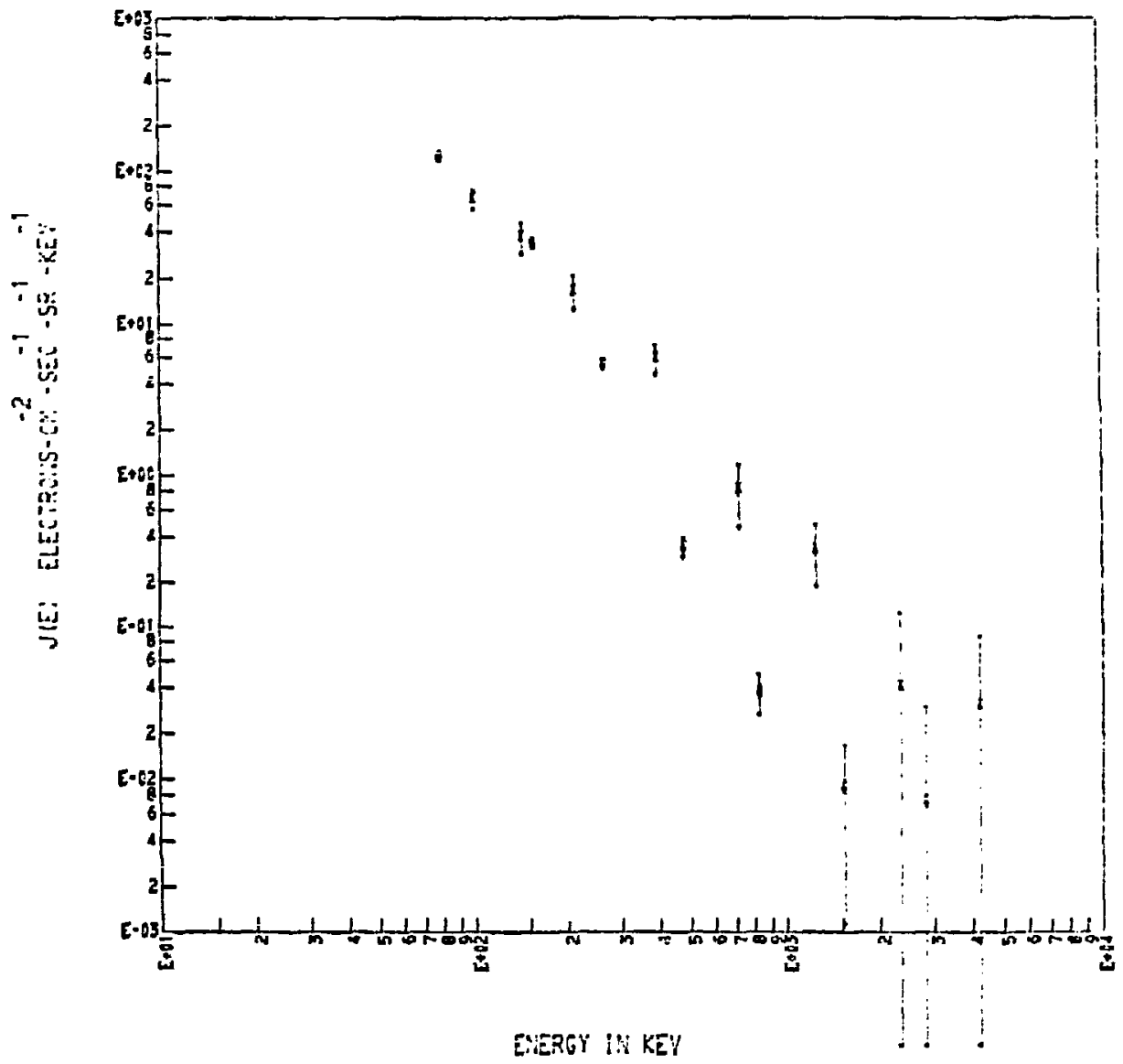

Fig. 36. Comparison of OSO-4 and OGO-5 electron energy spectra at $L=1.5$ and $\lambda=28^{\circ}$ in March 1968. The vertical bars indicate the uncertainty in each data set. Generally, the OSO-4 spectra revealed more hardening towards the higher energies than was evident in the OGO-5 data. 


\section{$L=1.2476$ LAMEDA $=-12.06$ DEGPFES ORBIT NO. 2336. MAR. 211968}

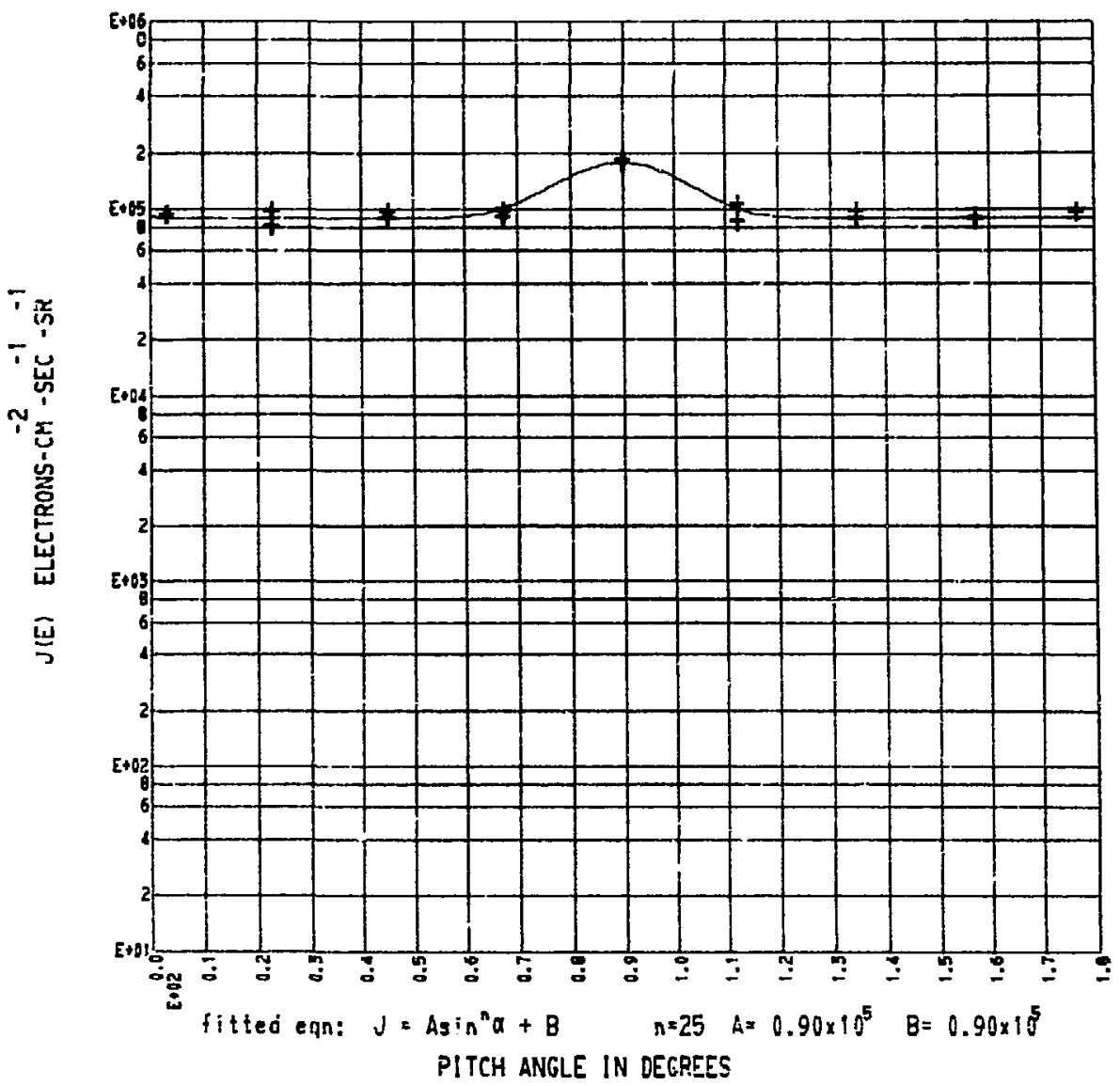

Fig. 37. Typical electron integral pitch-angle distributions. These were taken in March 1968 and November 1957 and selected for minimum $\lambda$ values. The fitted equations are indicated at the base of each plot. 


\section{ELECTRON PITCH ANGLE DISTRIBUTION Ee2BO KEV \\ $L=1.3029$ LAMBDA $=-15.96$ DEGREES ORBIT NO. 2336. MAR. 211968}

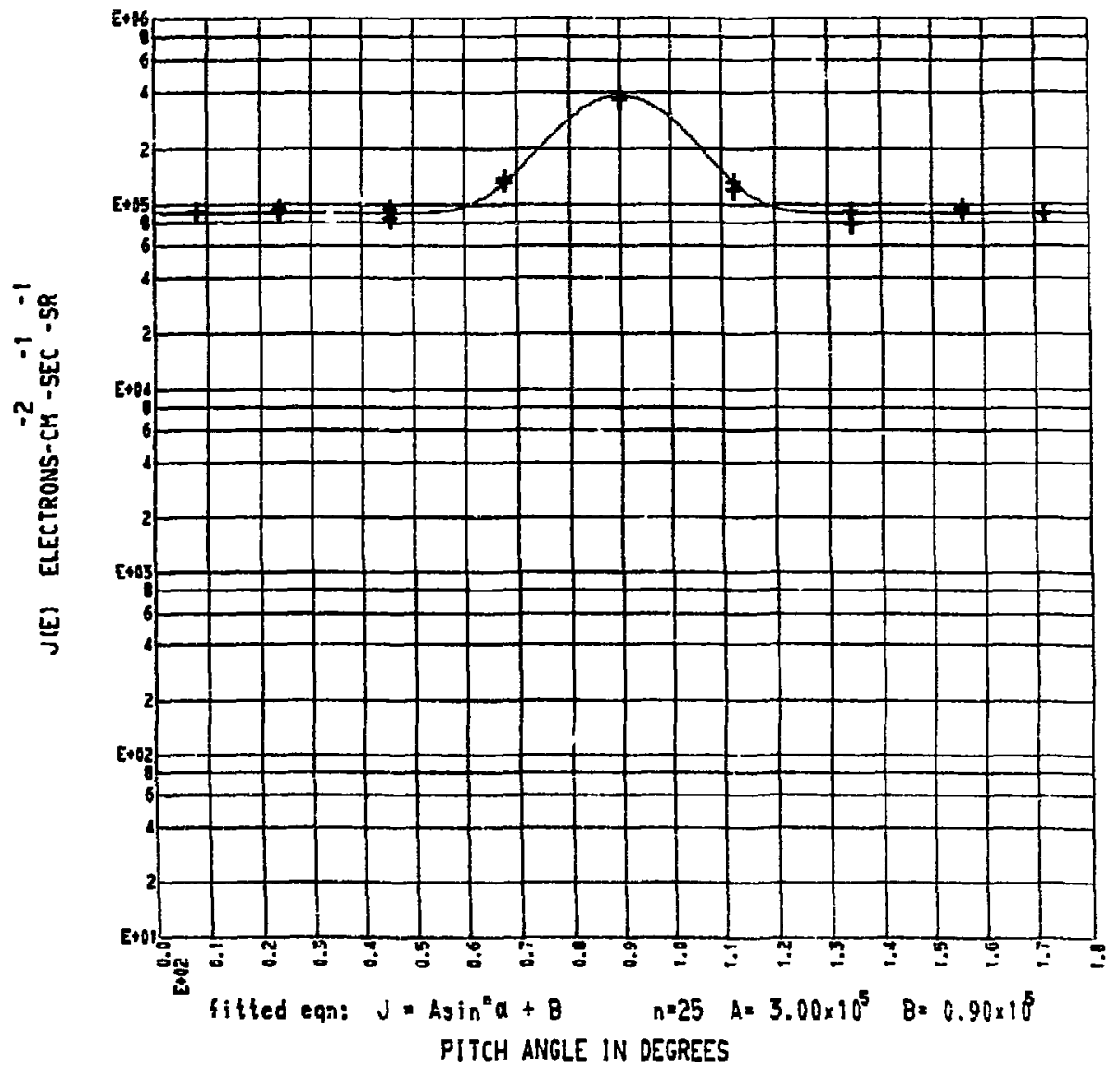

Fig. 38. Typical electron integral pitch-angle distributions. These were taken in March 1968 and November 1967 and selected for minimum $\lambda$ values. The fitted equations are indicated at the base of each plot. 


\section{$L=1.3503$ LAMBDh $=-18.75$ DEGREES ORBIT NO. 2336. MAR. 211968}

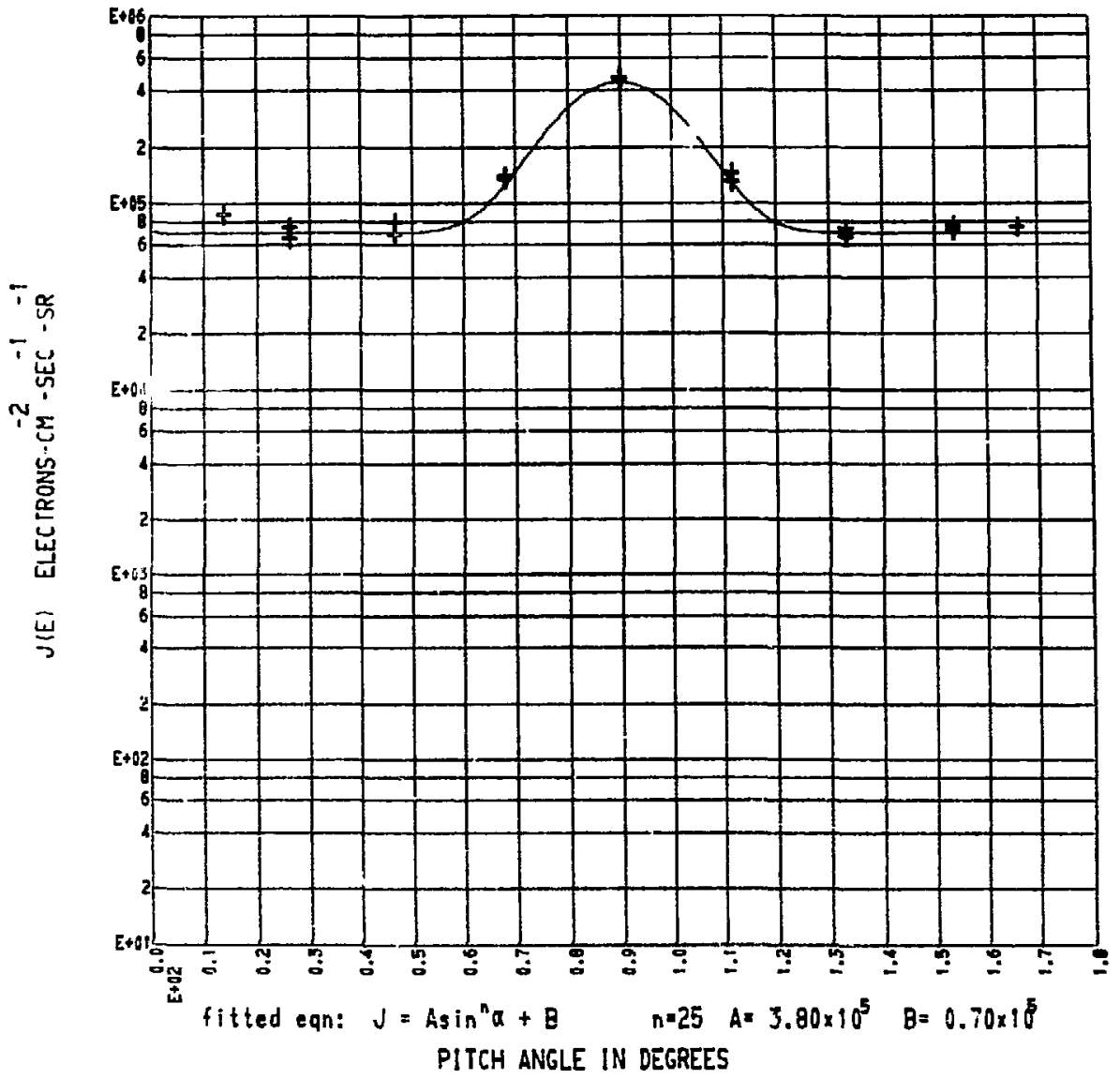

Fig. 39. Typical electron integral pitch-angle distributions. These were taken in March 1968 and November 1967 and selected for minimum $\lambda$ values. The fitted equations are indicated at the base of each plot. 


\section{$L=1.4033$ LAMBDA $=-21.44$ DEGREES ORBIT NO. 2336 . MAR. 211968}

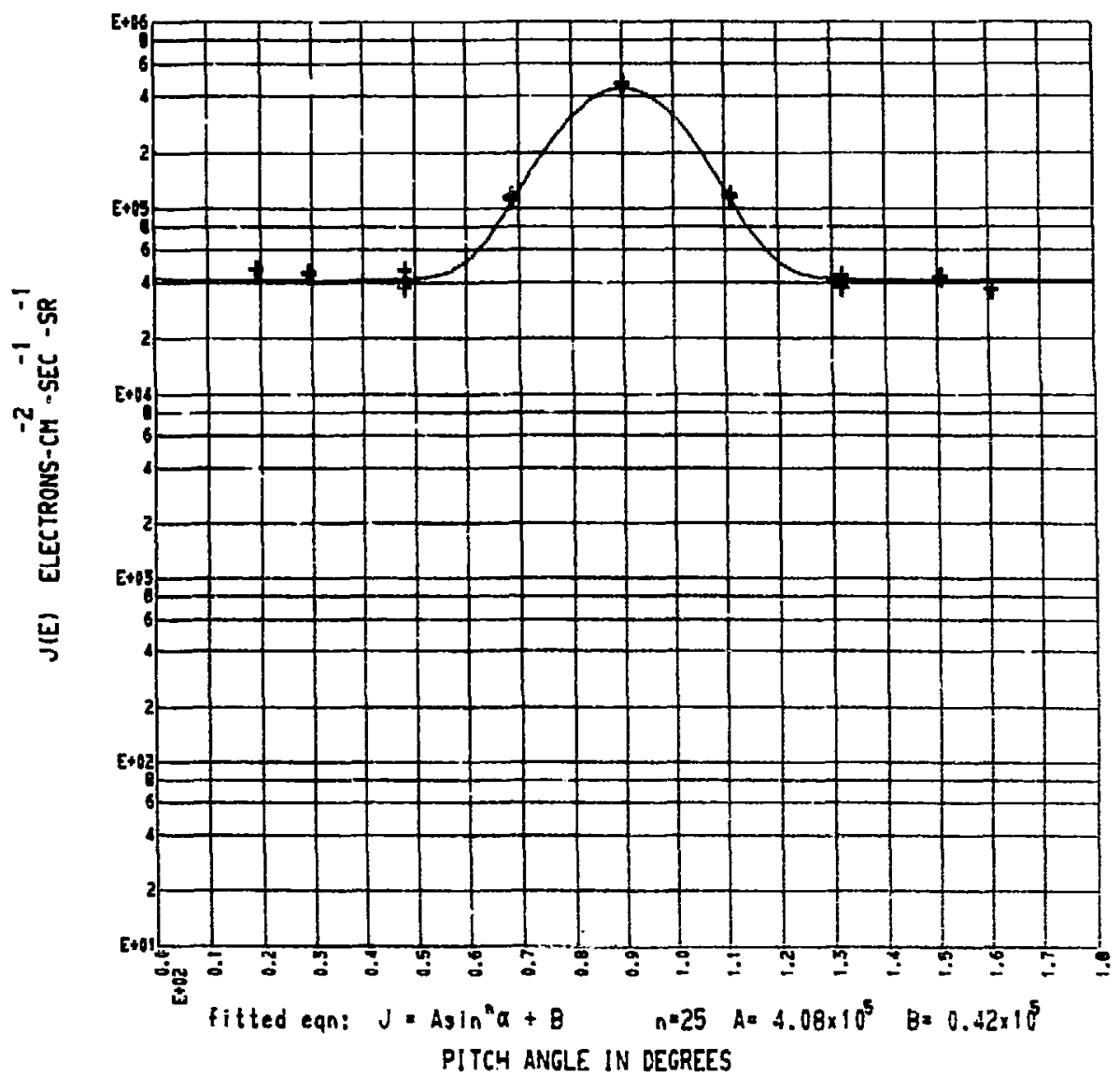

Fig. 40. Typical electron integral pitch-angle distributions. These were taken in March 1968 and November 1967 and selected for minimum $\lambda$ values. The fitted equations are indicated at the base of each plot. 


\section{$L=1.4488$ LAMBDA $=-23.50$ DEGREES ORBIT NO. 2336 . MAR. 211968}

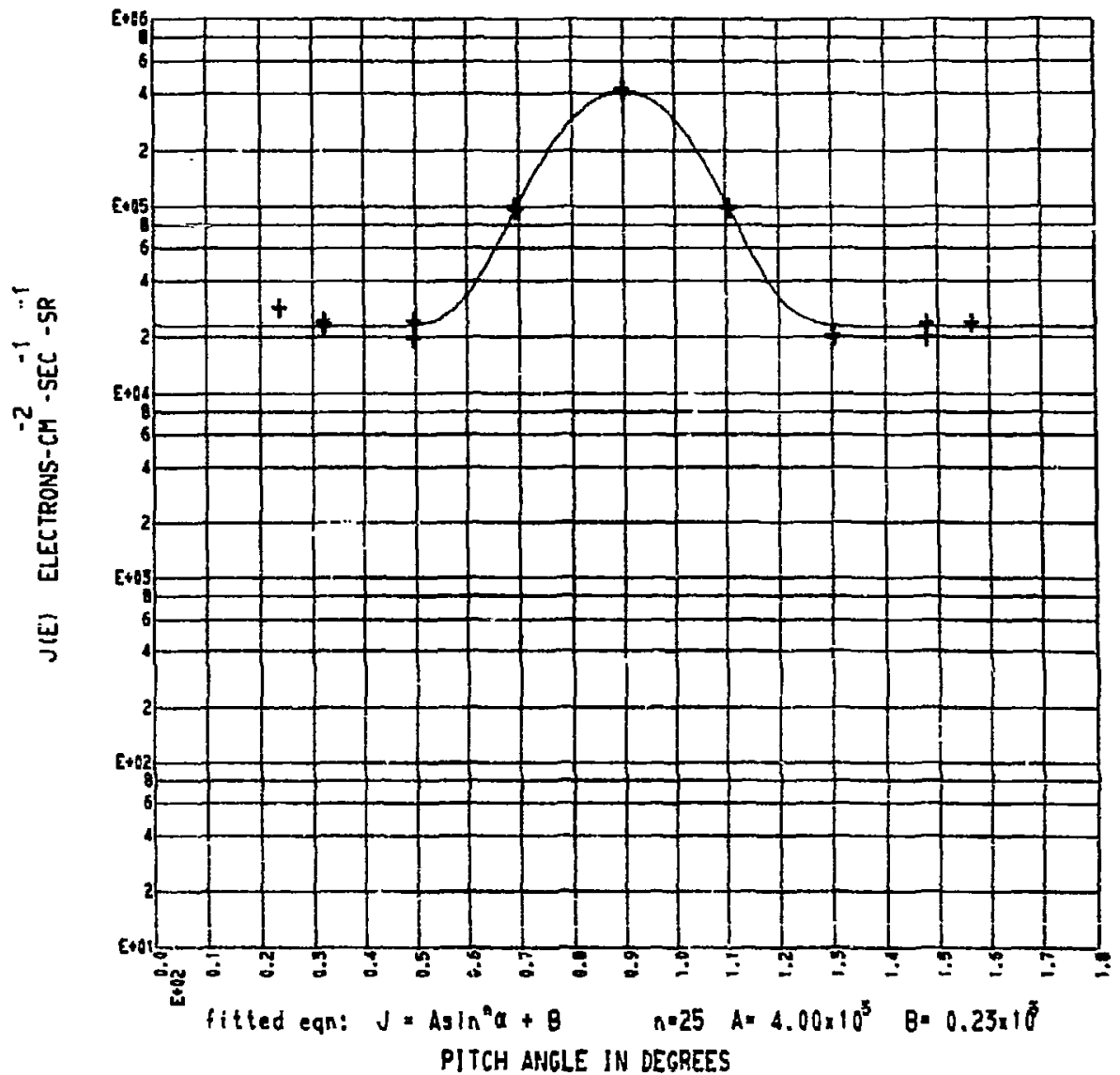

Fig. 41. Typical electron integral pitch-angle distributions. These were taken in March 1968 and November 1967 and selected for minimum $\lambda$ values. The fitted equations are indicated at the base of each plot. 


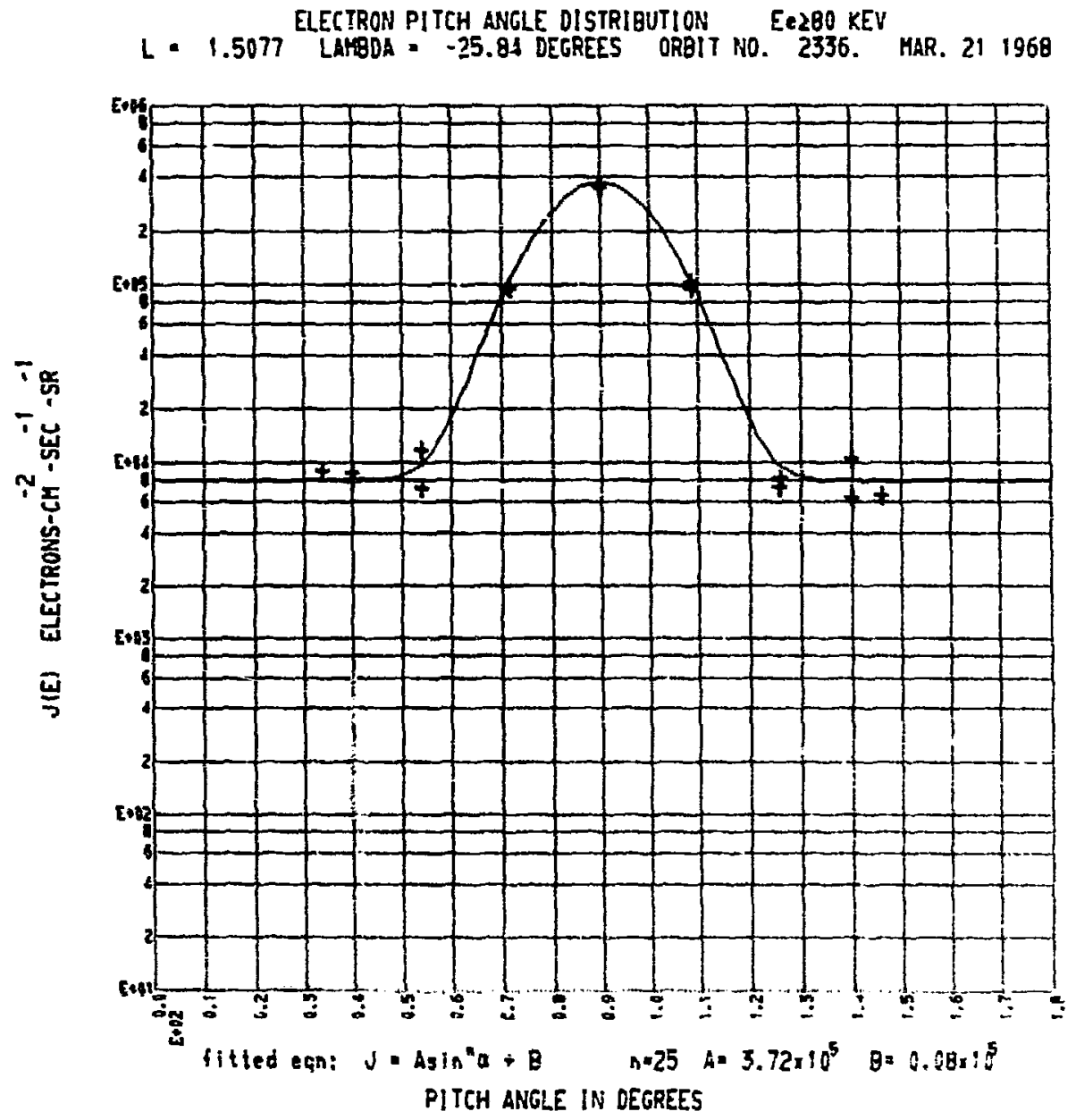

Fig. 42. Typical electron integral pitch-angle distributions. These were taken in March 1968 and November 1967 and selected for minimuin $\lambda$ values. The fitted equations are indicated at the base of each plot. 


\section{ELECTRON PITCH ANGLE DISTRIBUTION EE280 KEV \\ $L=1.5552$ LAYGDA $=-27.59$ DEGREES ORBIT NO. 2336. MAR. 211968}

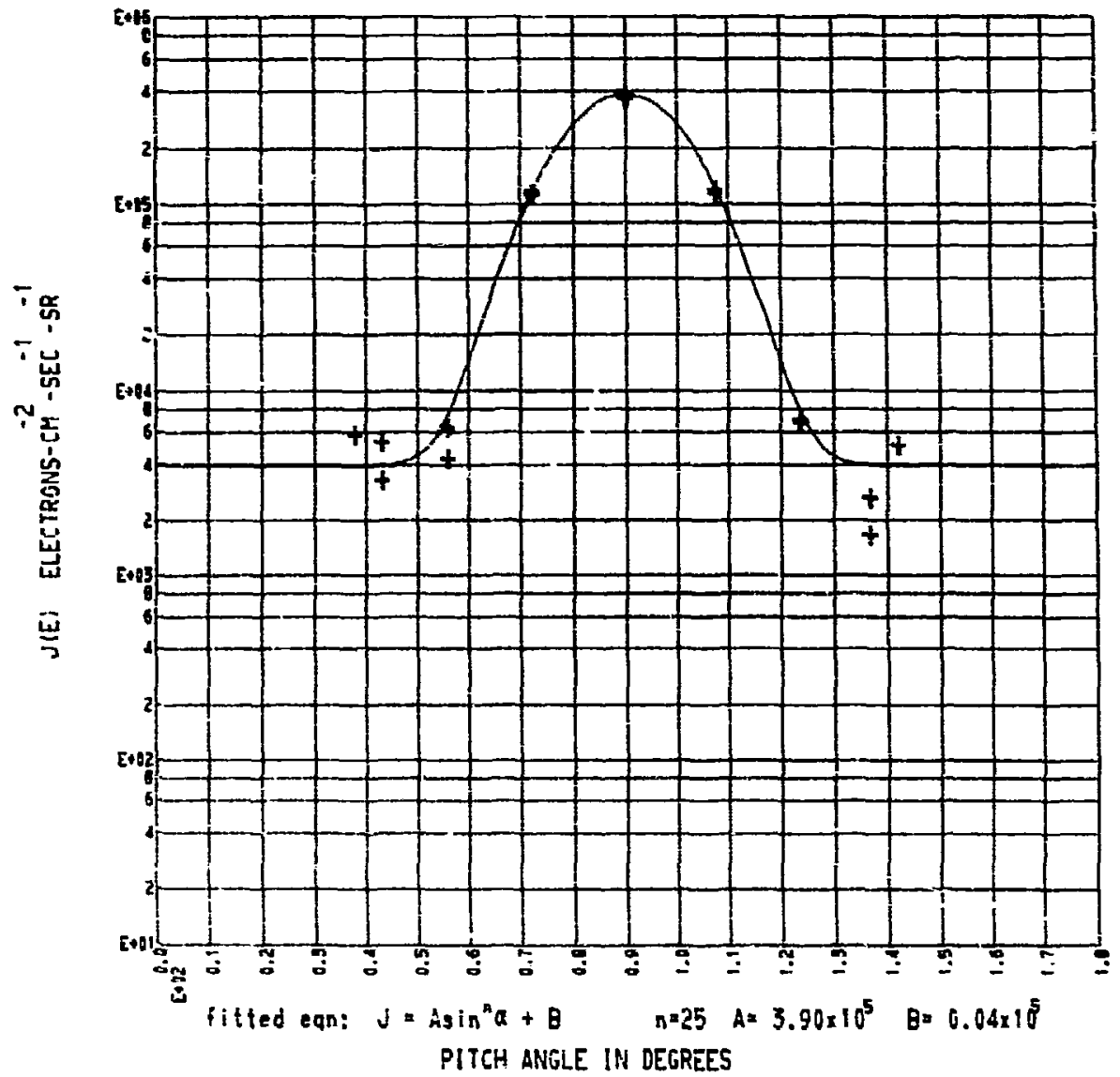

Fig. 43. Typical electron integral pitch-angle distributions. These were taken in March 1968 and November i967 and selected for minimum $\lambda$ valurs. The fitted equations are indicated at the base of each plot. 


\section{$L=1.6013$ LAMBDA $=-29.13$ OEGREES ORBIT NO. 2336 . MAR. 211968}

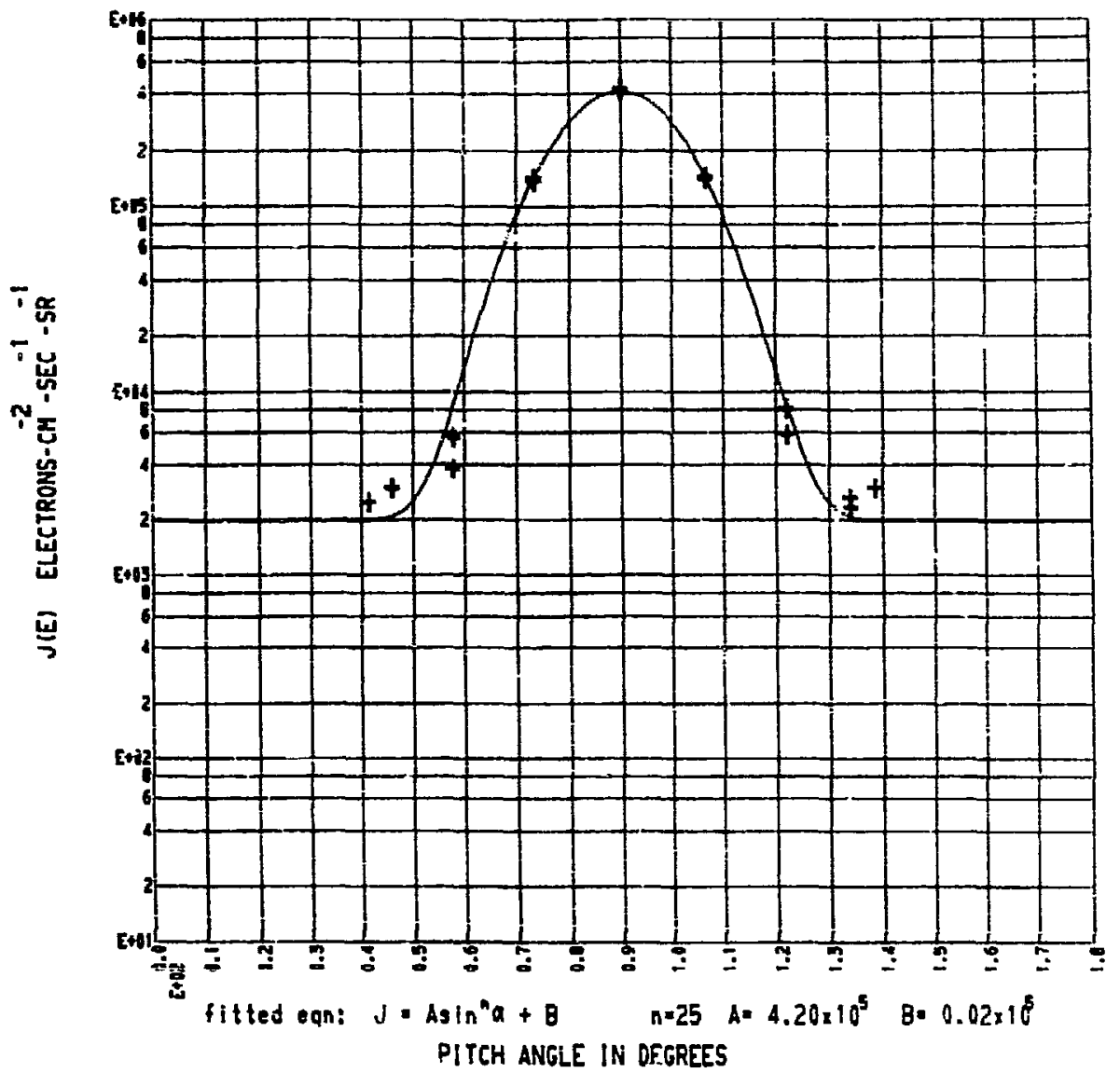

Fig. 44. Typical electron integral pitch-angle distributions. These were taken in imarch 1968 and November 1967 and selected for minimum $\lambda$ vaiues. The fitted equations are indicated at the base of each plot. 
ELECTRON PITCH ANGLE DISTRIBUTION EEZ280 KEV

$L=1.6540$ LAMEDA $=-30.86$ OEGREEJ JRBIT NO. 2336. MAR. 2! 1968

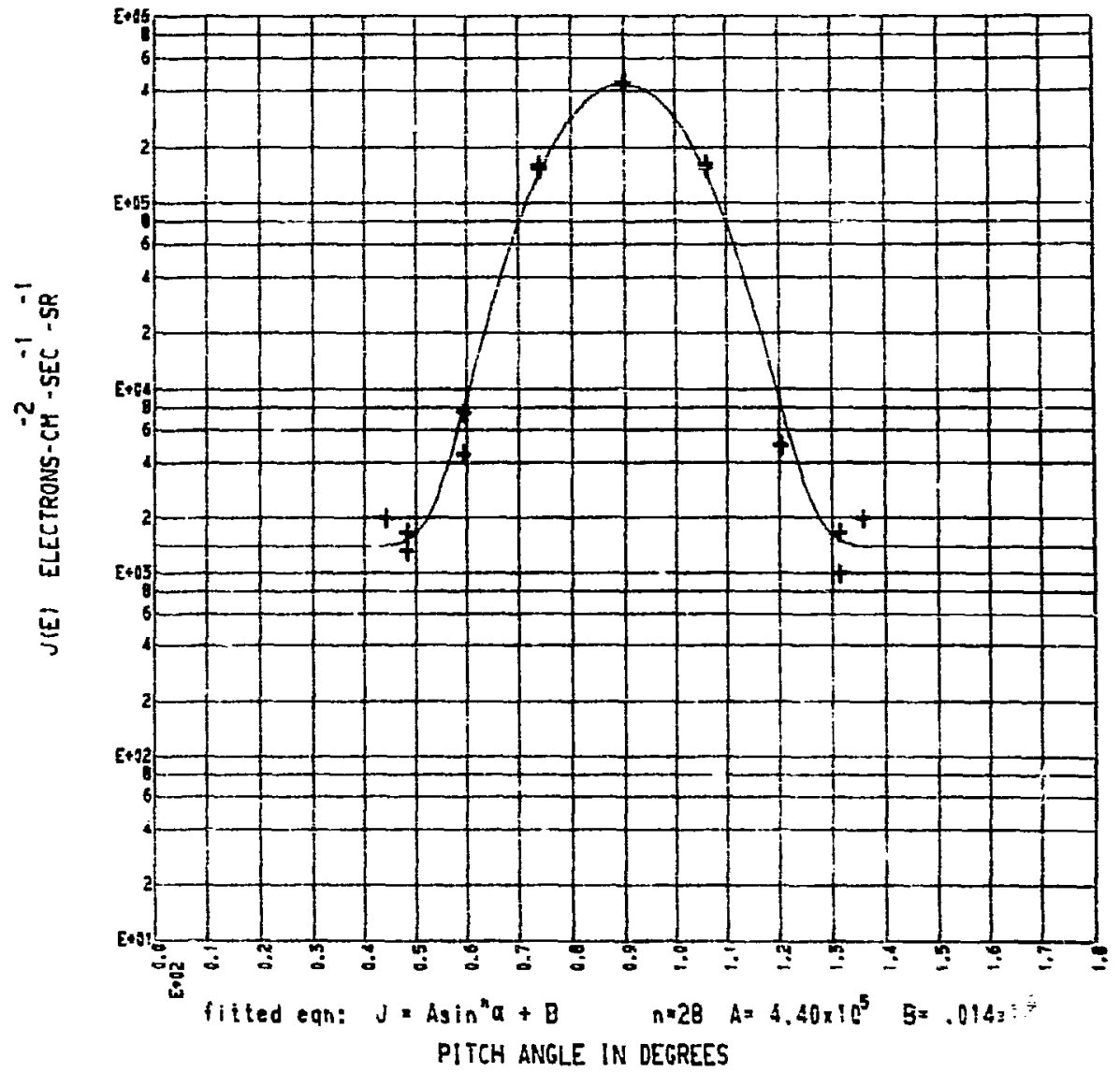

Fig. 45. Typical electron integral pitch-angle distributions. These were taken in March 1968 and November 1967 and selected for minimum $\lambda$ values. The fitted equations are indicated at the base of each plot. 


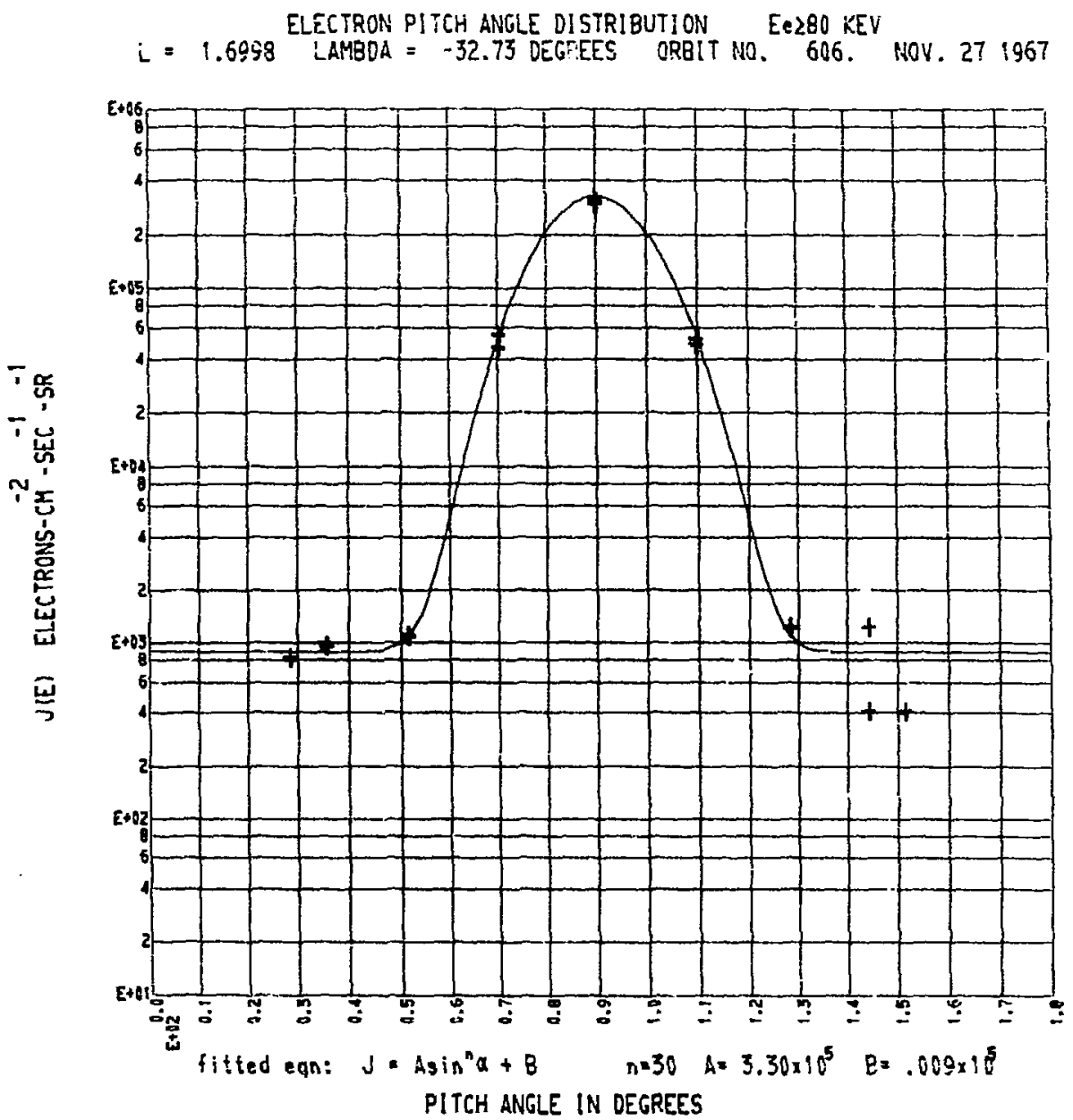

Fig. 46. Typical electron integral pitch-angle distributions. These were taken in March 1968 and November 1967 and selected for minimum $\lambda$ values. The fitted equations are indicated at the base of each plot. 

$L=1.7453$ LAMBDA $=-33.86$ DEGREES ORBIT NO. 606. NOV. 271967
ELECTRON PITCH ANGLE DISTRIBUTION
Ee280 KEV

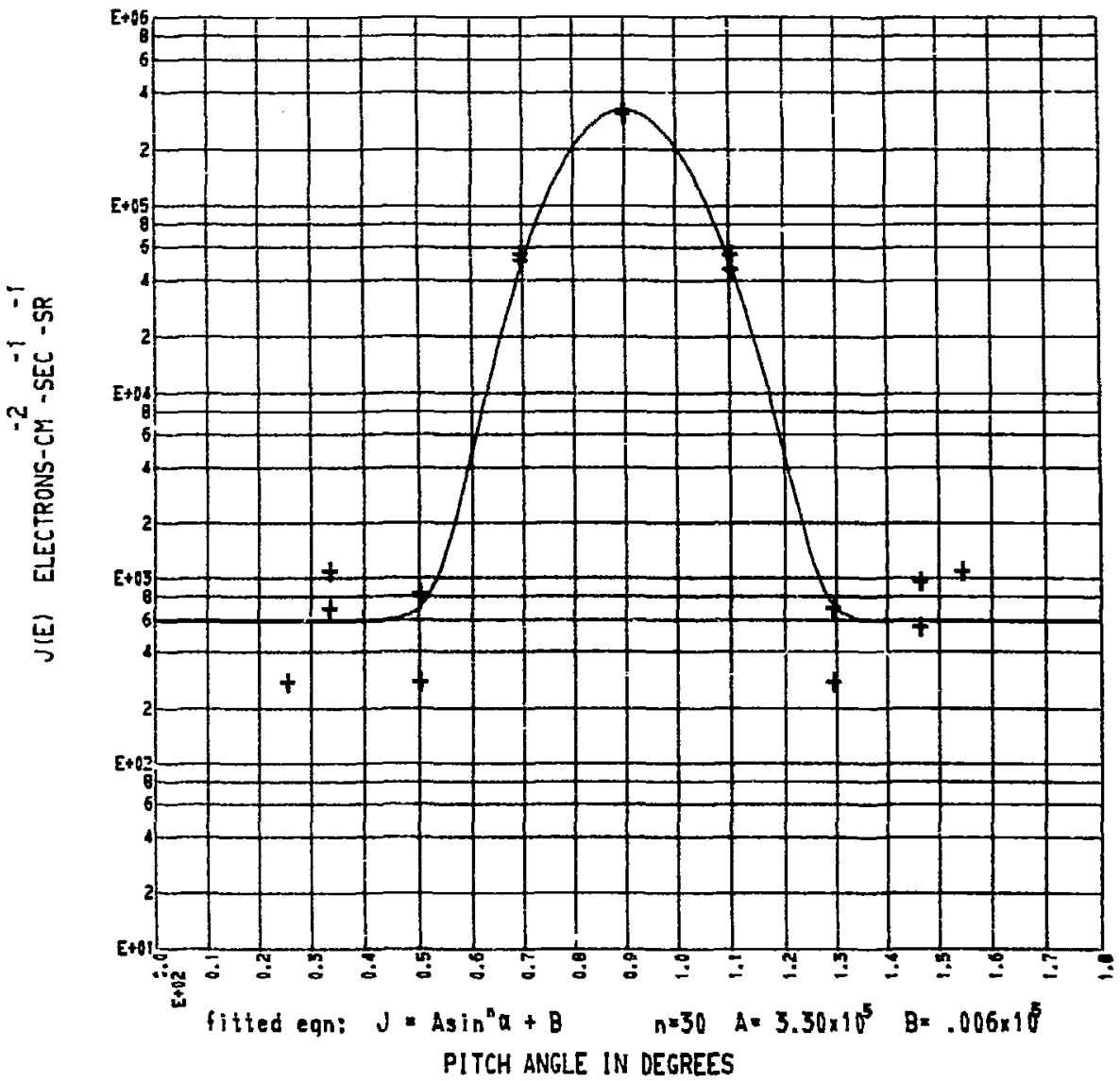

Fig. 47. Typical electron integral pitch-angle distributions. These were taken in March 1968 and November 1967 and selected for minimum $\lambda$ values. The fitted equations are indicated at the base of each plot. 


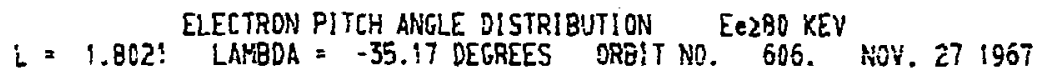

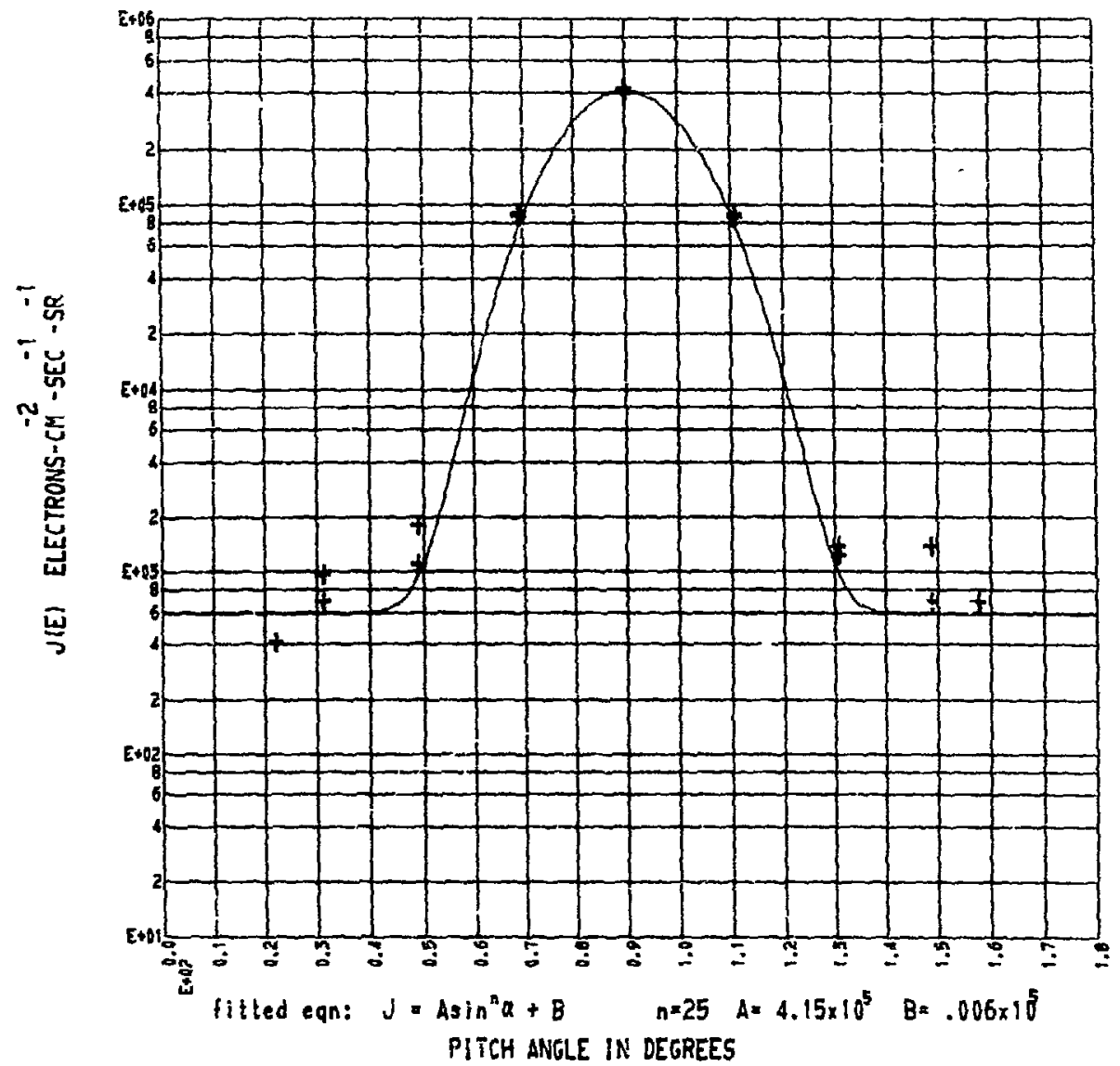

Fig. 48. Typical electron integral pitch-angle distributions. These were taken in March 1968 and November 1967 and selected for minimum $\lambda$ values. The fitted equations are indicated at the base of each plot. 


\section{$L=1.6523$ LAMBDA $=-36.27$ DEGREES ORBIT NO. 606 . NOV. 271967}

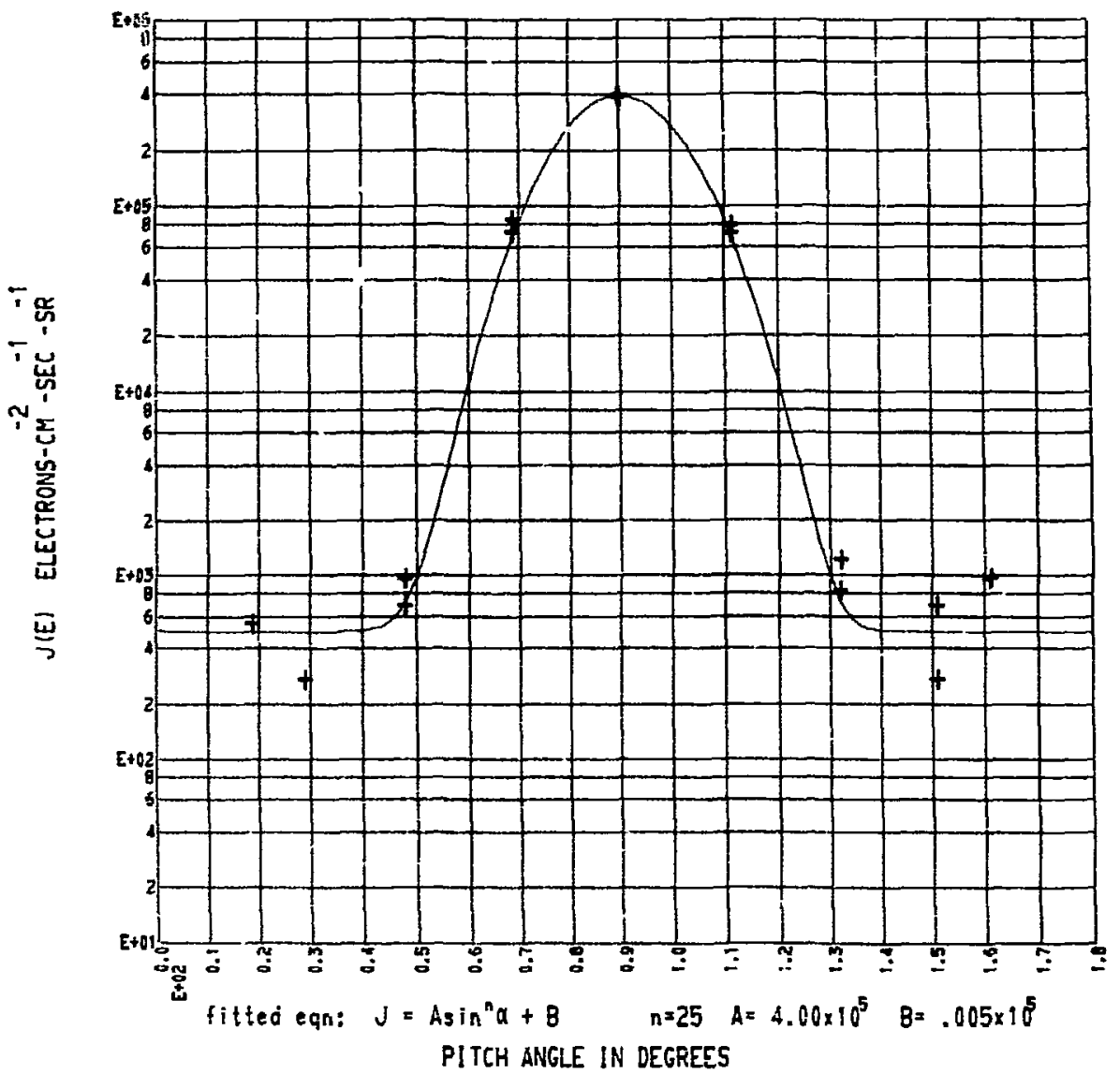

Fig. 49. Typical electron integral pitch-angle distributions. These were taken in March 1968 and November 1967 and selected for minimum $\lambda$ values. The fitted equations are indicated at the base of each piot. 
$L=1.9039^{\text {ELECTRON PITCH ANGLE OISTRIBUTION }} \begin{gathered}\text { Ee280 KEV } \\ \text { LAMBDA }=-37.42 \text { DEGREES ORBIT No. } 606 .\end{gathered}$

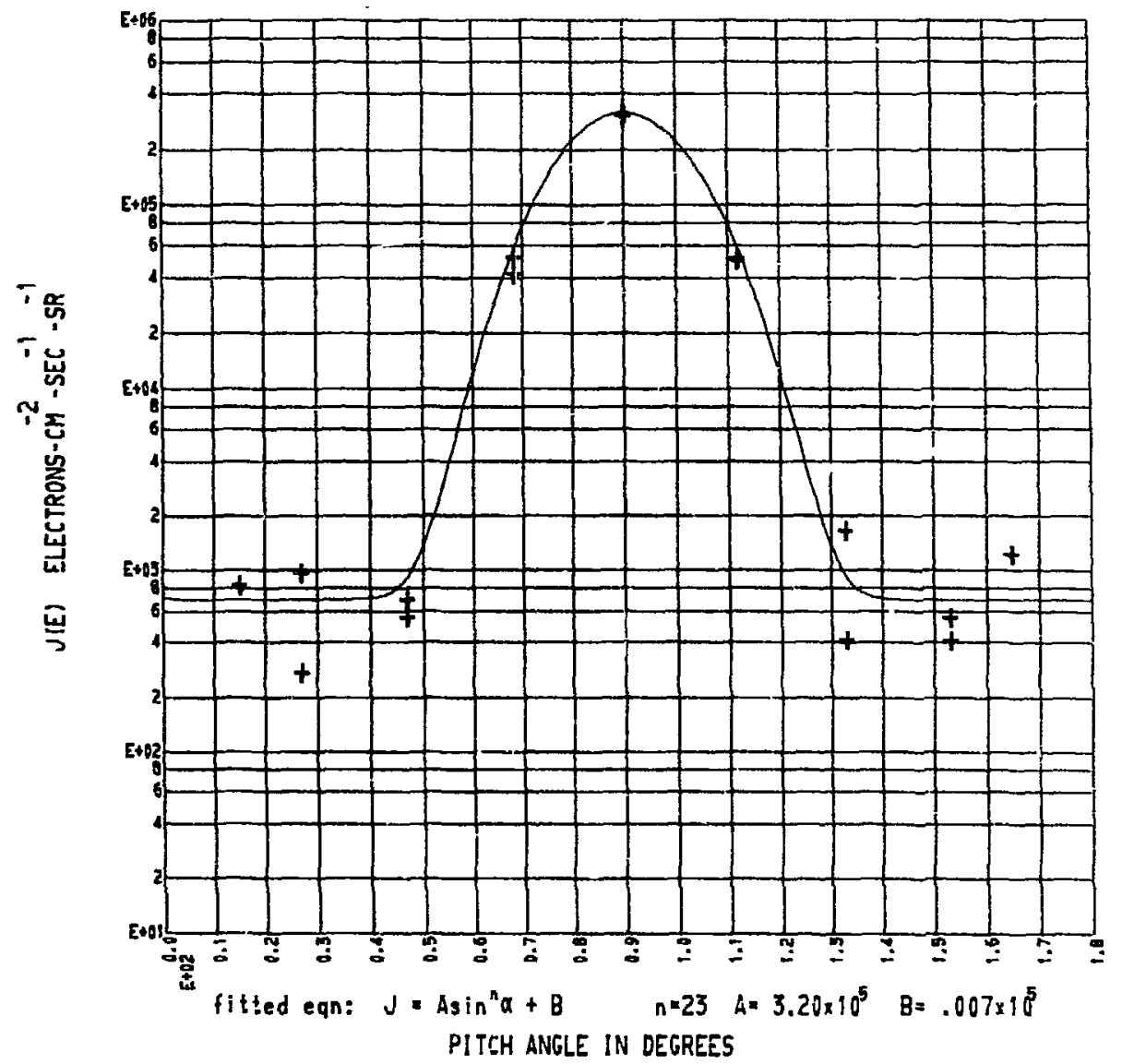

Fig. 50. Typical electron integral pitch-angle distributions. These were taken in March 1968 and November 1967 and selected for minimum $\lambda$ values. The fitted equations are indicated at the base of each plot. 


\section{ELECTRON PITCH ANGLE DISTRIBUTION EE2BO KEV \\ $L=1.9516$ LAMBDA $=-38.63$ DEGREES ORBIT NO. $606 . \quad$ NOV. 271967}

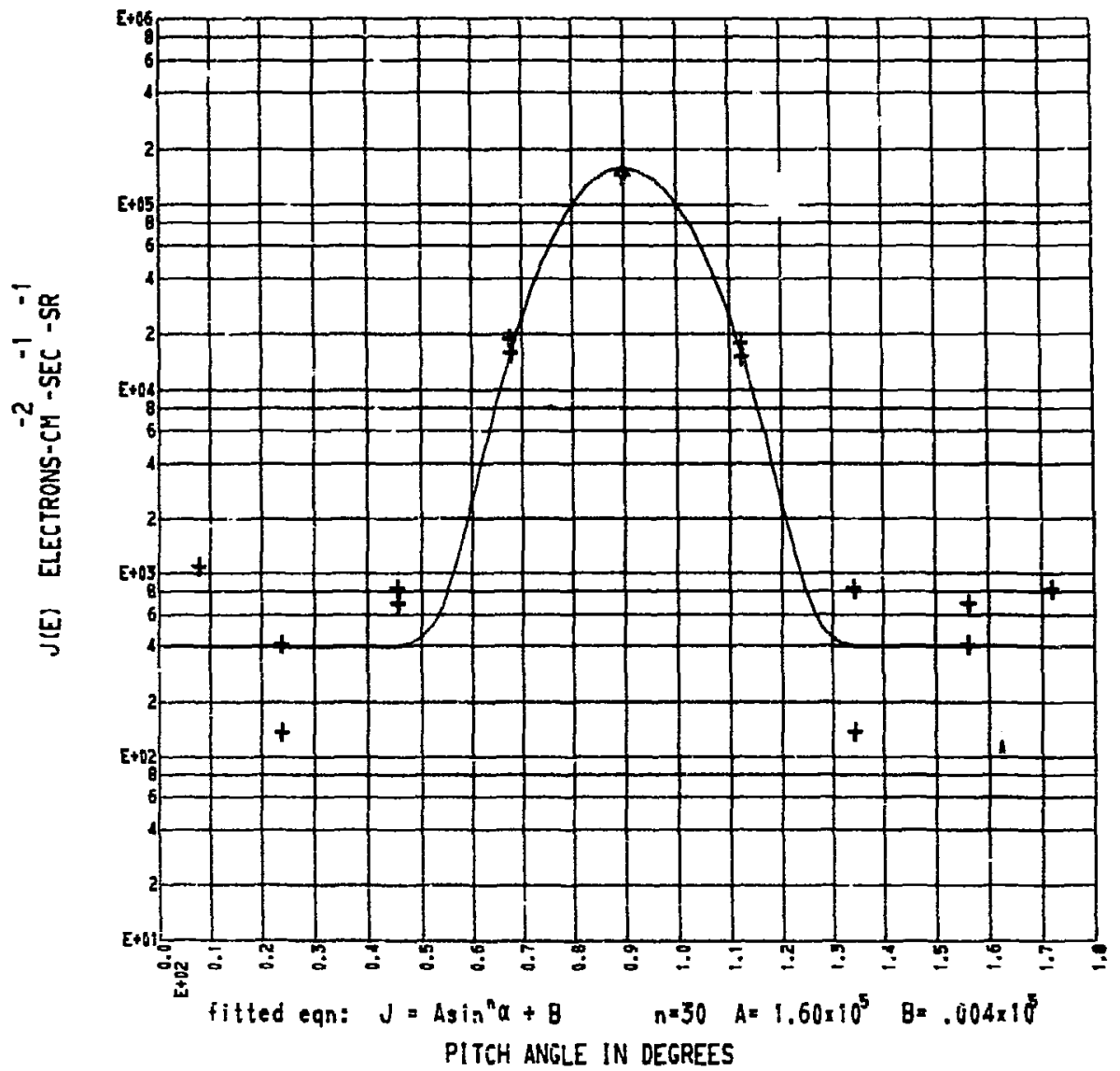

Fig. 51. Typical electron integral pitch-angle distributions. These were taken in March 1968 and November 1967 and selected for minimum $\lambda$ values. The fitted equations are indicated at the base of each plot. 


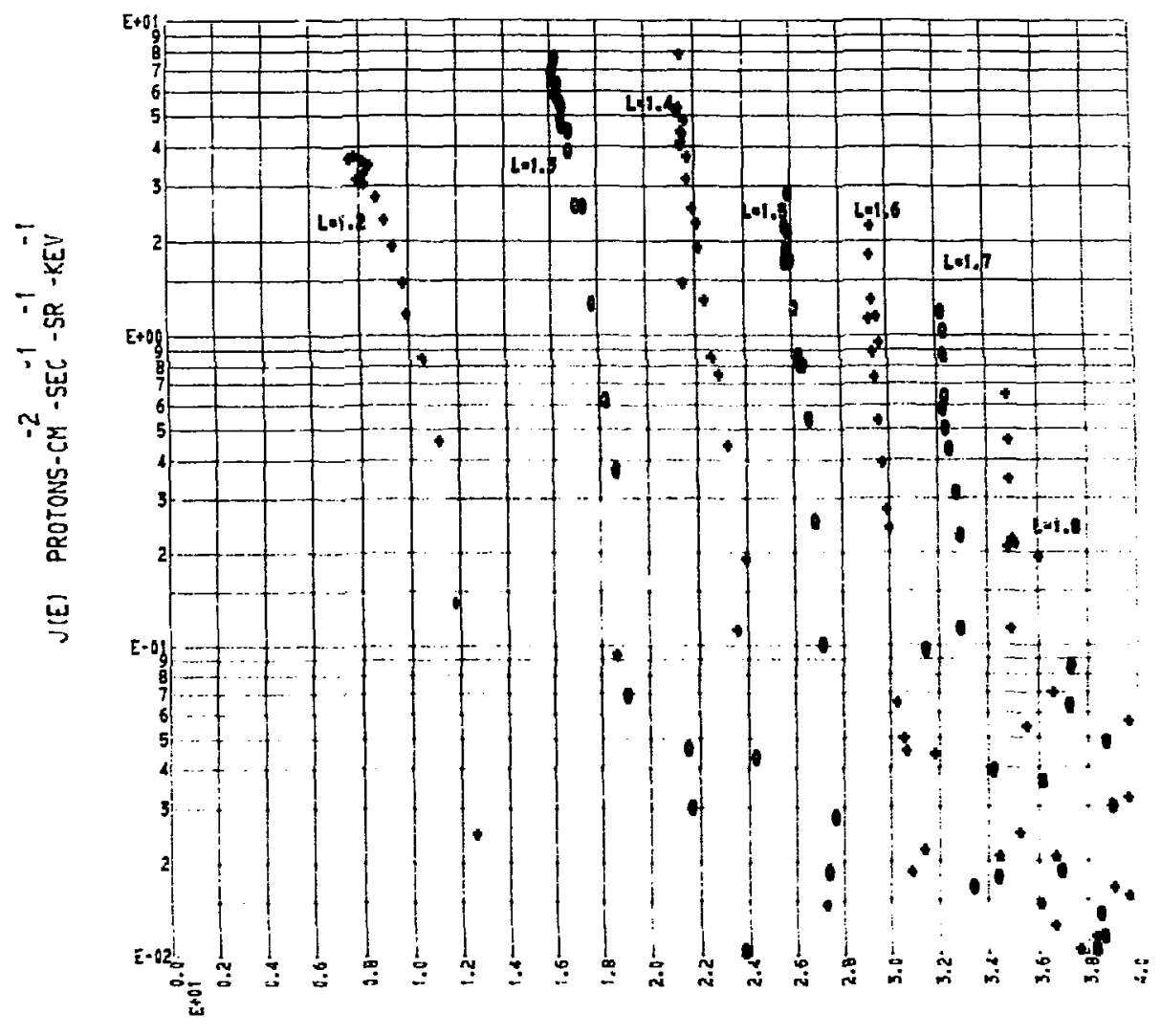

LANEQ 2 : :i SEGPEES

Fig. 52. Apparent perpendicular proton flux measured on several L-shells in March 1968. No backgrounds have been subtracted. 


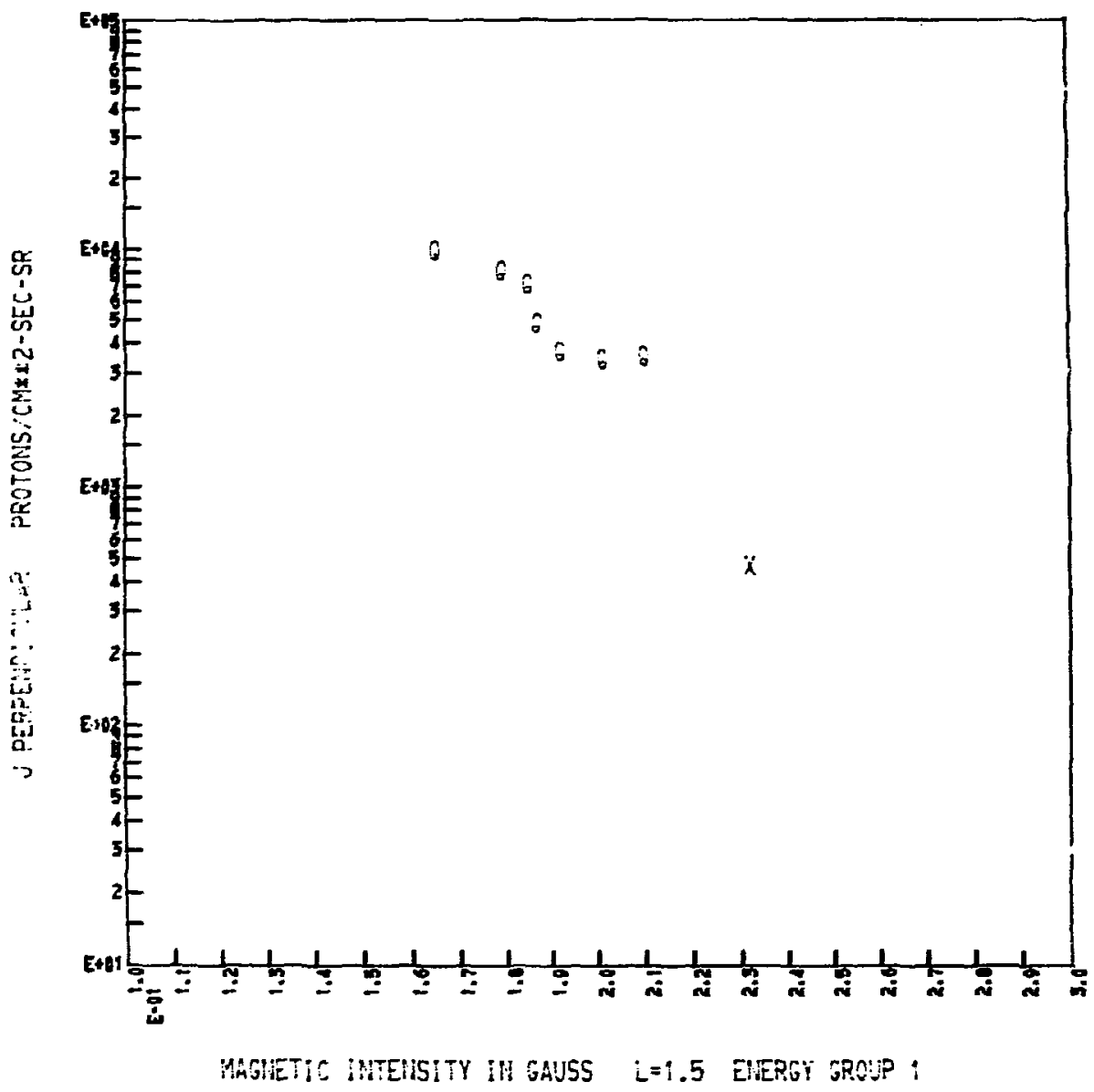

Fig. 53. Comparison of OSO-4 proton flux with Relay I proton intensities that were measured in 1963. Since no time changes in proton flux were observed from October 1967 through March 1958, OSO-4 proton values were selected from several random orbits with data points as close in $B, L$ space as possible for the comparisons. 


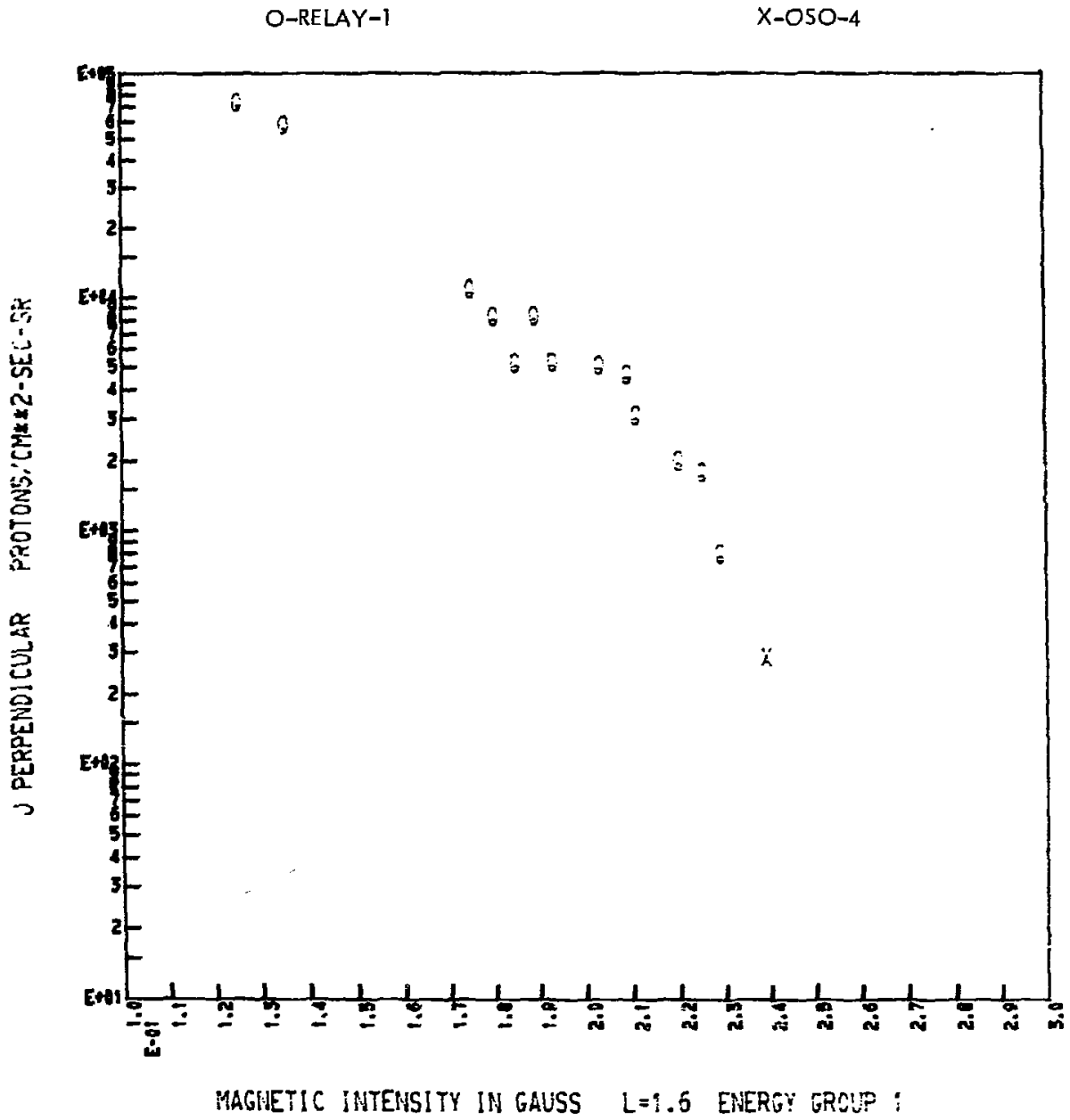

Fig. 54. Comparison of OSO-4 proton flux with Relay I proton intensities that were measured in 1963. Since no time changes in proton flux were observed from October 1967 through March 1968, OSO-4 proton values were selected from several random orbits with data points as close in $B, L$ space as possible for the comparisons. 


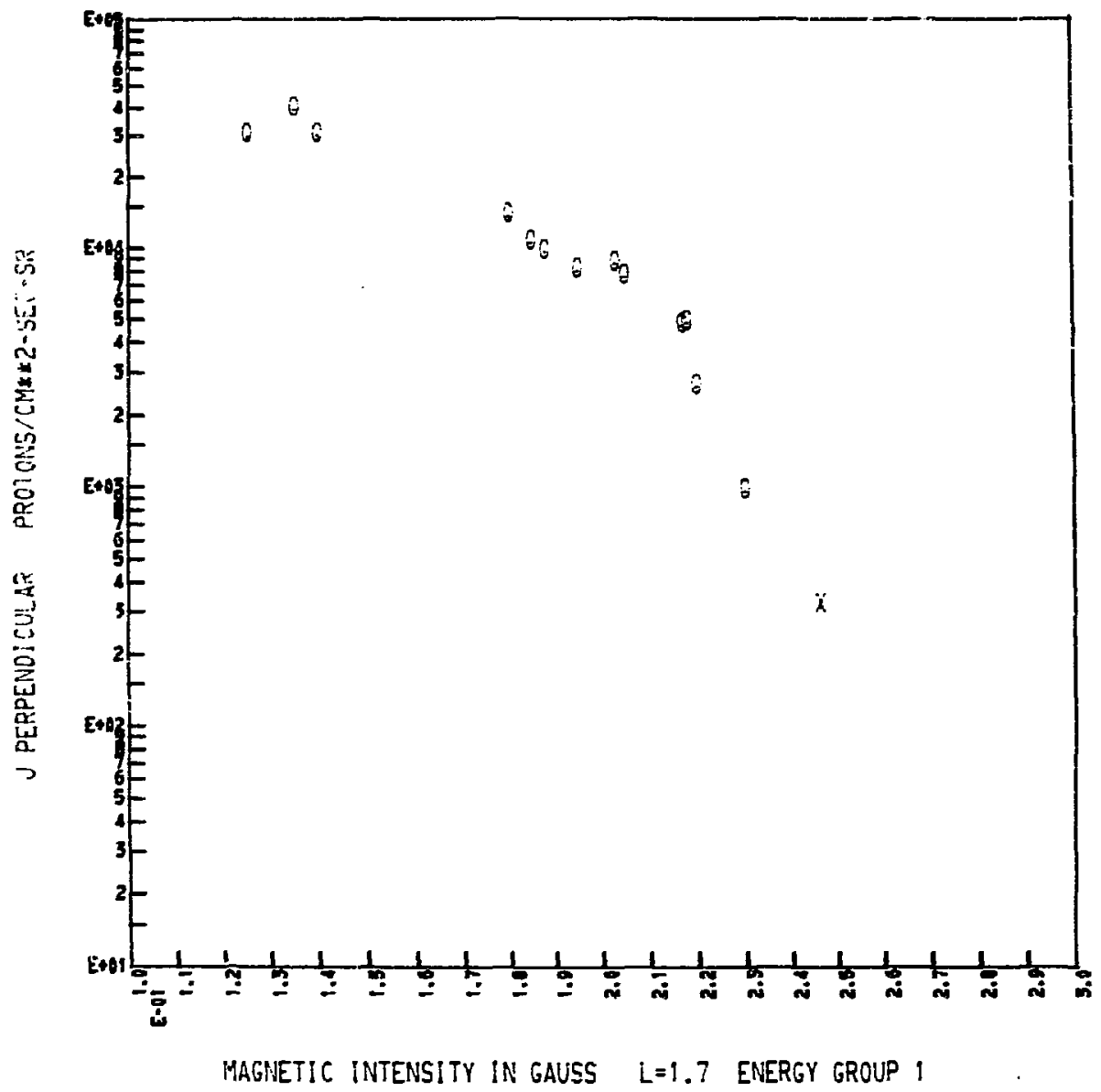

Fig. 55. Comparison of OSO-4 proton flux with Relay I proton intensities that were measured in 1963 . Since no time changes in proton flux were observed from October 1967 through March 1968, OSO-4 proton values were selected from several random orbits with data points as close in $B$, I space as possible for the comparizons. 


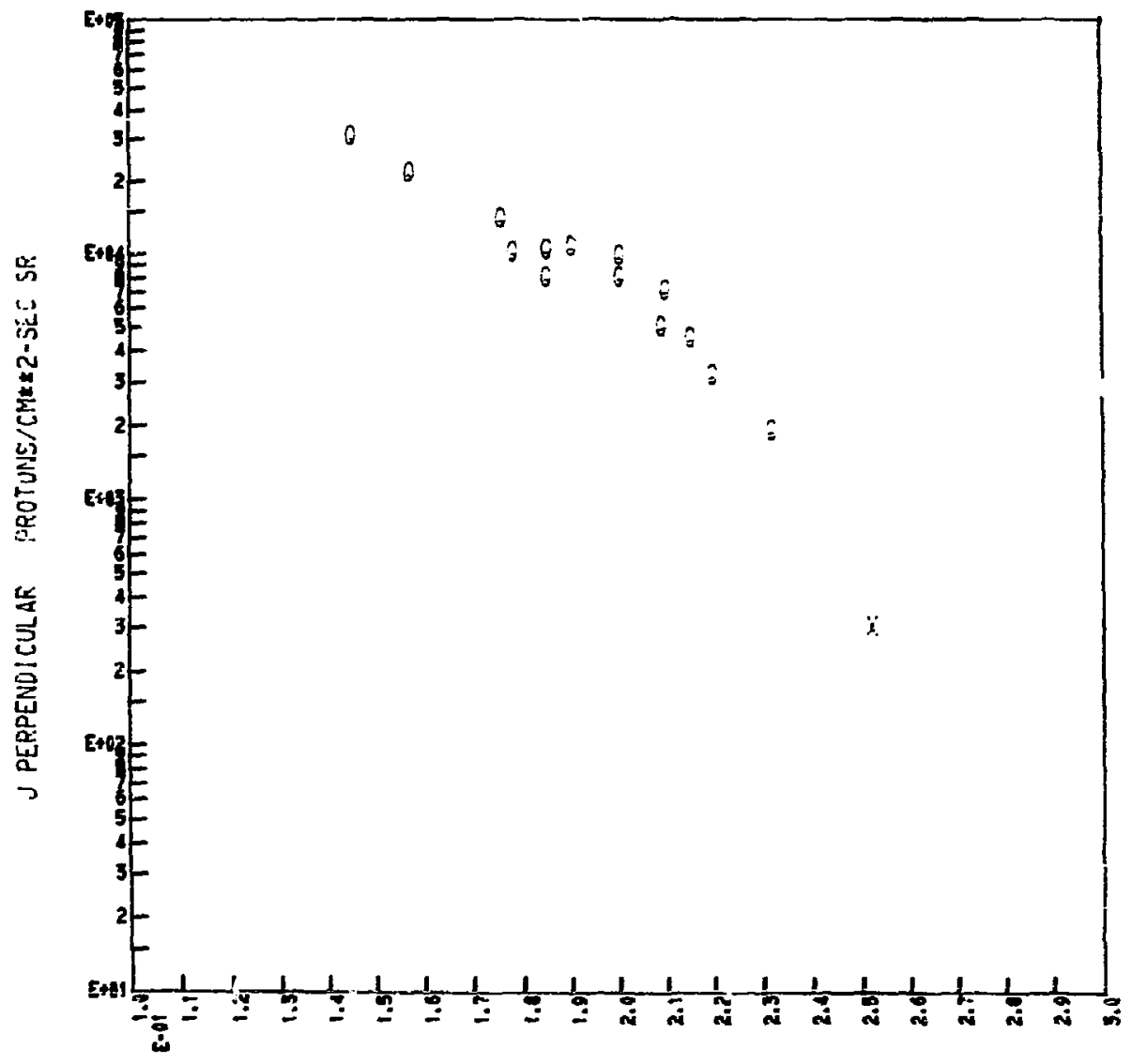

MAGNETIC INTENSITY IN GAUSS L=1.8 ENERGY GROUP ;

Fig. 56. Comparison of OSO-4 proton flux with Relay I proton intensities that were measured in 1963. Since no time changes in proton flux were observed from October 1967 through March 1968, OSO-4 proton values were selected from several random orbits with data points as close in $B, L$ space as possible for the comparisons. 


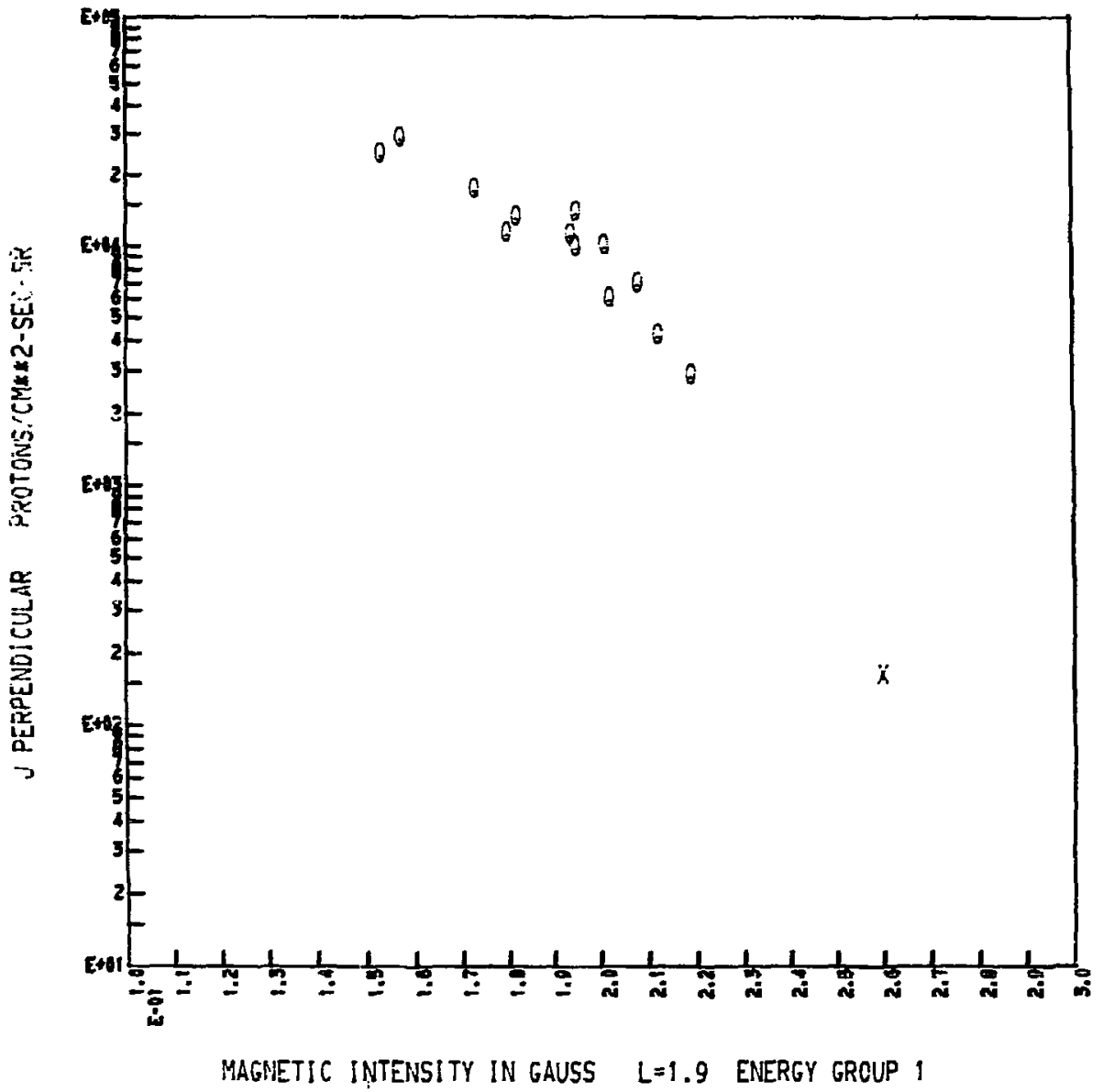

Fig. 57. Comparison of OSO-4 proton flux with Relay I proton intensities that were measured in 1963. Since no time changes in proton flux were cbserved from October 1967 through March 1968, OSO-4 proton values were selected from several random orbits with data points as close in $B, L$ space as possible for the comparisons. 


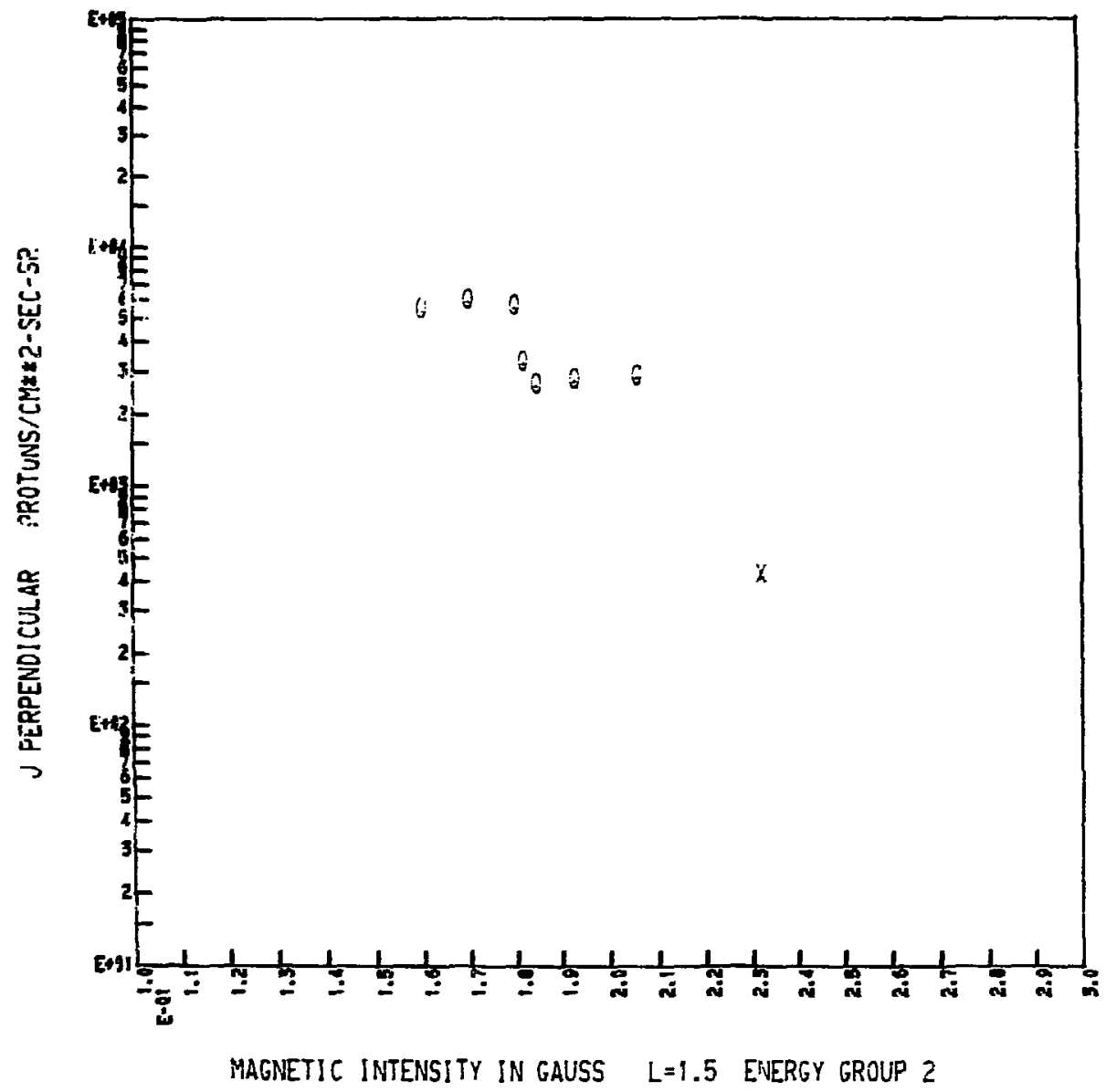

Fig. 58. Comparison of OSO-4 proton flux with Relay I proton intensities that were measured in 1963. Since no time changes in proton flux were observed from October 1967 through March 1968, OSO-4 proton values were selected from several random orbits with data points as close in $B, L$ space as possible for the comparisons. 


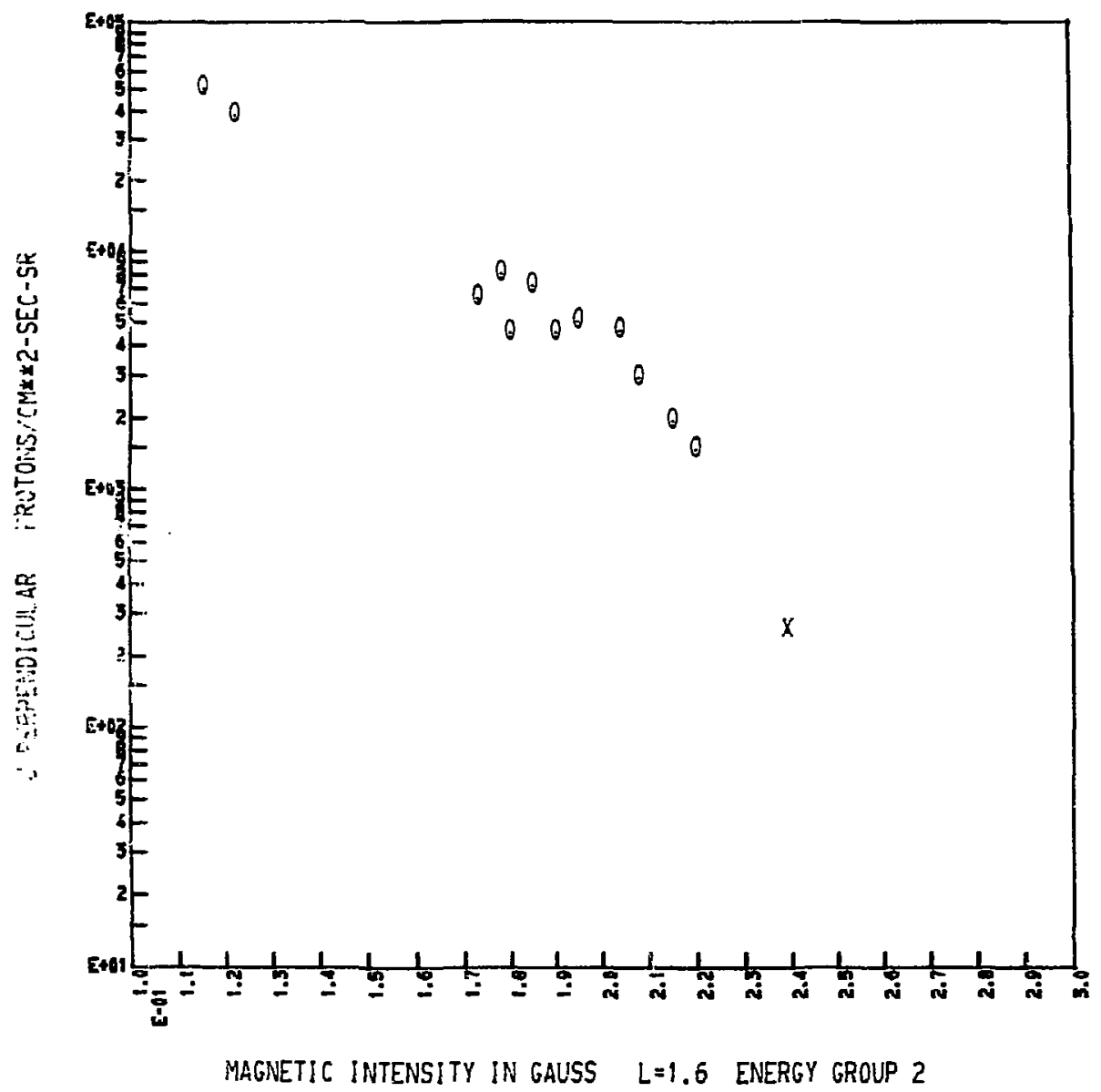

Fig. 59. Comparison of OSO-4 proion flux with Relay I proton intensities that were measured in 1963 . Since no time changes in proton flux were obs erved from October 1967 through March 1968, OSO-4 proton values were selected from several random orbits with data points as close in $B, L$ space as possible for the comparisons. 


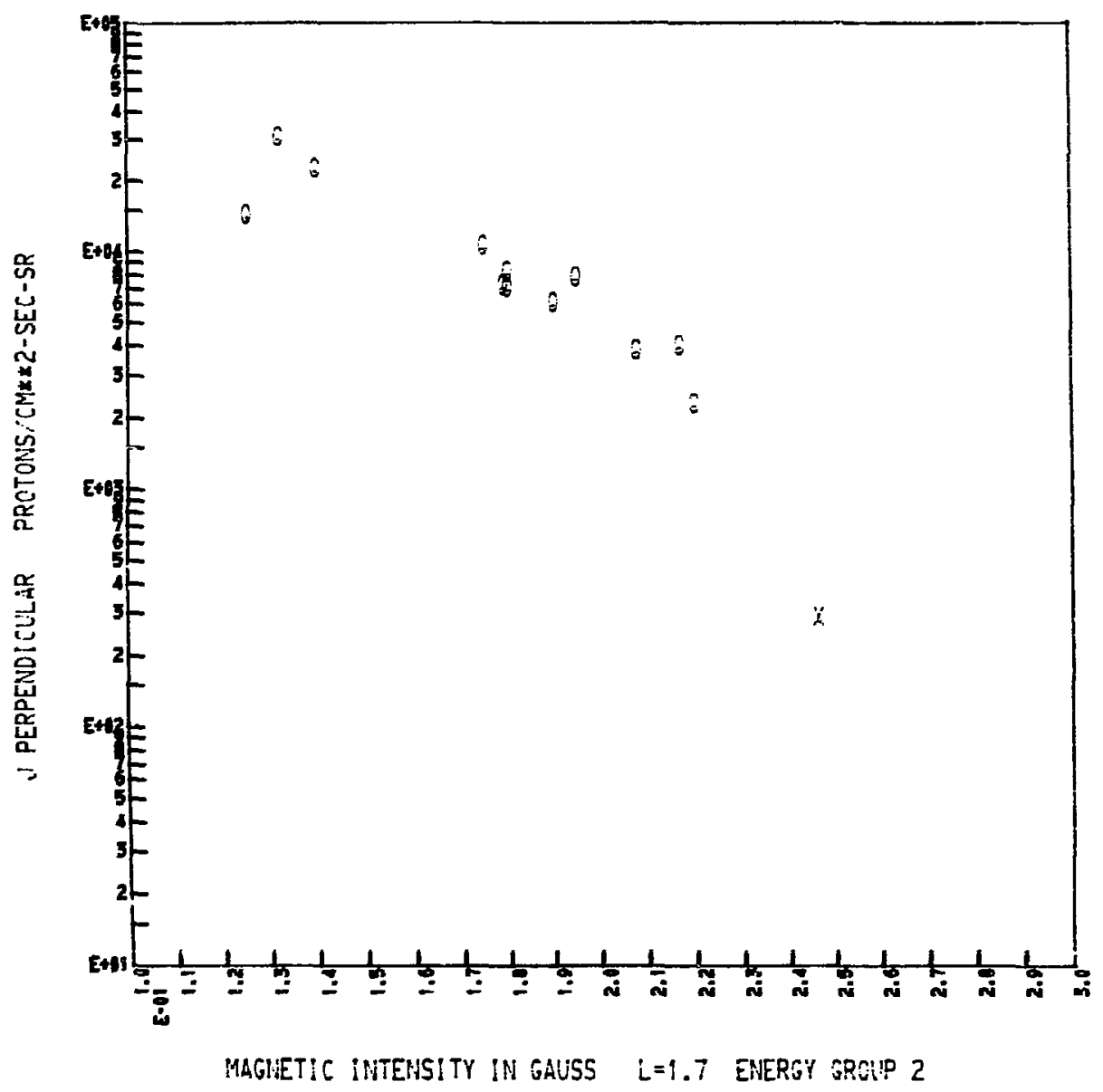

Fig. 60. Comparison of OSO-4 proton flux with Relay I proton intensities that were measured in 1963. Since no time changes in proton flux were observed from October 1967 through March 1968, OSO-4 proton values were selected from several random orbits with data points as close in $B, L$ space as possible for the comparisons. 


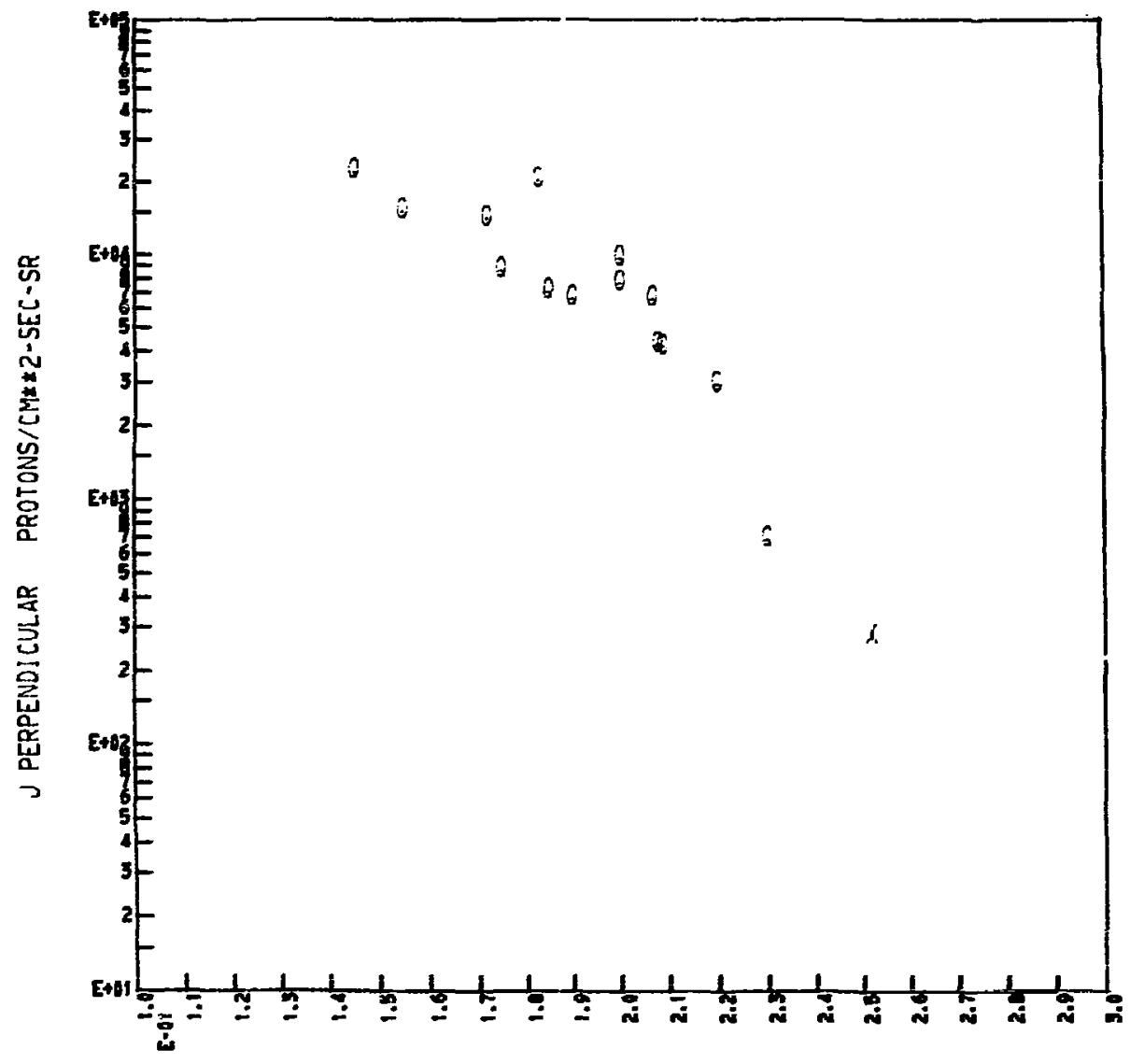

\section{MAGNETIC INTENSITY IN GAUSS L=1.8 ENERGY GROUP 2}

Fig. 61. Comparison of OSO-4 proton flux with Relay I proton intensities that were measured in 1963. Since no time changes in proton flux were observed from October 1967 through March 1968, OSO-4 proton values were selected from several random orbits with data points as close in $B, L$ space as possible for the comparisons. 
O-RELAY-1 X-OSO-4

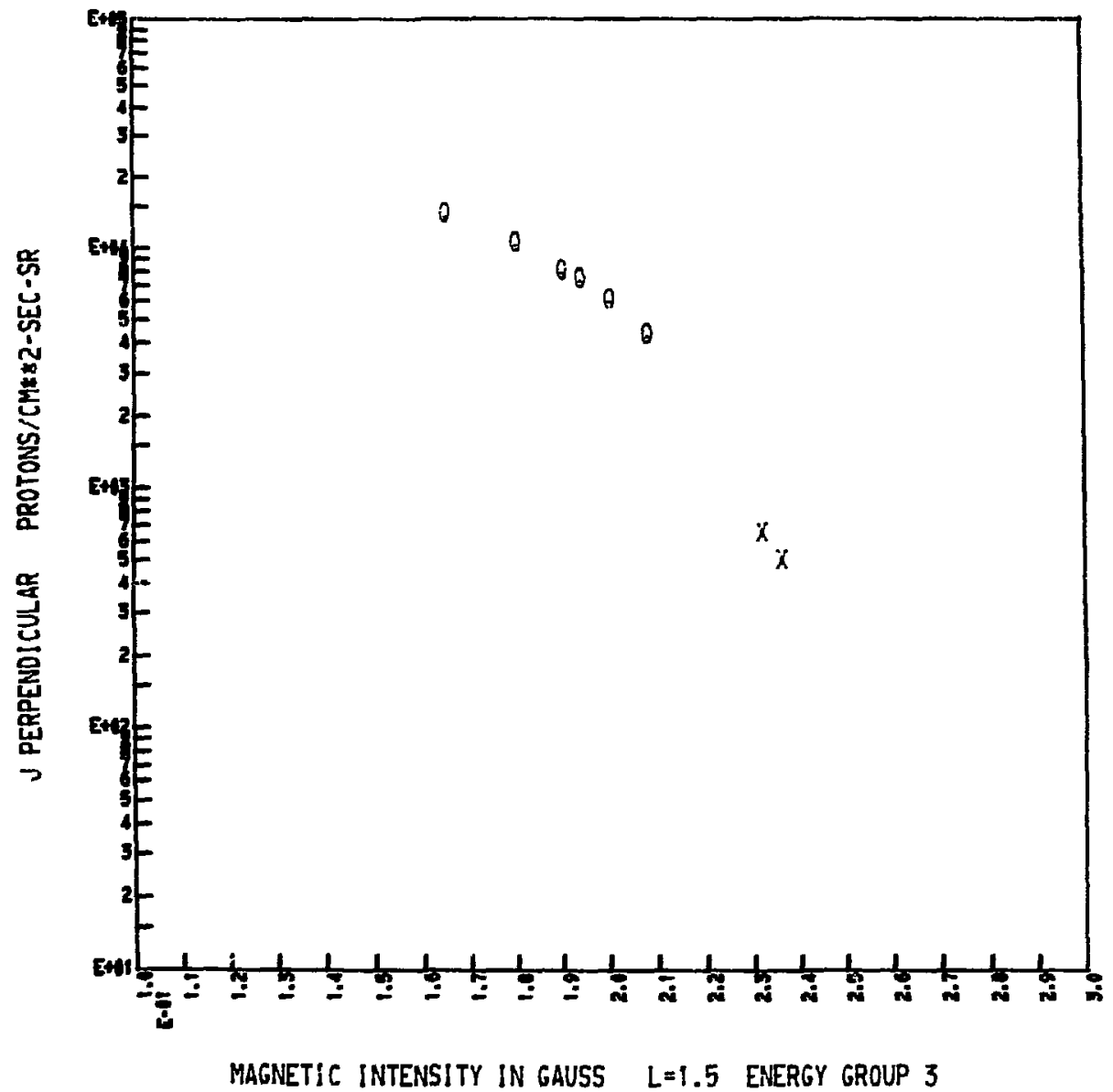

Fig. 62. Comparison of OSO-4 proton flux with Relay I proton intensities that were measured in 1963. Since no time changes in proton flux were observed from October 1967 through March 1968, OSO-4 proton values were selected from several random orbits with data points as close in $B$, I space as possible for the comparisons. 


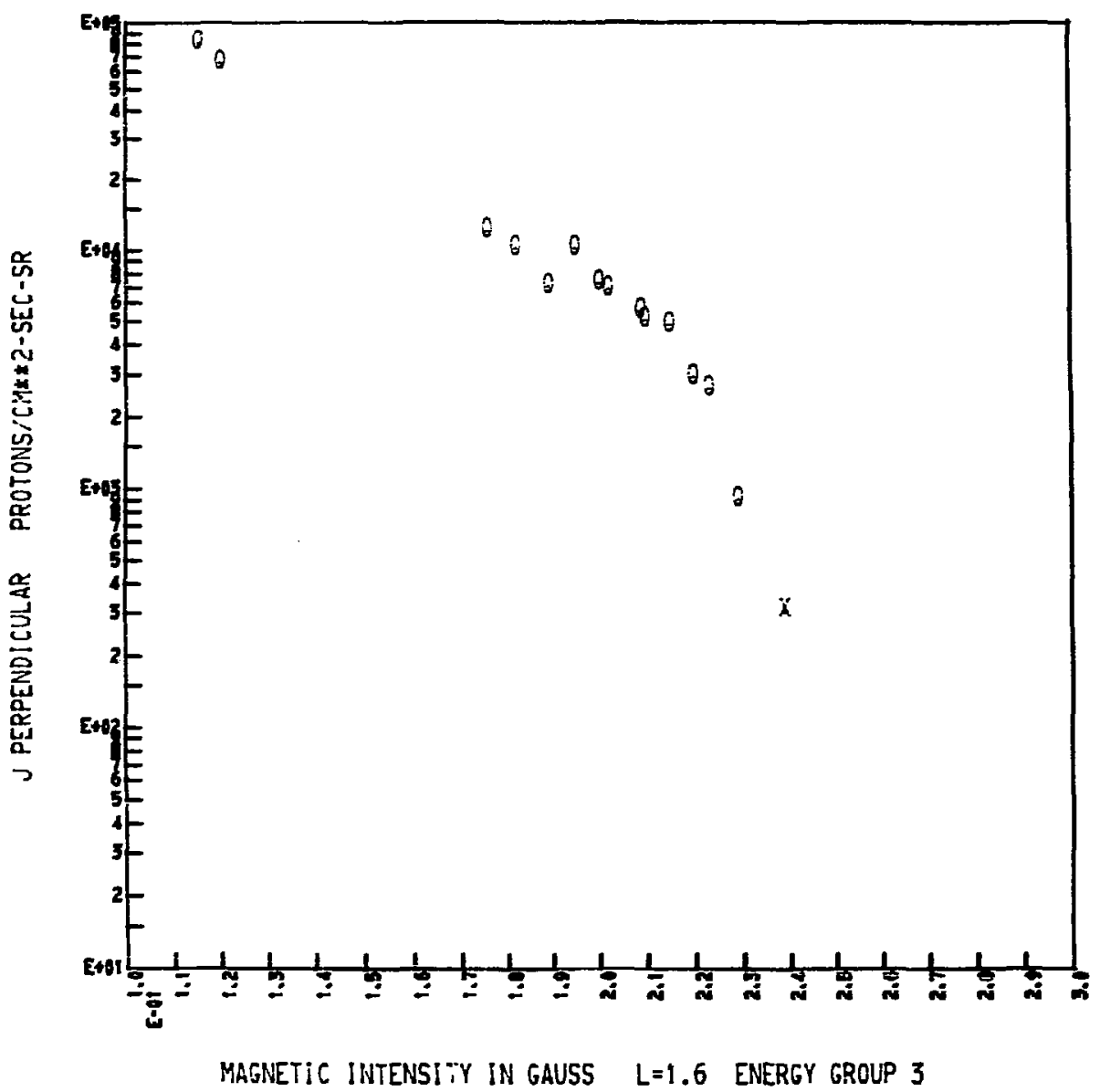

Fig. 63. Comparison of OSO-4 proton flux with Relay I proton intensities that were measured in 1963. Since no time changes in proton flux were observed from October 1967 through March 1968, OSO-4 proton valies were selected from several random orbits with data points as close in $B$, $L$ space as possible for the comparisons. 


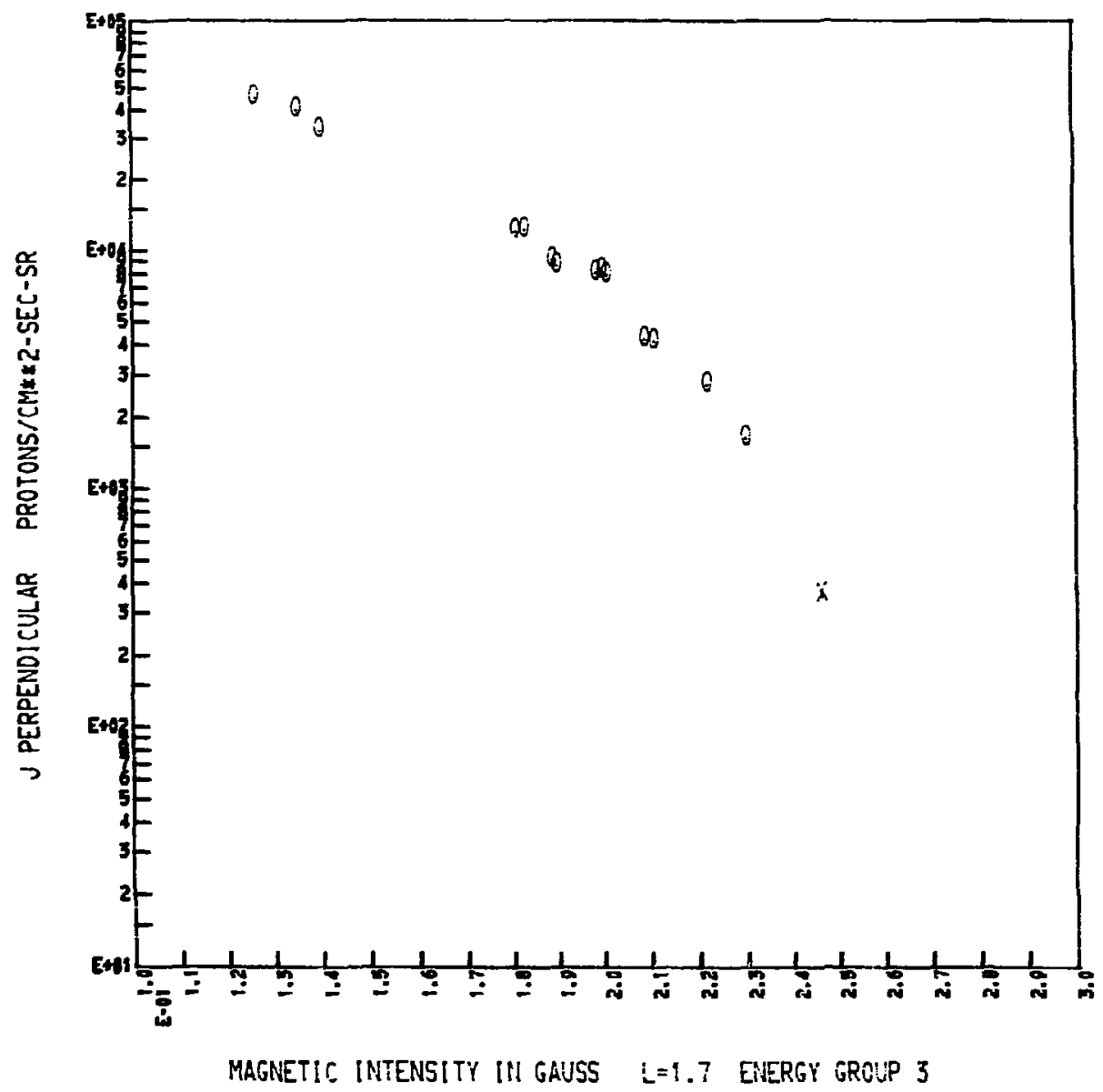

Fig. 64. Comparison of OSO-4 proton flux with Relay I proton intensities that were measured in 1963. Since no time changes in proton flux were observed from October 1967 through March 1968, OSO-4 proton values were selected from several random orbits with data points as close in $B, L$ space as possible for the comparisons. 
O-RELAY-1 X-OSO-4

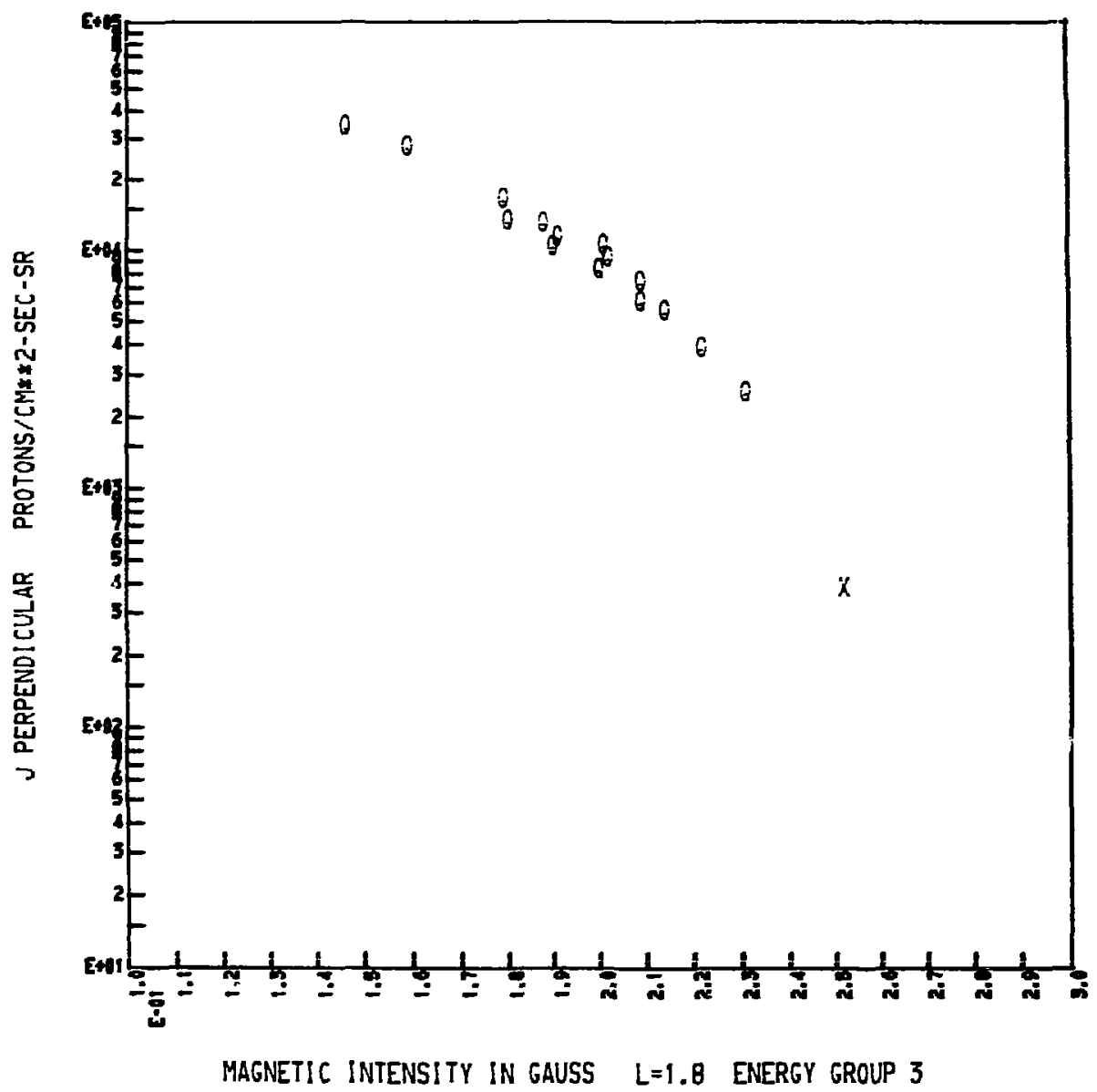

Fig. 65. Compasison of OSO-4 proton flux with Relay I proton intensities that were measured in 1963. Since no time changes in proton flux were observed from October 1967 through March 1968, OSO-4 proton values were selected from several random orbits with data points as close in $B, L$ space as possible for the comparisons. 
O-RELAY-1

$\mathrm{x}-\mathrm{OSO}-4$

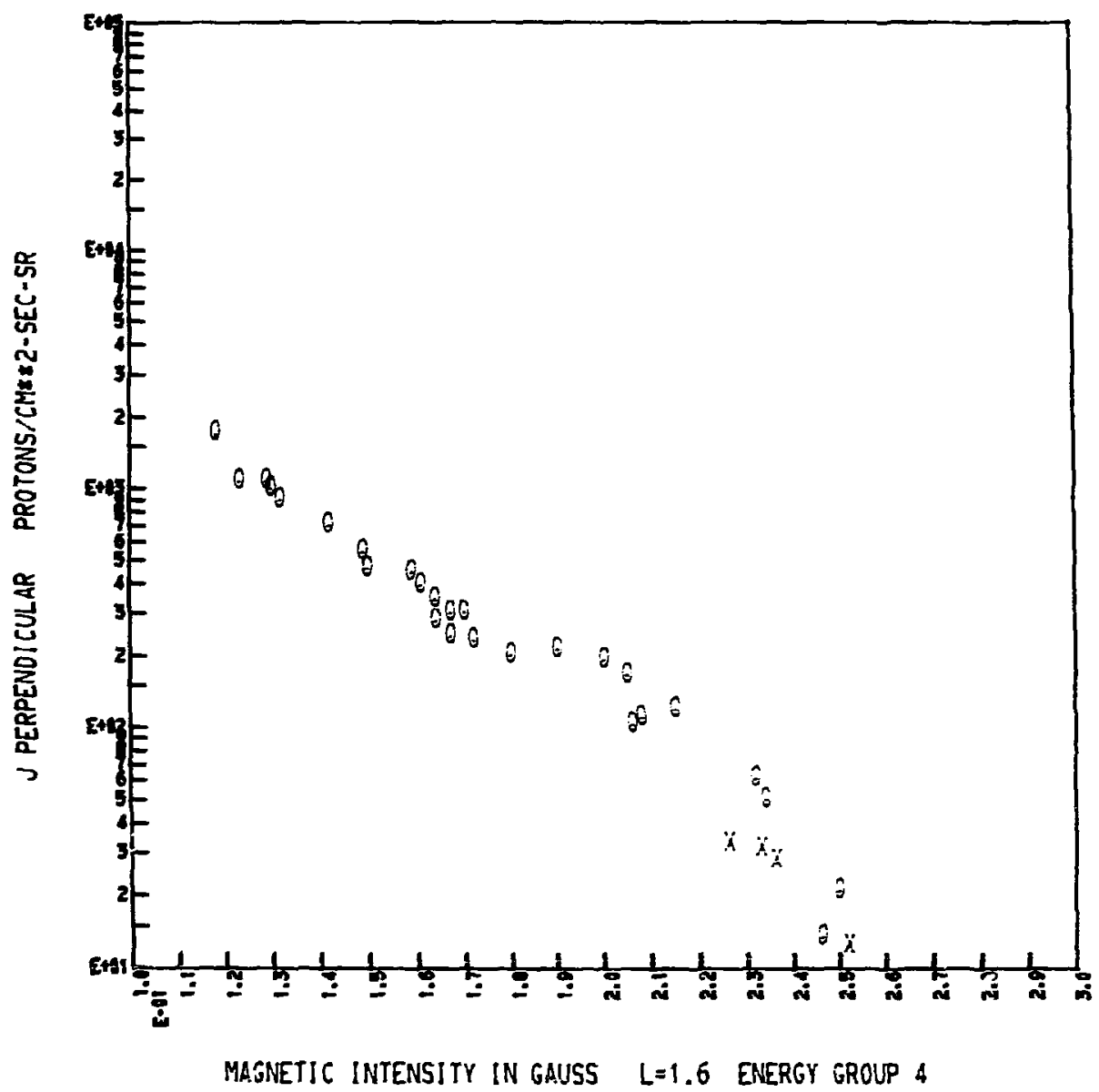

Fig. 66. Comparison of OSO-4 proton flux with Relay I proton intensities that were measured in 1963. Since no time changes in proton flux were observed from October 1967 through March 1968, OSO-4 proton values were selected from several random orbits with data points as close in B, L space as possible for the comparisons. 


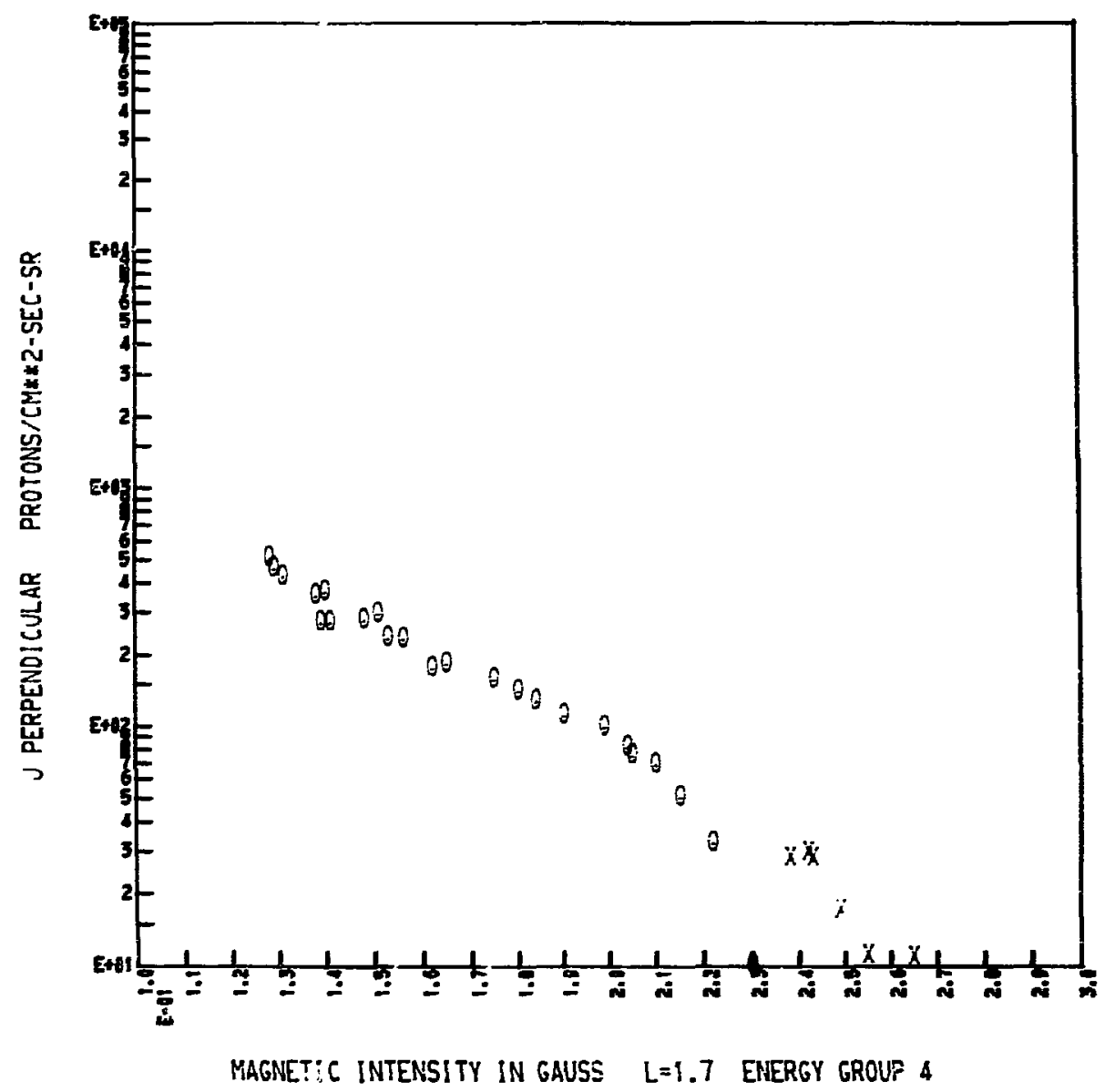

Fig. 67. Comparison of OSO-4 proton flux with Relay I proton intensities that were measured in 1963 . Since no time changes in proton flux vere observed from October 1967 through March 1968, OSO-4 proton values were selected from several random orbits with data points as close in $B, L$ space as possible for the comparisons. 


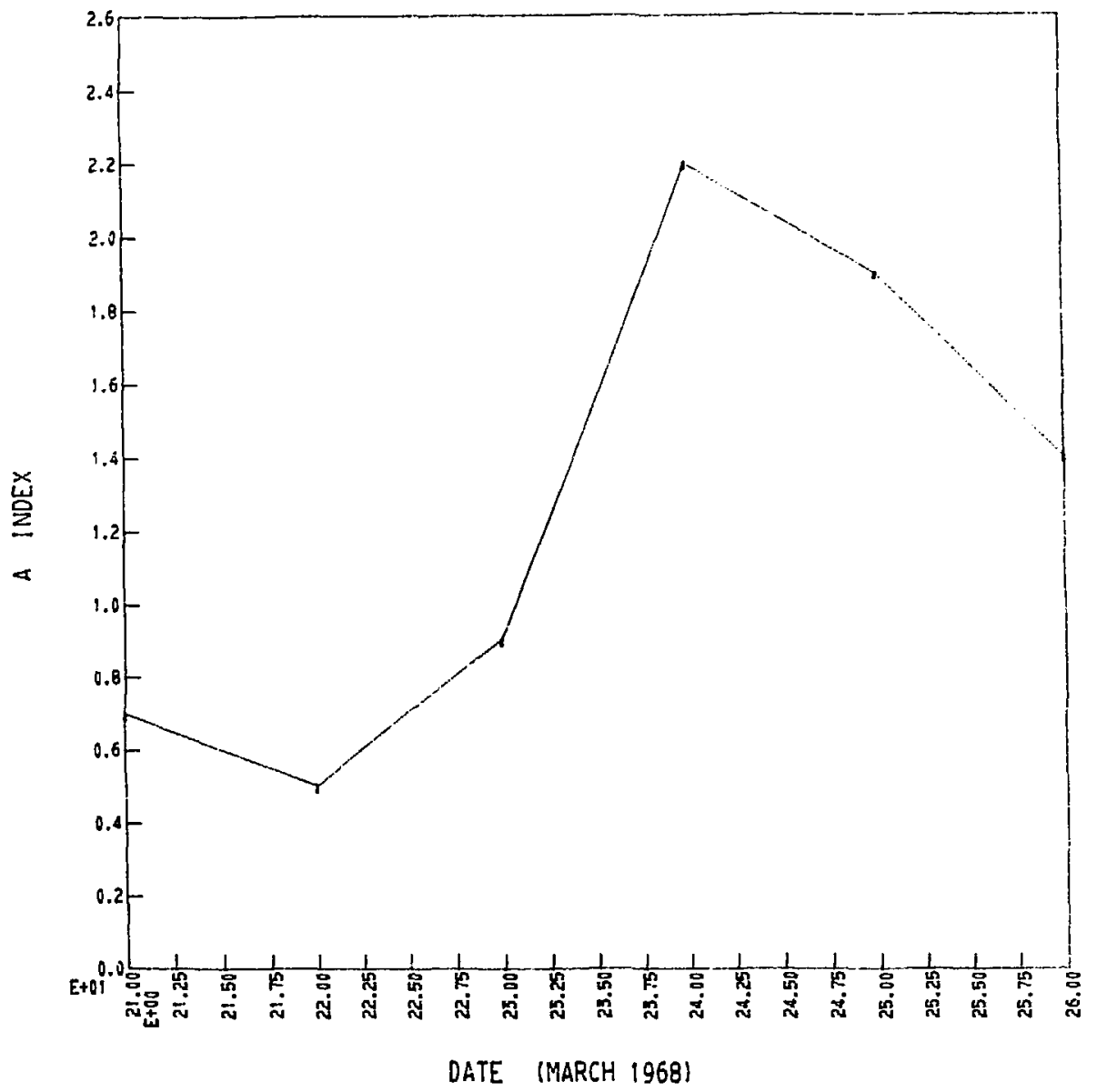

Fig. 68. The variation of the magnetic index A from March 21 through $26,1968$.
Note the peaking on day 24 . 


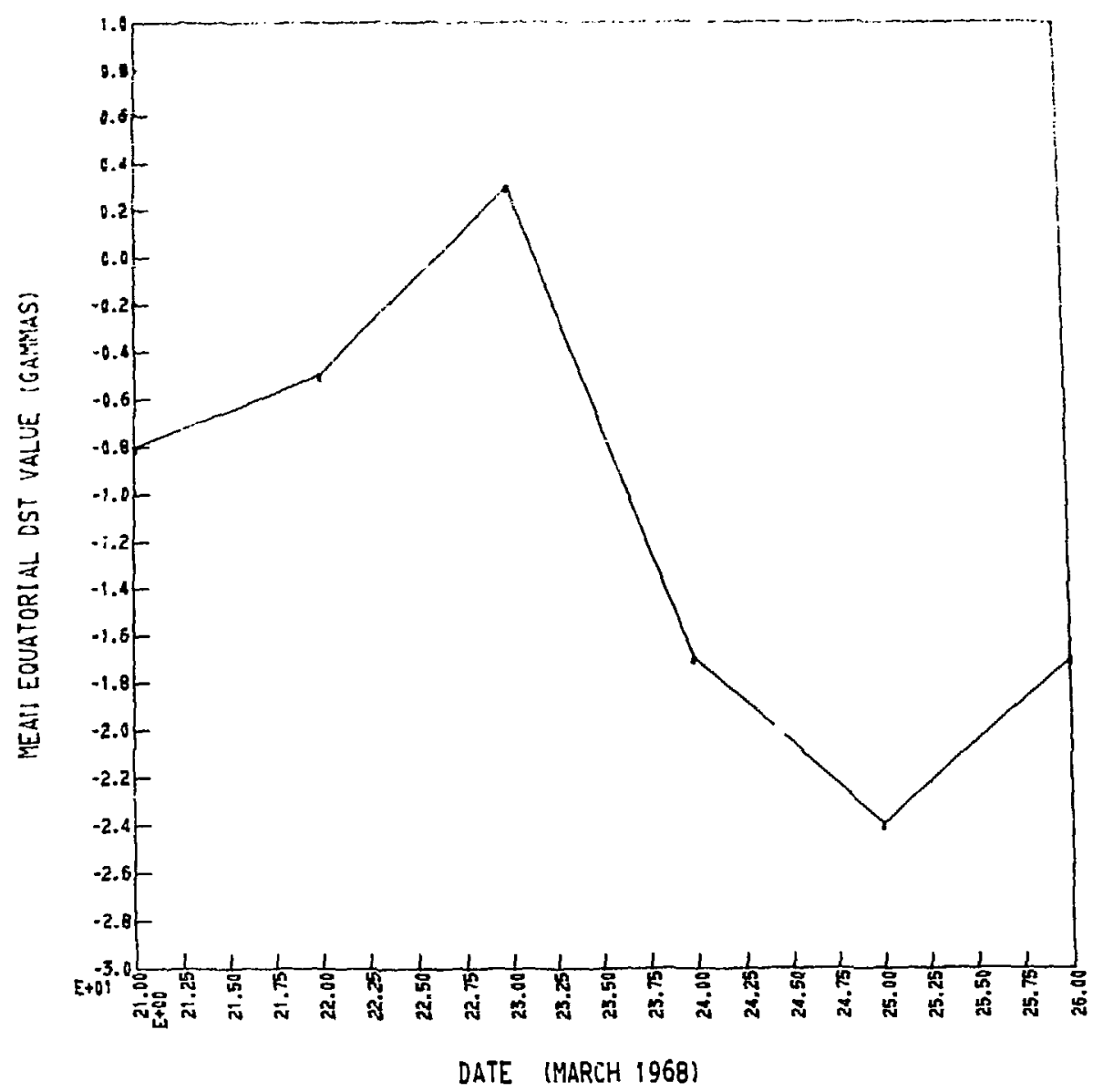

Fig. 69. The variation in the mean equatorial Dst value from March 21 through 26, 1968. INote the peaking on day 23. 
J PERPENR: GULAR IEE280 KEU;
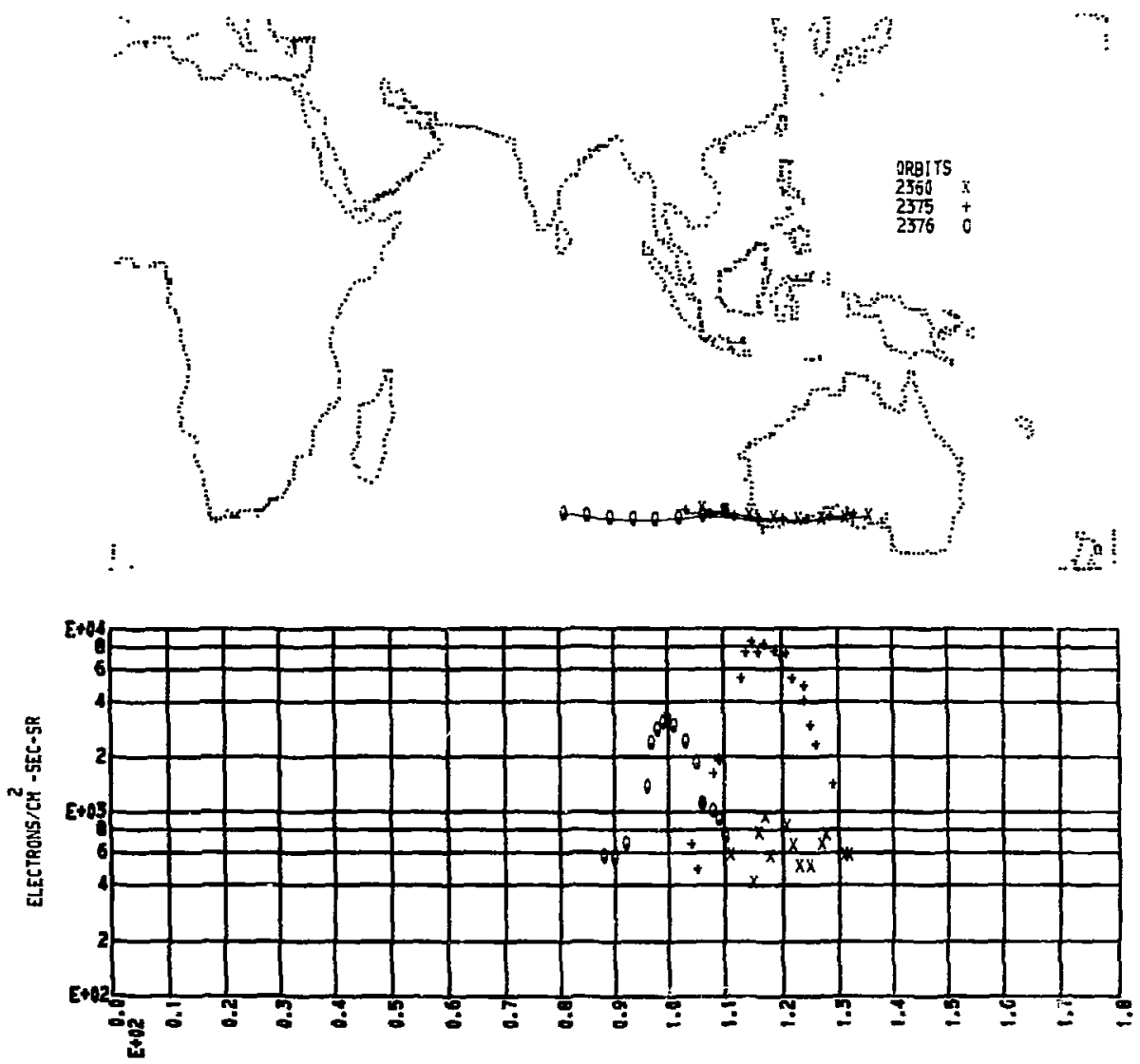

LOHGI TUDE III DEGREES

Fig. 70. Three histories of electron $\left(j_{1}\right)$ intensities measured along stretches of similar trajectories for $L \geq 2.0$ on March 23 and 24 . The observed increases in count rate can be correlated with the $A_{p}$ and Dst fluctuations
on those days. 


\section{References}

1. C. O. Bostrom, D. S. Beall, and J. C. Armstrong, J. Geophys, Res, 75, 1246 (1970).

2. A. Rosen, N. L. Sanders, R. Shelton, R. Potter, and E. Urban, J. Geophys. Res,, $\underline{73}, 1019$ (1968).

3. W. L. Imhof, J. Geophys. Res., 73, 4167 (1968).

4. K. A. Pfitzer and J. R. Winckler, J. Geophys, Res., 73, 5792 (1968).

5. H. I. West, Lawrence Livermore Laboratory, private communication (Dacember, 1971).

6. J. A. Waggoner, J. L. Held, W. R. Higley, and D. C. Peters, Instrumentation for the OSO-IV Charged Particle Experiment, Lawrence Livermore Laboratory, Rept. UCRL- 50745 (1969).

7. R. J. Knox, The OSO-D Codes Report, Lawrence Livermore Laboratory, Rept. UCW-15827 (1971).

8. R. W. Fillius and C. E. Mcllwain, A Survey of Inner Zone Protons, Dept. of Physics Rept. University of California, La Jolla, Calif. , April 13, 1965.

9. R. W. Fillius, J. Geophys. Res., 11, 97 (1966). 


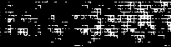

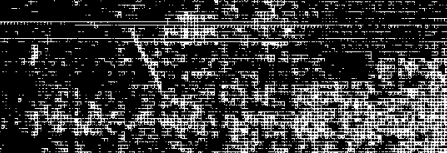

